\title{
Evaluation of Impact and Continuous Noise Exposure, Hearing Loss, Heat Stress, and Whole Body Vibration at a Hammer Forge Company
}

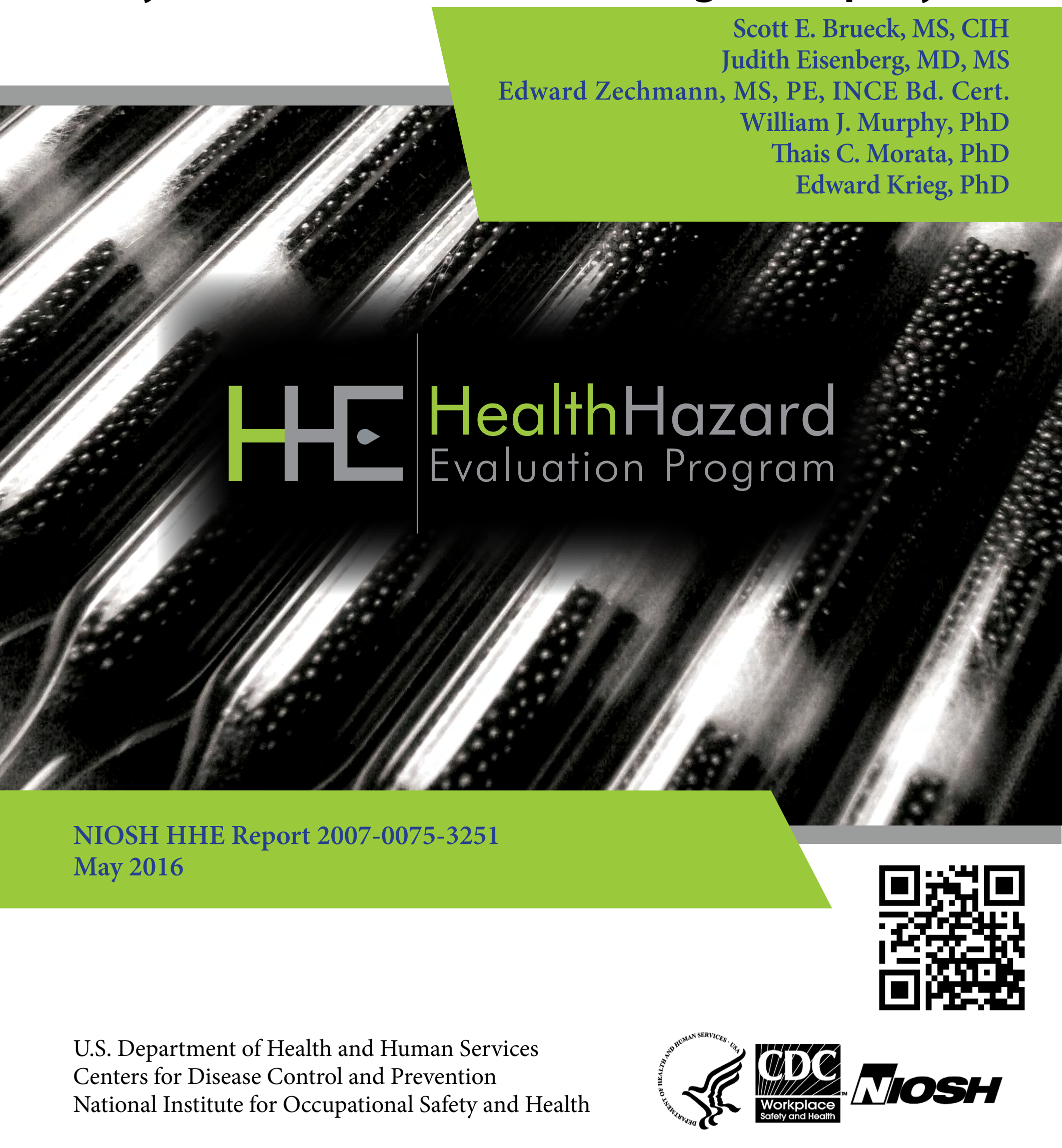




\section{Contents}

Highlights.

Abbreviations ...................................... iii

Introduction ............................................ 1

Methods .............................................. 3

Results and Discussion ........................ 5

Conclusions ....................................... 36

Recommendations............................. 37

Appendix A ..................................... 40

Appendix B ..................................... 43

Appendix C ......................................... 53

References............................................ 59

Acknowledgements......................... 65

The employer is required to post a copy of this report for 30 days at or near the workplace(s) of affected employees. The employer must take steps to ensure that the posted report is not altered, defaced, or covered by other material.

The cover photo is a close-up image of sorbent tubes, which are used by the HHE Program to measure airborne exposures. This photo is an artistic representation that may not be related to this Health Hazard Evaluation. Photo by NIOSH. 


\section{Highlights of this Evaluation}

The Health Hazard Evaluation Program received a request from the International Brotherhood of Boilermakers at a hammer forge company. The union was concerned about noise exposures and hearing loss, heat stress, and whole body vibration.

\section{What We Did}

- We measured employees' noise exposures in several work areas.

- We measured impact noise levels at forge hammers and at an upset press, shear, and grinder. We also measured noise frequencies at these locations.

- We interviewed employees about noise exposures, hearing loss, and heat stress.

- We evaluated how well hearing protectors worked.

- We analyzed hearing test results for the years 1981 to 2006.

- We measured whole body vibration at the hammers and hand-arm vibration at the grinders.

- We assessed heat stress.

\section{What We Found}

- Noise levels near the hammers, trim presses, furnaces, upset presses, shears, and grinders were very high (sometimes above 100 decibels). Most noise was caused by metalto-metal contact, compressed air, equipment vibration, or operation of grinders.

- Peak sound pressure levels during hammer strikes reached 148 decibels. NIOSH recommends a ceiling limit of 140 decibels for peak sound pressure levels.

- Nearly all production employees' noise exposures were above noise exposure limits.

- Hammer, trim press, and heater operators

We measured impact noise, noise exposures, whole body and hand-arm vibration, and heat stress in a hammer forge. Impact noise levels at the hammers were up to 148 decibels. Most employees' noise exposures were above noise exposure limits. Noise exposures near the hammers were above 100 decibels, A-weighted. Whole body vibration was above some recommended guidelines. Hand-arm vibration at the grinders could exceed recommended limits. We did not find excessive heat stress. We recommended installing noise controls and replacing current equipment with less noisy equipment. We also recommended using vibration isolation controls at the hammers and at the grinders. had noise exposures above 100 decibels, A-weighted. This is much higher than noise exposure limits.

- Many employees had hearing loss. Some employees had hearing loss within the first 5 years on the job, including employees under age 25 .

- Employees' hearing worsened with length of employment and age. 
- Some employees had permanent ringing in their ears because of noise exposure.

- Some employees did not insert foam ear plugs in the proper way.

- Whole body vibration was above some recommended guidelines.

- Hand-arm vibration levels at the grinders could be above recommended limits.

- Employees' exposures to heat stress were below exposure limits.

\section{What the Employer Can Do}

- Reduce noise caused by metal-to-metal contact.

- Maintain equipment to help reduce noise levels.

- Consult with equipment makers when purchasing new equipment or replacing equipment to buy equipment that makes the least amount of noise.

- Require employees who work near the hammers, trim presses, and furnaces to use both ear plugs and earmuffs.

- Make sure employees wear their hearing protection properly.

- Test employees' hearing protection to make sure it fits well and protects them from noise.

- Improve training on how to use hearing protection.

- Use National Institute for Occupational Safety and Health recommendations for evaluating employees' hearing tests.

- Install vibration isolation pads or vibration isolation mats on the hammer work platforms.

- Use vibration control measures in the machine grinder area.

\section{What Employees Can Do}

- Wear ear plugs and earmuffs when working near the hammers and furnaces.

- Wear hearing protection properly.

- Tell your doctor that you work in high noise levels, and report any hearing problems to your doctor.

- Tell your doctor about your exposure to whole body vibration if you work at the hammers or your exposure to hand-arm vibration if you work at the grinders. Report any problems from vibration exposure to your doctor.

- Know the signs and symptoms of heat stress and stay hydrated during hot weather. 


\section{Abbreviations}

ACGIH® $\quad$ American Conference of Governmental Industrial Hygienists

AL

ANSI

ARMS

CBT

CFR

$\mathrm{dB}$

dBA

HTL

$\mathrm{Hz}$

ISO

$\mathrm{kHz}$

$\mathrm{m} / \mathrm{s}^{2}$

msec

NIHL

NIOSH

NRR

OEL

OSHA

$\mathrm{Pa}$

PEL

REL

sec

STS

TLV®

TWA

WBGT

WEEL
Action level

American National Standards Institute

Acceleration root mean square

Core body temperature

Code of Federal Regulations

Decibels

Decibels, A-weighted

Hearing threshold level

Hertz

International Standards Organization

Kilohertz

Meter per second squared

Millisecond

Noise-induced hearing loss

National Institute for Occupational Safety and Health

Noise reduction rating

Occupational exposure limit

Occupational Safety and Health Administration

Pascals

Permissible exposure limit

Recommended exposure limit

Seconds

Standard threshold shift

Threshold limit value

Time-weighted average

Wet bulb globe temperature

Workplace environmental exposure level 
This page left intentionally blank 


\section{Introduction}

The Health Hazard Evaluation Program received a request from the International Brotherhood of Boilermakers at a hammer forge company. The union was concerned about hearing loss from exposure to continuous and impact noise. Additionally, the union was concerned about heat stress and whole body vibration.

At the time of the evaluation, the company produced customized impression die hot metal forgings made from carbon or alloy steel. Forging equipment included 17 pneumatic hammers with capacities ranging from 1 to 5 tons and capable of producing parts weighing over 200 pounds; 9 upset presses ranging in size from 3 to 8 inches that produced parts up to 10 inches in diameter; and 3 hydraulic screw presses that used up to 3,450 tons of force to produce parts weighing up to 100 pounds. The facility had a heat treat operation for normalizing, tempering, quenching, and annealing post-forged parts.

The facility had been in operation for more than 100 years and had 5 production buildings at the worksite. Most production operations ran 5 days per week with three 8-hour shifts. However, the heat treat operation ran 24 hours per day, 6 days per week. The company had about 145 employees on the first shift, 45 on the second shift, and 22 on the third shift. Most production was done on the first shift. Maintenance and machining were the primary work activities on the third shift.

\section{Process Description}

A process flow diagram for forge operations is provided in Figure 1. The company received and stored steel rods of varying thickness in the steel yard. Forklifts transported steel rods to the shear building. Here, employees cut the rods into ingots using metal saws, hydraulic shear presses, or mechanical shear presses. After cutting, ingots fell into metal bins. Full bins were taken by forklifts to the north forge, south forge, and upset press building.

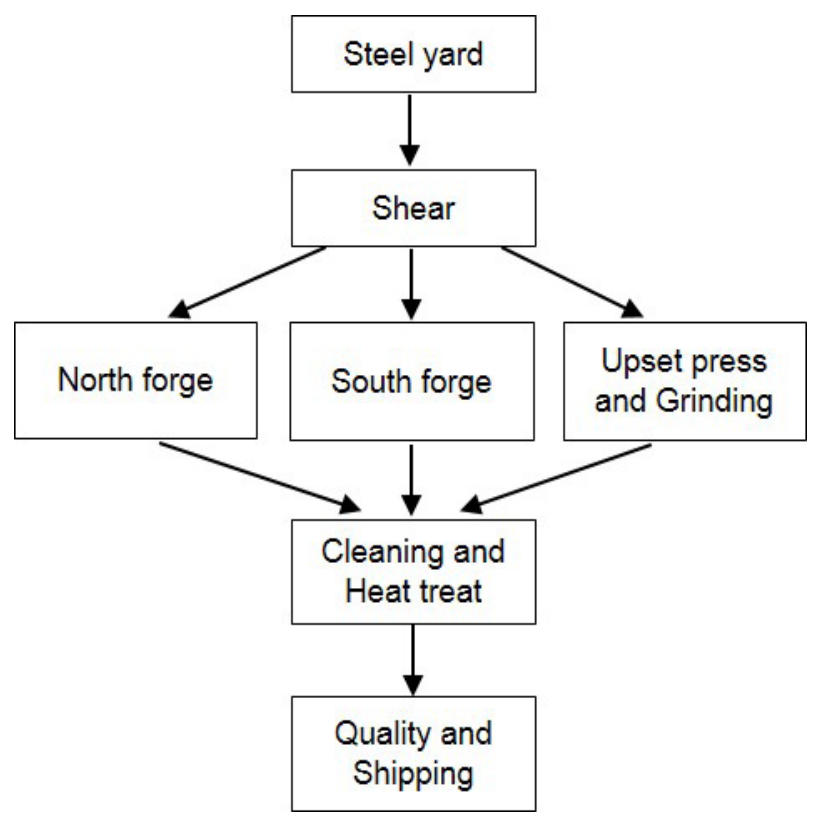

Figure 1. Process flow diagram for forge operations. 
Furnace operators (referred to as "heaters") manually loaded ingots into furnaces located adjacent to hammers or upset presses. Ingots were heated in the furnace (Figure 2) to a temperature of approximately 2,400 degrees Fahrenheit $\left({ }^{\circ} \mathrm{F}\right)$ for 20 to 25 minutes. While ingots were heating in the furnace (referred to as a "heat wait"), heaters, hammer operators, upset press operators, trim press operators, and helpers sometimes left the immediate vicinity of the furnaces and forges. They usually sat on benches or stood approximately 15 feet from the forges during the heat wait. Workers sometimes went to the air-conditioned production office or to picnic tables outside the forge building during the heat wait.

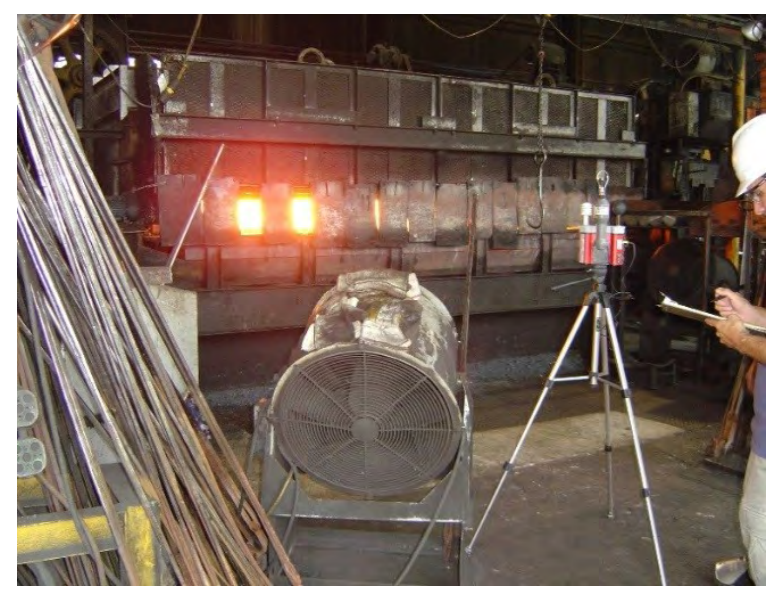

Figure 2. Furnace for heating metal ingots. Small metal flaps hang over the front of the furnace to cover the opening during heating. Photo by $\mathrm{NIOSH}$.

Once ingots were heated to the appropriate temperature, heaters used long metal tongs to manually place the molten ingots onto short conveyors that moved ingots to the hammer or upset press. A hammer or upset press operator also used metal tongs to pick up and position the ingot onto the hammer or upset press die. The operator used a foot-operated control bar to activate the hammer and shape the hot metal ingot into a forging with a series of vertical impact blows (Figure 3). During the initial series of hammer blows, a chemical releasing agent was sprayed onto the hammer and die. This chemical helped prevent the ingot from sticking to the hammer and die.

Hammers generated substantial impact forces. The largest hammers, located in the north forge, generated 35,000 pounds of force at the strike surface. Upset presses used horizontal blows to shape the ingots. Metal dies, which were custom machined on site, were changed by die operators or machinists as needed. Trim operators used metal tongs to manually carry forgings from the hammer or upset press to the trim press. Here, excess metal trim, a byproduct of the forge process, was removed by the trim press. 


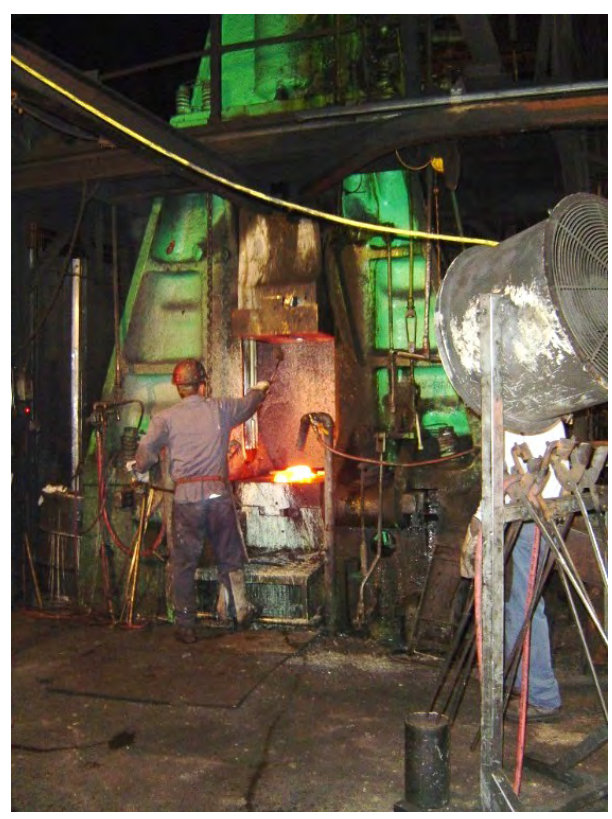

Figure 3. Operator standing at forge hammer. Photo by NIOSH.

Completed forgings were put into metal bins to cool. Each production run took about 30 to 45 minutes to complete. The grinding building, attached to the upset press building, housed five large machine grinders that were used to smooth forged pieces that came from upset presses. After cooling, forged pieces were taken to the heat treat building. Fully enclosed shot blast units used small diameter steel shot to smooth rough edges on forgings. Additionally, forgings were "heat treated." In this process, forgings were immersed in heated quenching oil in annealing furnaces to increase the strength, hardness, or machining characteristics of the metal.

\section{Methods}

Our objectives included evaluating the following:

- Forge employees' full-shift time-weighted average (TWA) noise exposures

- Impact noise levels and characteristics of forge equipment

- One-third octave band noise frequency levels

- Possible noise control options

- Attenuation of hearing protection used by forge employees

- Hearing loss trends and the risk of hearing loss in forge employees

- Whole body vibration at forge hammers and hand-arm vibration at grinders

- Heat stress conditions

During our initial site visit in April 2007, we toured the facility and observed work processes, equipment, engineering controls, and personal protective equipment. We measured sound levels near operating equipment throughout the facility. We also selected a convenience 
sample of 10 employees from a list of 89 production employees provided by company managers. We interviewed employees privately regarding workplace health concerns.

During our second visit in May 2007, we measured the full-shift personal noise exposures of 36 production employees in 15 job titles. Because previous research had shown that noise dosimeters do not adequately measure impulsive noise levels greater than 140 decibels (dB) [Kardous et al. 2003; Kardous and Willson 2004], we used a noise measurement system designed by researchers at the National Institute for Occupational Safety and Health (NIOSH). We took multiple impact noise measurements at an upset press, a shear press, four forge hammers (one in the north forge and three in the south forge), and in the grinder area during production. Each impact noise measurement lasted 15-61 seconds (sec). We took 16-37 measurements at each location. The total measurement time at each location ranged about 2-8.5 minutes. We also measured one-third octave band noise levels at an 8-inch upset press, 700-pound shear, grinders, and at three hammers. At each of these areas we measured one-third octave band noise levels simultaneously at two separate locations: close to the equipment and at a distance of about 6 feet from the equipment. We also reviewed the company's hearing conservation program.

During our third site visit in August 2007, we measured whole body vibration at the hammer forges and hand-arm vibration at the grinders. We measured whole body vibration using accelerometers attached to the platform where workers stood. For measurement of hand-arm vibration at four of the grinder work stations, we attached the accelerometers to handles of the grinders.

We also assessed the attenuation of two foam insert hearing protectors, $3 \mathrm{M}^{\mathrm{TM}} \mathrm{E}-\mathrm{A}-\mathrm{R}^{\mathrm{TM}}$ Classic $^{\mathrm{TM}}$ and $3 \mathrm{M}^{\mathrm{TM}} \mathrm{E}-\mathrm{A}-\mathrm{Rsoft}^{\mathrm{TM}}$, which all forge employees were required to wear. We measured the noise exposure levels in the headform of an acoustic mannequin with and without hearing protectors. We placed the acoustic mannequin near the hammer operator's work position. We used the same impact noise measurement system that we had used during the second site visit.

In addition, we took heat stress measurements and spoke with 15 employees about their work activities in high temperature conditions and their training about heat stress. We used direct reading wet bulb globe temperature (WBGT) monitors to measure and assess environmental heat stress conditions. We placed the instruments at locations where employees typically worked. We took measurements at two south forge hammers, at one north forge hammer, and in the heat treat department during the first shift, and at one south forge hammer, one north forge hammer, one upset press, and in the heat treat department during the second shift. We observed and documented work-rest schedules for several employees working at hammers and furnaces.

After the site visit, we obtained an electronic database of 7,908 historical audiograms from the company. The data were for 618 current or former employees for the years 1981-2006. For employee privacy, we removed personal identification information from the audiometric test records. We used NIOSH audiometric quality assurance screening guidelines, detailed in Appendix $\mathrm{C}$, to identify and remove audiograms that were incomplete or had audiometric patterns indicating hearing loss could have resulted from non-occupational factors or 
inaccurate audiometric thresholds [Franks 1999]. Following screening, we analyzed employee audiometric test history to assess hearing loss. We compared the results to an International Standards Organization (ISO) unscreened reference population [ISO 1999]. For analysis, we used SAS Institute $\mathrm{SAS} \circledast$ version 9.3 software.

Details on the methods used for noise dosimetry, impact noise measurements, hearing loss analysis, vibration assessment, and heat stress measurements are provided in Appendix C.

\section{Results and Discussion}

\section{Personal Noise Exposures}

Table 1 provides a summary of personal noise exposure measurements by job title.

The Occupational Safety and Health Administration (OSHA) and NIOSH measure and calculate noise exposures in slightly different ways. For an 8-hour work shift, the NIOSH recommended exposure limit (REL) is 85 decibels, A-weighted (dBA). The OSHA action level (AL) is $85 \mathrm{dBA}$, and the OSHA permissible exposure limit (PEL) is $90 \mathrm{dBA}$. Additional details on differences between NIOSH and OSHA noise exposure limits are provided in Appendix B. Employees in all of the job titles monitored for noise, except a machinist, had 8 -hour TWA noise exposures above the OSHA AL and NIOSH REL of $85 \mathrm{dBA}$. The TWA noise exposures also exceeded the OSHA PEL of $90 \mathrm{dBA}$, except for employees in the die repair and machinist jobs.

Table 1. Range of personal noise dosimetry measurements

\begin{tabular}{lcccc}
\hline Job title & Number of & \multicolumn{3}{c}{ TWA noise measurements (dBA) } \\
\cline { 3 - 5 } & measurements & OSHA AL & OSHA PEL & NIOSH REL \\
\hline Hammer operator & 7 & $97.4-107.0$ & $97.0-106.8$ & $98.8-110.4$ \\
Trim press operator & 6 & $97.3-101.7$ & $97.1-101.6$ & $98.9-104.1$ \\
Heater & 6 & $96.6-99.5$ & $96.4-99.2$ & $98.8-101.2$ \\
Shear operator & 2 & $94.5-96.1$ & $93.9-95.6$ & $97.4-98.4$ \\
Forklift operator & 1 & 96.5 & 96.1 & 98.3 \\
Shotblast operator & 2 & $91.9-93.4$ & $90.2-91.6$ & $95.3-97.9$ \\
Upset heater & 2 & $94.4-96.6$ & $94.0-96.6$ & $95.7-97.7$ \\
Tow motor driver & 1 & 95.1 & 94.2 & 97.1 \\
Line-up & 2 & $93.2-93.5$ & $91.9-92.3$ & $95.4-96.8$ \\
Maintenance & 1 & 93.3 & 92.9 & 96.4 \\
Upset operator & 2 & $93.1-95.4$ & $92.3-95.3$ & $94.0-96.1$ \\
Grinder operator & 1 & 94.2 & 93.9 & 94.8 \\
Heat treat helper & 1 & 92.0 & 90.9 & 94.2 \\
Die repair & 1 & 86.9 & 85.3 & 91.4 \\
Machinist & 1 & 81.4 & 65.2 & 83.4 \\
\hline Noise exposure limits & & 85.0 & 90.0 & 85.0 \\
\hline
\end{tabular}


The primary source of noise exposure for jobs at or near the hammers (hammer operators, trim press operators, heaters) was impact noise from the hammers striking the metal forgings and dies. Secondarily, noise from the gas burners on furnaces, mechanical noise from the drive chain links and sprockets during chain conveyor movement, and releases of compressed air contributed to noise exposures. Some hammer operators and trim press operators had TWA noise exposures greater than $100 \mathrm{dBA}$ on the basis of NIOSH and OSHA measurement criteria. Heaters had TWA noise exposures greater than $100 \mathrm{dBA}$ on the basis of NIOSH measurement criteria, but slightly below $100 \mathrm{dBA}$ on the basis of OSHA criteria. Our noise exposure measurement results for hammer operators were similar to those reported by Surorov et al. [2001] and slightly lower than reported by Taylor et al. [1984]. NIOSH and OSHA recommend the use of dual hearing protection, that is, the combination of insert hearing protectors and earmuffs, when TWA noise exposures are above $100 \mathrm{dBA}$.

Noise dosimeters have been shown to underestimate noise measurement results in highly impulsive noise environments when peak levels are greater than $140 \mathrm{~dB}$ [Kardous et al. 2003; Kardous and Willson 2004]. Therefore, the personal TWA noise measurements for jobs with substantial impact noise, such as near forge hammers, should be interpreted cautiously and could underrepresent full-shift noise exposures.

The noise dosimeters used for this evaluation integrated noise at a 50-hertz $(\mathrm{Hz})$ sampling rate every second during monitoring. Therefore, each dosimeter recorded approximately 28,800 individual 1-sec averaged noise exposure measurements for a full shift. Figure 4 provides the noise exposure time history profile for a hammer operator, trim press operator, and heater working at hammer 3-2. The profile shows 19 production runs. These three job titles had very similar noise exposure time history profiles, but noise exposure decreased during production runs as distance from the hammer increased. The noise exposure level for the hammer operator reached $115 \mathrm{dBA}$ or more during production runs. The trim press operator and heater worked farther away from the hammer, and their noise exposures during production runs reached approximately $110 \mathrm{dBA}$ and $107 \mathrm{dBA}$, respectively. Noise exposure time history profiles for employees working at other hammers had similar patterns. 


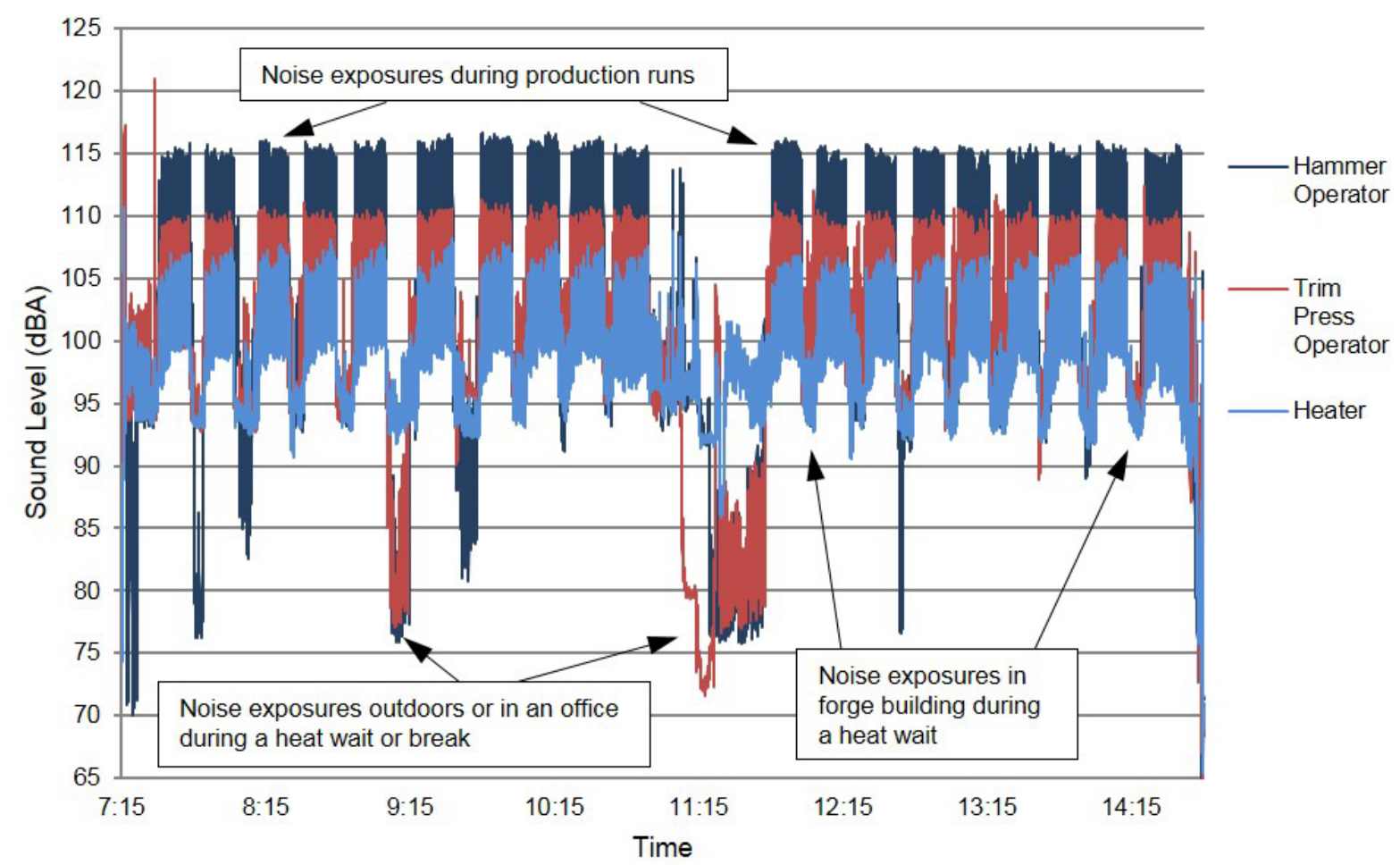

Figure 4. Noise exposure time history profile for a hammer operator, trim press operator, and heater working at hammer 3-2.

Employees' noise exposures decreased to approximately 92-97 dBA when they stayed in the north forge or south forge during the heat wait. It is noteworthy that noise exposures decreased an additional 10-15 dBA, to less than $80 \mathrm{dBA}$, when employees went outdoors or into a production office during the heat wait or during breaks. Employees did not have specific tasks to complete during the heat wait, but some employees preferred to remain in the vicinity of the forge hammers while waiting for the next production cycle to start. During inclement weather or temperature extremes, some employees reported that they were less likely to go outside during the heat waits.

Noise exposures during production runs at the upset presses were lower than the hammers. For example, the time history profile for an 8-inch upset press operator and heater over 16 production runs is shown in Figure 5. Noise exposure levels reached approximately 102-107 dBA during the production run. Noise exposures decreased to approximately 90-95 dBA when employees stayed in the production area during the heat wait and were less than $80 \mathrm{dBA}$ when employees left the building. 


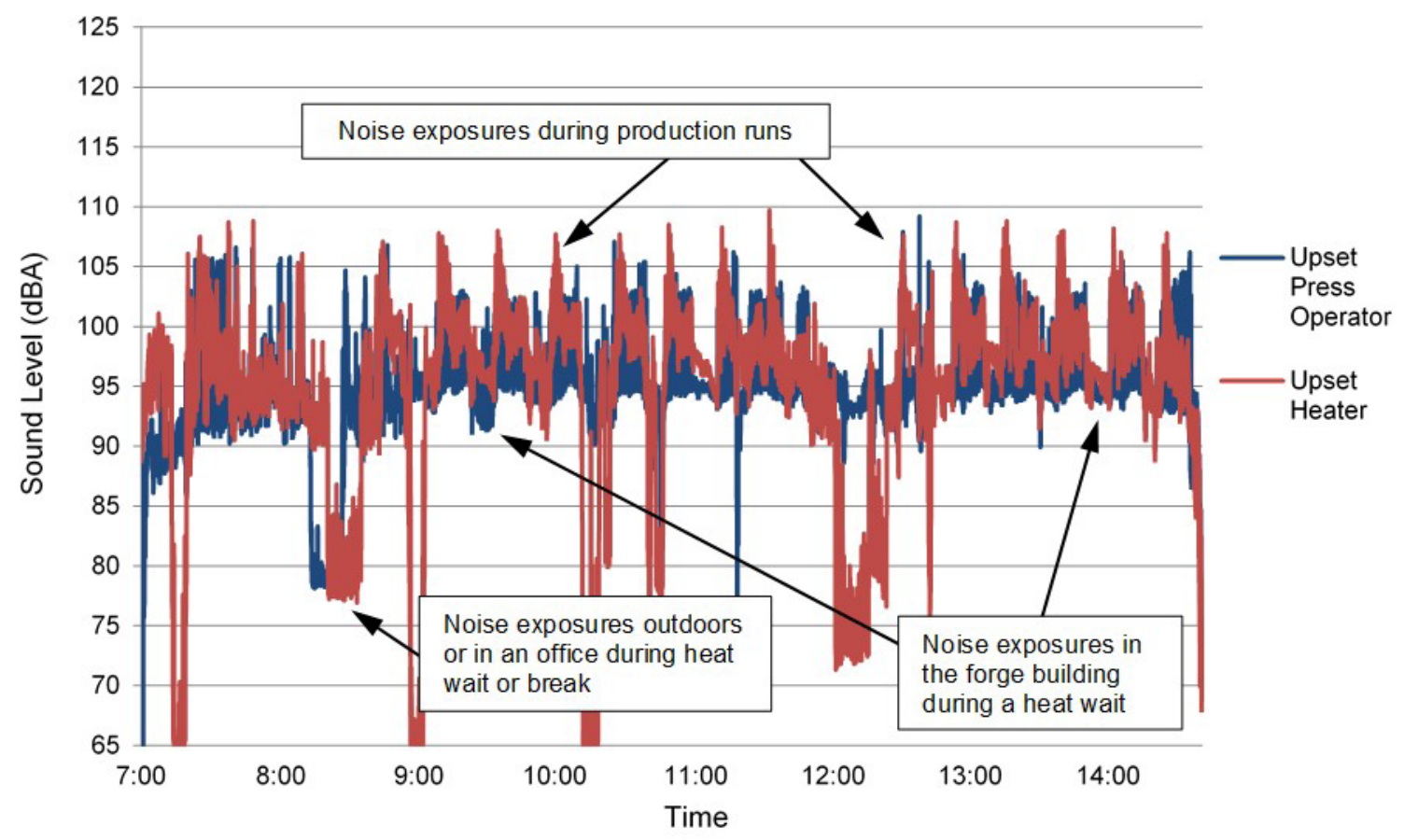

Figure 5. Noise exposure time history profile for an upset press operator and upset heater at an 8-inch upset press.

Table 2 shows the total number of production runs at the hammers and upset presses where we measured employees' full shift noise exposures. The number of production runs at the hammers and upset presses varied each day depending on the type of part forged, size of forged parts, production rate per part, number of parts in the job order, and hammer downtime due to changing dies or maintenance needs. Employees' daily TWA exposures also varied on the basis of the number of production runs and the number and force of hammer strikes per part.

Table 2. Total number of production runs at hammers and upset presses on day of noise monitoring

\begin{tabular}{lc}
\hline Equipment & Number of production runs \\
\hline 6-inch upset & 21 \\
Hammer 3-2 & 19 \\
Hammer 10-1 & 16 \\
8-inch upset & 16 \\
Hammer 5-4 & 15 \\
Hammer 5-1 & 13 \\
Hammer 10-2 (day 1) & 12 \\
Hammer 35-2 & 12 \\
Hammer 10-2 (day 2) & 7 \\
\hline
\end{tabular}


Time history noise exposure profiles and sound level measurements showed that noise exposures during production runs were over $100 \mathrm{dBA}$ near the hammers and other forge operations. Using the noise measurement data downloaded from the dosimeters, we calculated the amount and percent of time noise exposures exceeded $100 \mathrm{dBA}$ for each job title that was monitored. We also calculated the amount of time and percent of time exposures exceeded $90 \mathrm{dBA}$. These results are provided in Table 3. Jobs near the hammer (hammer operator, trim press operator, and heater) had the highest percentage of time in which noise exposures exceeded $100 \mathrm{dBA}$. For most of the jobs we monitored, noise exposures exceeded $90 \mathrm{dBA}$ for most of the work shift.

Table 3. Total time and percent time noise exposures exceeded $100 \mathrm{dBA}$ and $90 \mathrm{dBA}$

\begin{tabular}{cccccc}
\hline Number of & Job title & \multicolumn{2}{c}{ Exposures $>100 \mathrm{dBA}$} & \multicolumn{2}{c}{ Exposures $>90 \mathrm{dBA}$} \\
\cline { 3 - 6 } measurements & & Minutes & Percent & Minutes & Percent \\
\hline 6 & Trim press & $67-272$ & $15-59$ & $240-422$ & $54-91$ \\
7 & Hammer operator & $84-261$ & $18-56$ & $205-431$ & $56-89$ \\
6 & Heater & $129-178$ & $29-37$ & $178-468$ & $59-98$ \\
2 & Shear operator & $64-99$ & $14-22$ & $233-257$ & $50-56$ \\
1 & Forklift operator & 91 & 19 & 320 & 66 \\
2 & Upset heater & $10-84$ & $2-18$ & $365-391$ & $80-84$ \\
1 & Tow motor driver & 65 & 15 & 237 & 54 \\
1 & Maintenance & 41 & 9 & 210 & 46 \\
2 & Line-up & $39-40$ & $8-9$ & $199-224$ & $42-47$ \\
2 & Upset operator & $2-40$ & $0.5-19$ & $317-426$ & $69-92$ \\
2 & Shotblast operator & $19-20$ & 4 & $186-215$ & $41-47$ \\
1 & Die repair & 17 & 4 & 88 & 19 \\
1 & Grinder operator & 8 & 2 & 385 & 83 \\
1 & Machinist & 0.1 & 0.03 & 9 & 2 \\
\hline
\end{tabular}

Hammer and trim press operators were exposed to noise above $100 \mathrm{dBA}$ for slightly more than 1 hour to about 4.5 hours. This variability is a reflection of the number and length of production runs at each hammer during the shift. Employees working at the furnace (heaters) were exposed to noise levels above $100 \mathrm{dBA}$ for about 2 to 3 hours. Most employees in other job titles also had substantial exposures to noise greater than $100 \mathrm{dBA}$. However, they worked farther away from the hammers or in a different building and as a result most had less overall time exposed to noise levels greater than $100 \mathrm{dBA}$.

Daily TWA exposures are directly related to the length of time exposures exceed $100 \mathrm{dBA}$. For a noise exposure of $100 \mathrm{dBA}$, the NIOSH REL is exceeded after 15 minutes, the OSHA AL is exceeded after 1 hour, and the OSHA PEL is exceeded after 2 hours. The differences between the NIOSH REL and OSHA AL, which both have an exposure limit of $85 \mathrm{dbA}$, is due to NIOSH using a 3-dB exchange rate and OSHA using a 5-dB exchange rate for noise dose accumulations (Appendix B). 
Figures 6 and 7 show time history noise exposure profiles for a shear operator and shotblast operator. Noise levels were 105-110 dBA during the process of cutting long metal rods into shorter ingots and when the ingots dropped about 3 to 4 feet into metal transport bins. At the shotblast, noise was generated by metal parts tumbling within the shot blast unit and by parts moving on the metal shaker platform from the shotblast to the metal transport bin. Substantially higher intermittent noise levels, sometimes exceeding $115 \mathrm{dBA}$, were generated when metal parts were dumped from the shotblast onto the shaker platform and when the metal parts fell from the shaker platform into the metal transport bin, particularly when the bin was mostly empty. Reduction of noise at both of these work areas should focus on reduction of noise generated by metal-to-metal contact and from metal dropping into transport bins (Figure 8).

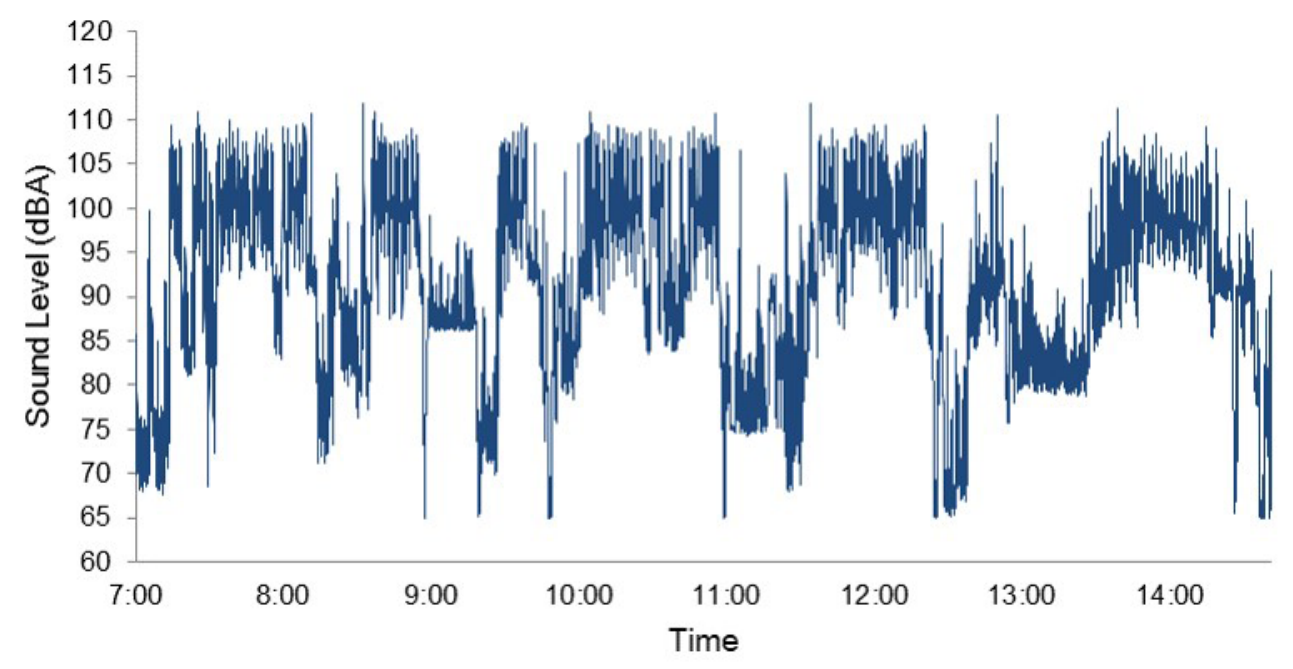

Figure 6. Shear operator noise exposure time history profile.

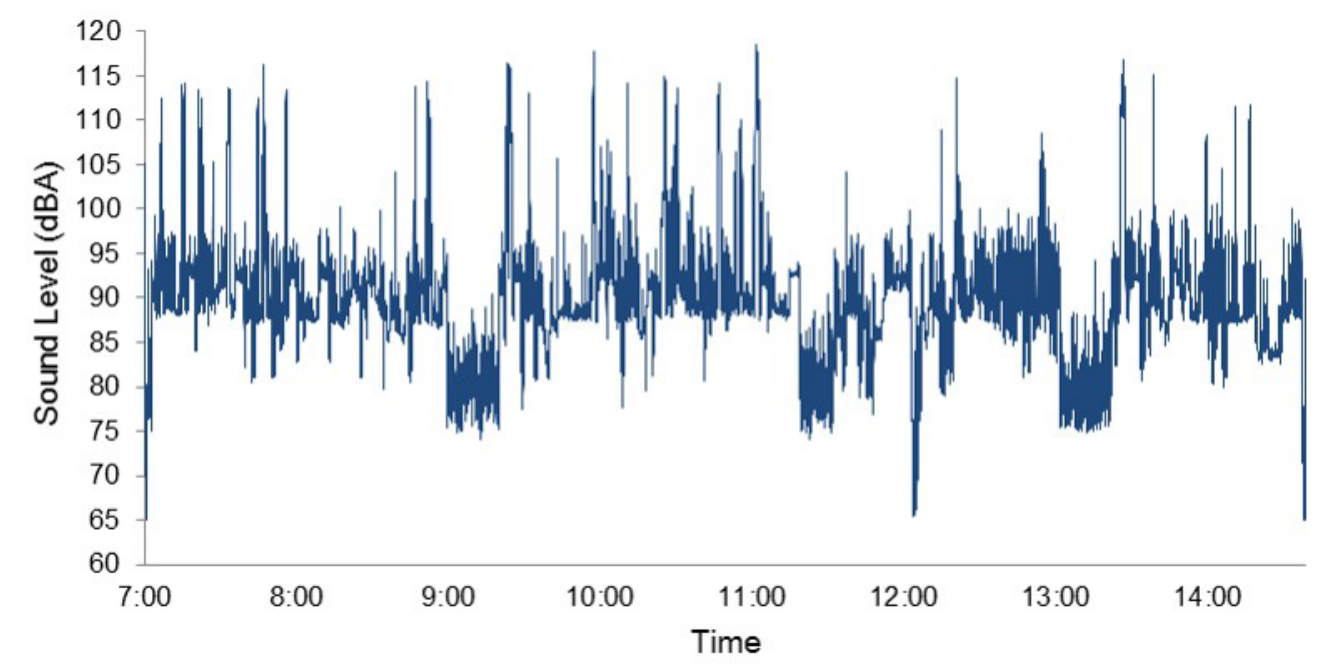

Figure 7. Shotblast operator noise exposure time history profile. 


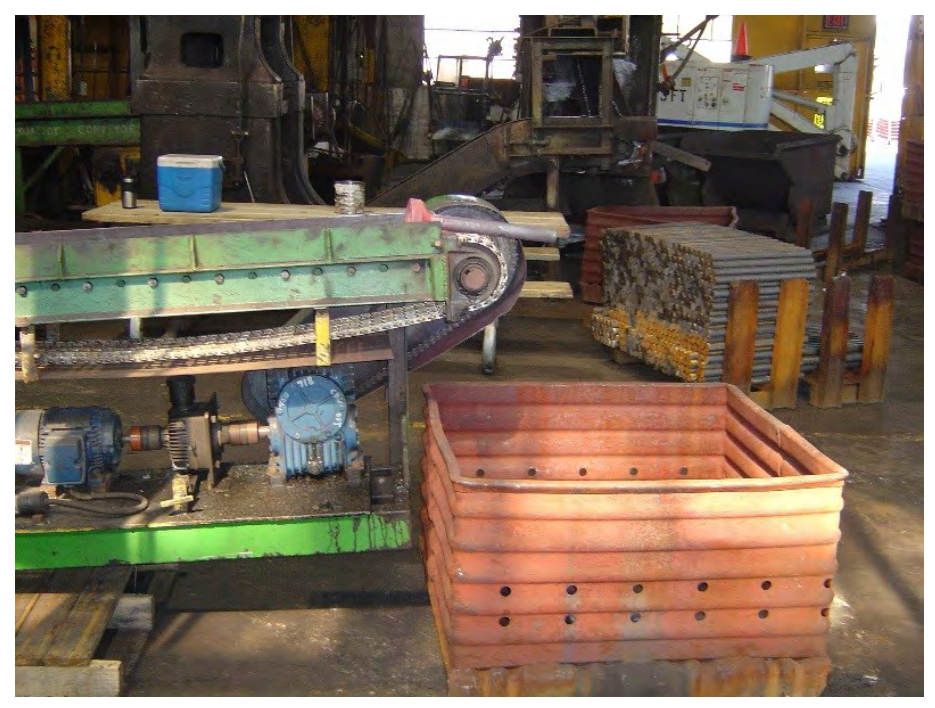

Figure 8. Metal bin below conveyor. These bins were used throughout facility for holding ingots and forgings. Photo by NIOSH.

Forge hammers striking molten ingots generate substantial impact noise. Figure 9 shows the sound pressure waveform for a single strike of a 5,000-pound forge hammer. The measurement units for reporting sound pressure in impact noise waveforms are pascals (Pa) rather than $\mathrm{dB}$. Pa can be converted to $\mathrm{dB}$ using the following formula:

Sound level $(\mathrm{dB})=20 \log _{10}\left(\mathrm{~Pa} / 2 \times 10^{-5}\right)$. The maximum peak for the 5,000-pound hammer was approximately $300 \mathrm{~Pa}(143.5 \mathrm{~dB})$.

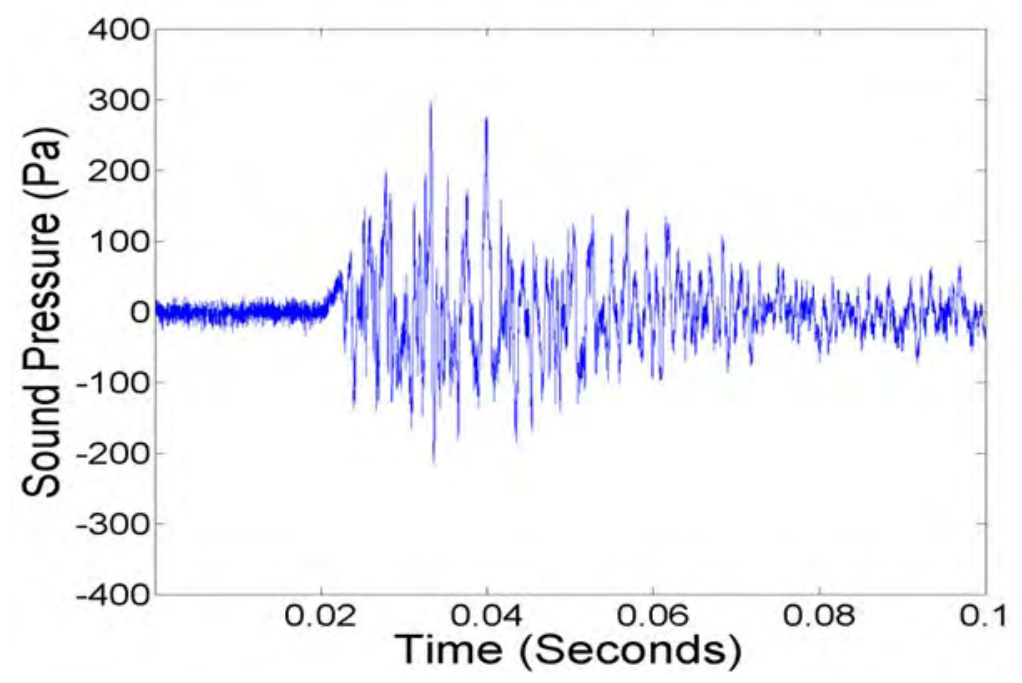

Figure 9. Typical sound pressure waveform for single hammer strike (hammer 5-4). 
The initial $0.02 \mathrm{sec}$ of the waveform reflects ambient background noise. The hammer strike is characterized by a large peak in sound energy caused by sudden deceleration of the upper die and ram upon impact, which is then followed by "ringing" of decreasing intensity over time. The ringing is caused by vibration of the hammer forge structure and can last for several tenths of a second. Ringing accounts for most of the sound energy from a hammer strike [Lam and Hodgson 1993]. Reduction of the ringing would reduce the TWA noise levels of each hammer strike.

The number, impact noise intensity, and sequence pattern of hammer strikes per forge part varied by size and type of part. Smaller or less complex parts usually required fewer hammer strikes than larger or more complex parts. Figure 10 shows impact noise for a sequence of seven hammer strikes for a single metal part at hammer 5-2. For this part the hammer strikes were grouped in pairs with approximately $1 \mathrm{sec}$ of elapsed time between each pair of hammer strikes and $3 \mathrm{sec}$ of elapsed time between successive pairs. As can be seen in the figure, not all hammer strikes are applied with the same force. Typically a molten metal part is struck with a few preliminary strikes of somewhat lower force followed by a short series of hammer strikes using full force. The highest peak tends to occur because of die to die impact after the part has been completely forged into its final shape [Rivin 2007].

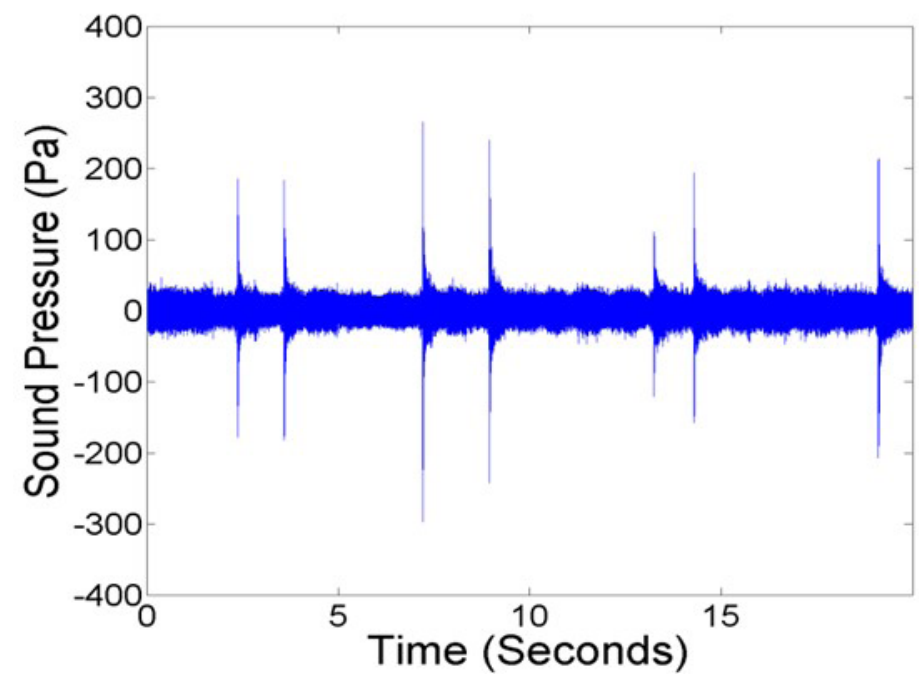

Figure 10. Sequence of hammer strikes for a single metal part at hammer 5-2.

Figure 11 shows a sequence of 22 hammer strikes for a larger metal part at hammer 5-4. The hammer strikes for that part occurred in groups of 2, 3, or 4. Approximately 1-2 sec elapsed between successive strikes within a group, and about 5-10 sec elapsed between groups of hammer strikes. The intensity of hammer strikes varied with several preliminary strikes of relatively lower intensity followed by hammer strikes of higher intensity. This figure also shows noise generated when the die is sprayed with a chemical releasing agent to prevent molten metal from sticking to the workpiece and die. 


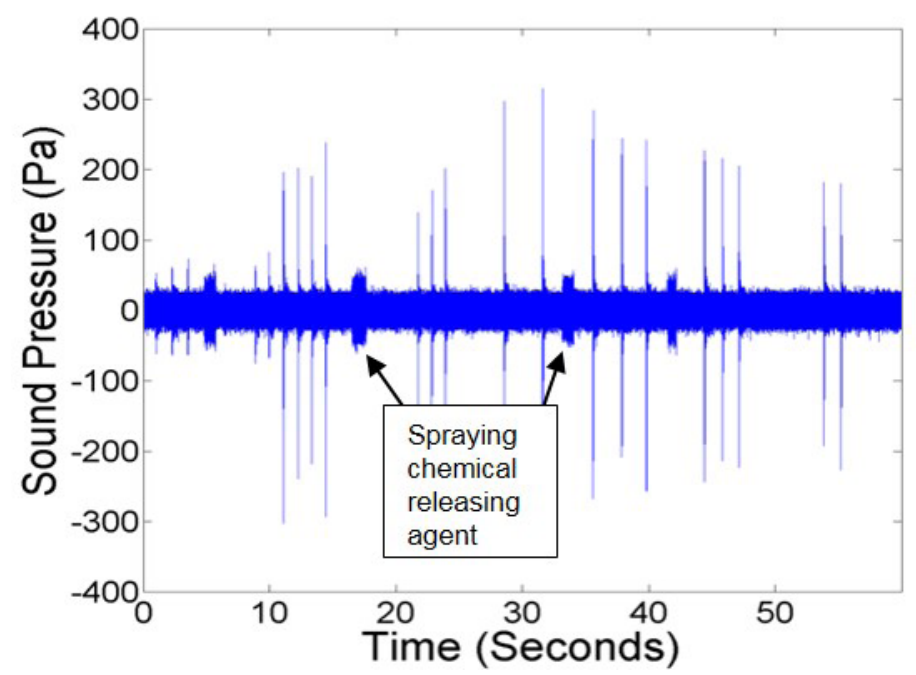

Figure 11. Sequence of hammer strikes for a single metal part at hammer 5-4.

The characteristics of impact noise at the forge hammers, upset press, shear press, and grinders where we collected measurements are summarized in Table 4. Maximum peaks during impacts at the hammers were 147-148 dB and averaged 138-143 dB. These levels are generally similar to those reported in other studies of noise in hammer forges [Taylor et al. 1984; Kamal et al. 1989; Sulkowski et al. 1999; Suvorov et al. 2001]. Maximum peak levels at the shear reached $140 \mathrm{~dB}$ but were below $140 \mathrm{~dB}$ at the upset press and grinder.

Table 4. Impact noise characteristics

\begin{tabular}{lcccccc}
\hline $\begin{array}{l}\text { Location of } \\
\text { measurement }\end{array}$ & $\begin{array}{c}\text { Peak } \\
\text { range } \\
(\mathrm{dB})\end{array}$ & $\begin{array}{c}25 \% \text { to } \\
75 \% \\
\text { percentile } \\
\text { range }(\mathrm{dB})\end{array}$ & $\begin{array}{c}\text { Average } \\
\text { peak } \\
(\mathrm{dB})\end{array}$ & $\begin{array}{c}\text { Peak rise } \\
\text { time } \\
\text { robust mean } \\
(\mathrm{msec})\end{array}$ & $\begin{array}{c}\text { Peak } \\
\text { A-duration } \\
\text { robust mean } \\
(\mathrm{msec})\end{array}$ & $\begin{array}{c}\text { Time between } \\
\text { impacts } \\
\text { robust mean } \\
(\mathrm{sec})\end{array}$ \\
\hline Hammer 5-1 & $123-148$ & $131-141$ & 138 & 0.138 & 0.443 & 0.8 \\
Hammer 5-2 & $135-148$ & $140-145$ & 143 & 0.251 & 0.844 & 3.1 \\
Hammer 5-4 & $128-147$ & $132-144$ & 140 & 0.138 & 0.492 & 1.3 \\
Hammer 10-1 & $135-148$ & $138-143$ & 141 & 0.398 & 0.914 & 0.9 \\
8-inch upset & $118-127$ & $119-122$ & 120 & 0.877 & 2.446 & 1.3 \\
press & & & & & & \\
700-pound & $128-140$ & $131-133$ & 132 & 0.877 & 0.377 & 1.8 \\
shear & & & & & & \\
Grinder & $119-135$ & $120-128$ & 125 & 0.262 & 0.674 & 1.3 \\
\hline
\end{tabular}

msec $=$ millisecond 
Impact peak rise times at the hammers were about $0.14-0.40 \mathrm{msec}$. However, the rise times we measured for the upset press and shear were more than double those of the hammers. The rise time for an impact waveform is the time from the beginning of the impact noise to its peak level. Faster rise times usually coincide with higher intensity impulse noises. The average repetition rate (i.e., the time between impacts) for hammer impacts was one impact every $0.8-3.1 \mathrm{sec}$. Impact waveform rise times and repetition rate for the hammers we measured were similar to those reported by Taylor et al. [1984].

A-duration times ranged $0.38-0.91 \mathrm{msec}$ at all locations except the 8-inch upset press, which had an A-duration of $2.4 \mathrm{msec}$. "A-duration" is an acoustical term that refers to the duration of the initial overpressure of the impact wave. The length of the A-duration time is related to the noise frequency spectral content of the impact. As A-duration times increase, the low frequency content of the impulse frequency spectrum also increases.

Peak noise levels during hammer strikes ranged from approximately $120 \mathrm{~dB}$ to nearly $150 \mathrm{~dB}$. Figure 12 shows the proportion of peak noise levels in three noise ranges at the hammers, upset press, shear press, and grinder. Nearly all hammer strikes generated peak noise levels greater than $130 \mathrm{~dB}$, and $37 \%-80 \%$ of noise peaks exceeded $140 \mathrm{~dB}$. However, less than $1 \%$ of the peak noise levels at the upset press, shear, and grinder were greater than $140 \mathrm{~dB}$. The total number of impact noise peaks greater than $140 \mathrm{~dB}$ that hammer operators are exposed to on a given day will depend on the type of forging, number of production runs, number of parts per production run, and number of hammer strikes per part. However, this number could range from a few hundred to a few thousand per day.

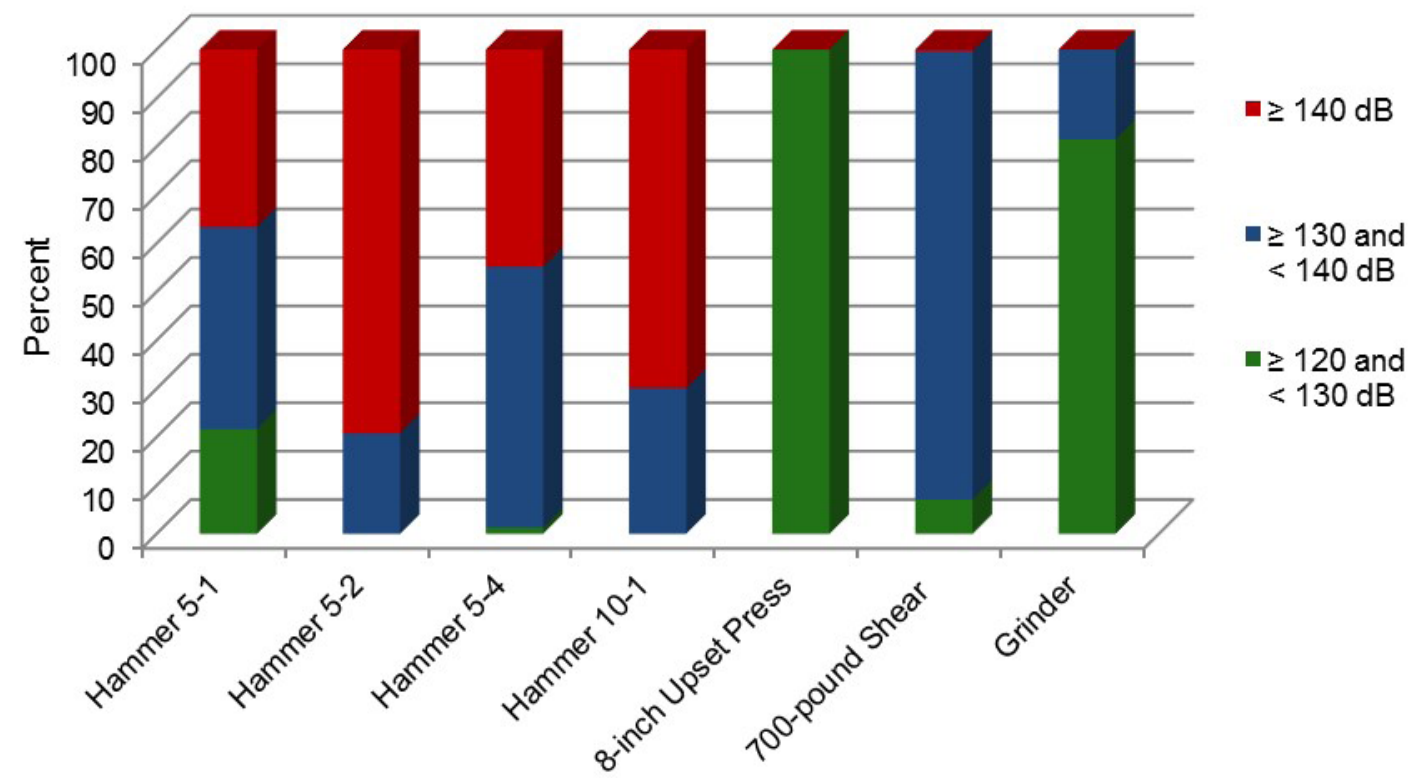

Location

Figure 12. Proportion of impact peak noise levels within three different ranges during hammer strikes. 


\section{Octave Band Noise Frequency Analysis and Noise Control}

Most workplace noise is broadband noise, which is distributed over a wide range of frequencies. For analysis of the frequency distribution characteristics of workplace noise, the frequency spectrum is broken into smaller frequency bands called bandwidths, the most common being the octave band, which is defined as a frequency band where the upper band frequency is twice the lower band-edge frequency. The one-third octave band further divides each of the single octave bands into three smaller frequency bands to provide even more detailed information about the noise frequency distribution characteristics. This information is useful for identifying the dominant frequencies of noise sources and determining appropriate engineering controls or other noise reduction measures. One-third octave band measurement results are shown in Figures A1-A6 in Appendix A.

Noise generated during hammer forging is primarily a result of the following actions [Riven 2007]:

- Sudden deceleration of impacting dies

- Rapid sideways expansion of the forge piece during a hammer strike

- Structural ringing of the hammer

- Discharge of air from between dies

- Noise from vibration of the floor or ground around the hammer

The level of noise produced during hammer strikes depends on several factors including the magnitude and duration of the hammer blow pulse from decelerating dies, intensity of the strike, velocity of the strike, die design, cross sectional size of the forged part and die, and transverse stiffness of the part. Additionally, structural ringing of the hammer can be much greater if the hammer strike is off center [Rivin 2007].

The highest noise levels at the hammers were at frequencies at or below $63 \mathrm{~Hz}$, in the frequencies of $250-2,000 \mathrm{~Hz}$, and at frequencies above $8,000 \mathrm{~Hz}$. The very low frequency noise was caused by transmission of vibration from hammer strikes to the surrounding metal structure of the hammer and to the surrounding floor area. Some employees reported that the intense downward forces generated during hammer strikes caused the forge hammers to slowly sink over time, which required the hammers to be raised occasionally and additional support structures to be installed beneath the hammers.

Predominant noise in the $250-2,000 \mathrm{~Hz}$ frequencies at hammers most likely reflects sudden deceleration of the ram and upper die at impact and ringing of the machine structure immediately following impact. A research study evaluating and predicting ringing noise from forge hammers reported that the major energy content from deceleration of the ram occurred in noise frequencies of 500-1,000 Hz. The study also reported that noise from ringing occurs in the 2,000 Hz octave band [Lam and Hodgson 1993].

The high noise levels at frequencies above $8,000 \mathrm{~Hz}$ during hammer operation were likely due to noise from discharging compressed air and spraying the chemical releasing agent 
onto the dies through open ended hollow tubes (Figure 13). Octave band measurements showed that noise levels in these high frequencies were lower at a distance of 2 meters than the measurements taken near the hammer. In addition to decreasing noise with increasing distance due to the inverse square law, noise may have further decreased because hammer operators sometimes stood between the hammer and the second microphone thereby blocking some of the high frequency noise. Noise from discharge of compressed air can be reduced by using nozzles that are designed to produce less noise. High frequency noise exposures can be also reduced by using equipment enclosures or noise barriers [Driscoll and Royster 2003]. An enclosure for the hammers may not be practical or feasible. However, construction and use of sound insulating, freestanding observation booths near the heat wait benches would provide employees a place to observe hammer operations during heat waits or at other times, but with lower noise levels.

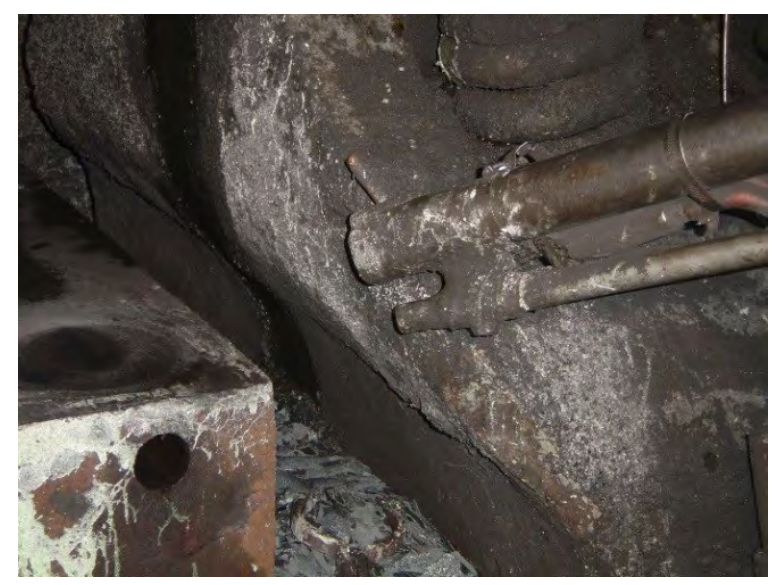

Figure 13. Open tube nozzles directed toward hammer block. Photo by NIOSH.

Although the forge hammers generated the highest noise levels in the facility, other considerable noise sources included metal-to-metal noise from dumping or dropping ingots or forgings onto metal surfaces, noise from the burners in the furnace, and noise from the release of compressed air. In the grinding area, employees sometimes tossed forgings into nearby metal bins. Metal-to-metal noise resulted from the impact of ingots or forgings falling onto or being dumped onto other metal surfaces such as metal chutes (Figure 14), conveyor pans, and metal bins and the subsequent vibration and noise reverberation of the metal surfaces that were struck, particularly when a metal bin was empty or mostly empty. For example, high noise levels at the shot blast were generated by dumping forgings into the shot blast unit, tumbling of forgings, and dumping forgings from the shot blast onto the metal conveyor. Noise was also produced by vibration of the conveyor pan, metal forgings bouncing on the conveyor pan as they moved to a metal bin, and the forgings dropping down from the conveyor pan into a metal bin (Figure 15). 


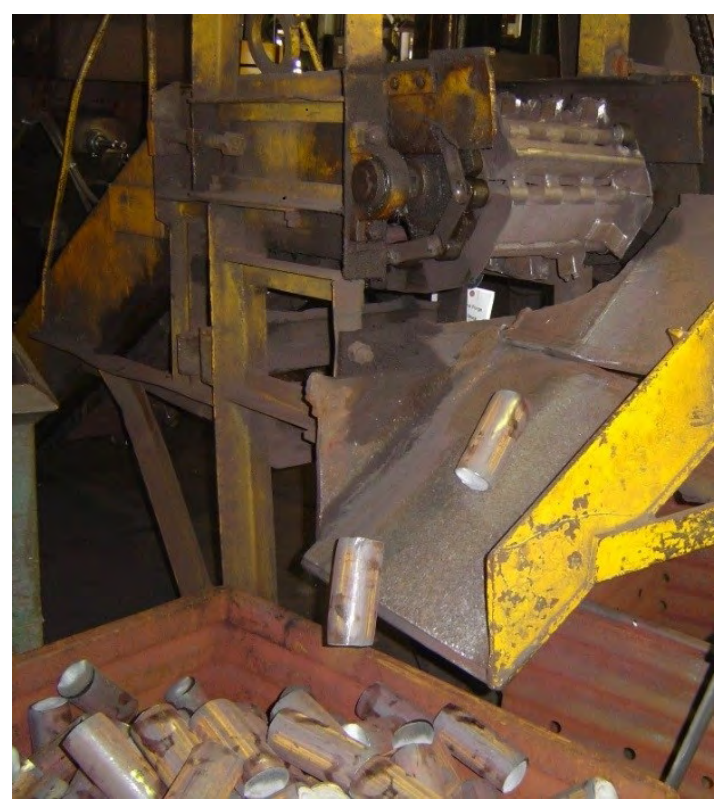

Figure 14. Ingots dropping from the shear onto a metal chute and falling into a metal bin. Photo by $\mathrm{NIOSH}$.

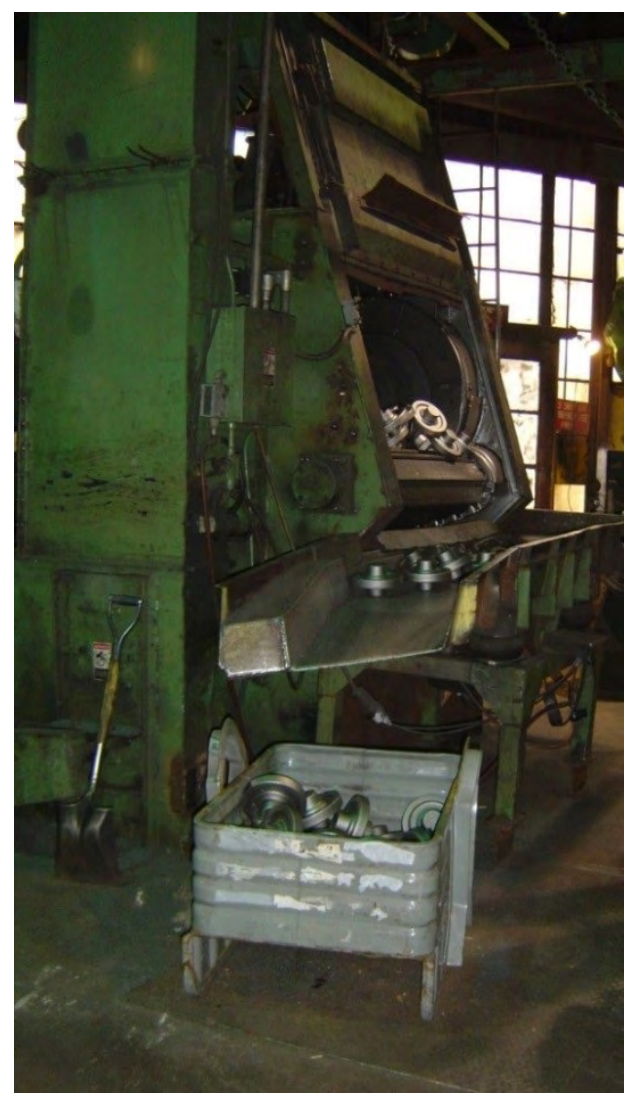

Figure 15. Forgings being dumped from a shotblast onto a vibrating conveyor pan and moving down the conveyor to fall into a metal bin. Photo by $\mathrm{NIOSH}$. 
Reducing the force of impacts and reducing vibration and resulting reverberant ringing of metal surfaces after impact can help decrease metal-to-metal noise. Overall noise reduction strategies to achieve this include reducing the distance that metal ingots or forgings fall into bins or conveyor pans, increasing the thickness or adding constrained layer damping to metal surfaces, covering metal surfaces with durable polymers, and replacing metal bins with durable plastic bins.

The upset press, shear, and grinders all had dominant noise frequencies below $63 \mathrm{~Hz}$ due to vibration of the equipment. This low frequency noise could be attenuated by reducing equipment vibration and transmission of vibration to surrounding floor surfaces. For example, placement of appropriately designed vibration isolation pads or springs under heavy equipment can reduce the vibration transmitted from equipment to the surrounding floor and all surfaces. The shear had secondary frequency peaks between 2,000 and 4,000 Hz, and the upset press had secondary frequency peaks between 125 and $500 \mathrm{~Hz}$. The one-third octave band frequency patterns at the upset press, shear, and grinders were similar for the measurements collected at a distance of 2 meters or more from the equipment.

In addition to the discharge of compressed air and chemical releasing agents onto the dies during hammer operation, employees also used compressed air to clean debris off forgings or work surfaces. Some of the compressed air nozzles used a thin length of hollow metal tubing. Blowing air out of an open tube generates air turbulence and high noise levels, particularly high frequency noise, as the air exits the tip of the tube. Open tube nozzles also use much more compressed air than necessary and are therefore more costly. Some manufacturers of engineered compressed air nozzles have shown that open tube nozzles generate up to $10 \mathrm{~dB}$ more noise than properly engineered nozzles. In contrast, efficient air nozzles not only produce less noise, but also reduce compressed air consumption by $30 \%$ to $60 \%$, resulting in substantial cost savings [Saidur et al. 2010]. Additionally, the open tube design can present a safety risk because the nozzle does not have a mechanism to reduce air pressure to less than 30 pounds per square inch if the end of the nozzle becomes blocked.

Proper maintenance of equipment can also help reduce noise. For example a worn or poorly maintained clutch in a hammer, worn out motor bearings, or loose and rattling metal parts generate unnecessary noise that can be eliminated.

Because noise engineering controls are sometimes difficult to design and retrofit on existing equipment, noise reduction should also be part of an overall long-term strategy. For example, when equipment is replaced, the amount of noise generated by the new equipment should be considered as part of the purchasing decision. "Buy Quiet" is a concept by which companies can reduce hazardous noise levels through their procurement process. Through this process, purchasers are encouraged to consult with equipment and tool manufacturers, compare noise emission levels for differing models of equipment and, whenever possible, choose equipment that produces less noise and vibration.

\section{Analysis of Hearing Protectors}

We used an acoustic mannequin head (Figure 16) to assess the attenuation of the two types of insert foam hearing protectors, 3M E-A-R Classic and 3M E-A-Rsoft, worn by forge workers. 


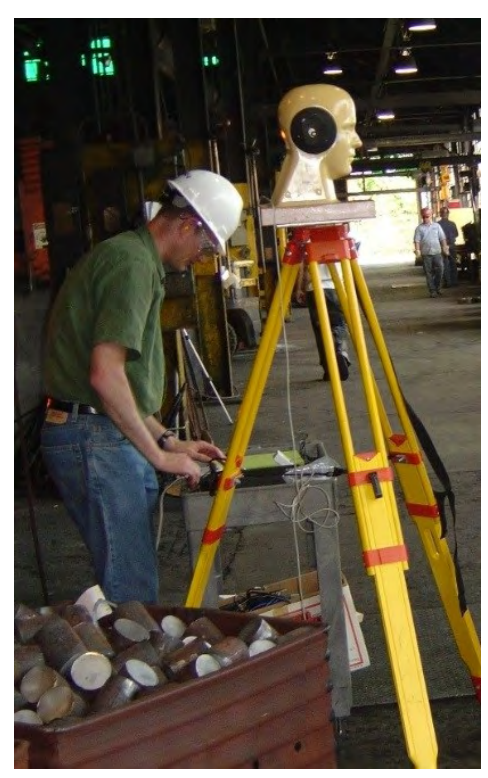

Figure 16. $\mathrm{NIOSH}$ researcher preparing to take hearing protector noise attenuation measurements using an acoustic mannequin head. Photo by NIOSH.

We did these tests at two forge hammers (hammer 5-4 and hammer 10-2) during normal production operations. Results for these tests are shown in Figures 17 and 18. The red vertical bars on Figures 17 and 18 show the noise exposure level we measured near the mannequin head, and the red horizontal line on each figure shows the frequency-specific noise levels we measured. The blue vertical bars show the noise levels we measured under the hearing protector (protected mannequin level), which the NIOSH researcher inserted into the mannequin head. The blue horizontal line on the figure is the frequency-specific noise level we measured under the hearing protection. The measured noise exposure levels under the hearing protection in the mannequin indicate the noise attenuation potentially achieved by deeply inserted hearing protectors. The E-A-R Classic had less attenuation than the E-A-Rsoft at frequencies below $250 \mathrm{~Hz}$; however, both hearing protectors provided similar overall noise attenuation of $42-44 \mathrm{~dB}$ when properly inserted by the NIOSH researcher into the mannequin.

For comparison, the black vertical bars on the figures show the estimated noise exposure level under the hearing protection that might be expected for employees wearing these hearing protectors (estimated protection level), based on the noise levels we measured at the mannequin head. The hearing protector attenuation used to determine the "estimated protection level" were based on previous subject fit-test studies, which estimated an average attenuation of 28-29 dB for these hearing protectors [Murphy et al. 2011]. The wide black horizontal line is the average frequency-specific estimated protection level, and the progressively lighter shading extends to three standard deviations. The range of attenuation varies from very little attenuation to an attenuation similar to what we found in our testing of hearing protectors in the acoustic mannequin. 
Peak noise levels measured at hammers 5-4 and 10-2 were 144-146 dB. However, with E-A-R Classic or E-A-Rsoft inserted into the mannequin head, peak noise levels were $116-124 \mathrm{~dB}$ under the hearing protection. This $20 \mathrm{~dB}$ to $30 \mathrm{~dB}$ potential reduction in peak noise reinforces the importance of employees wearing properly fitting hearing protection.
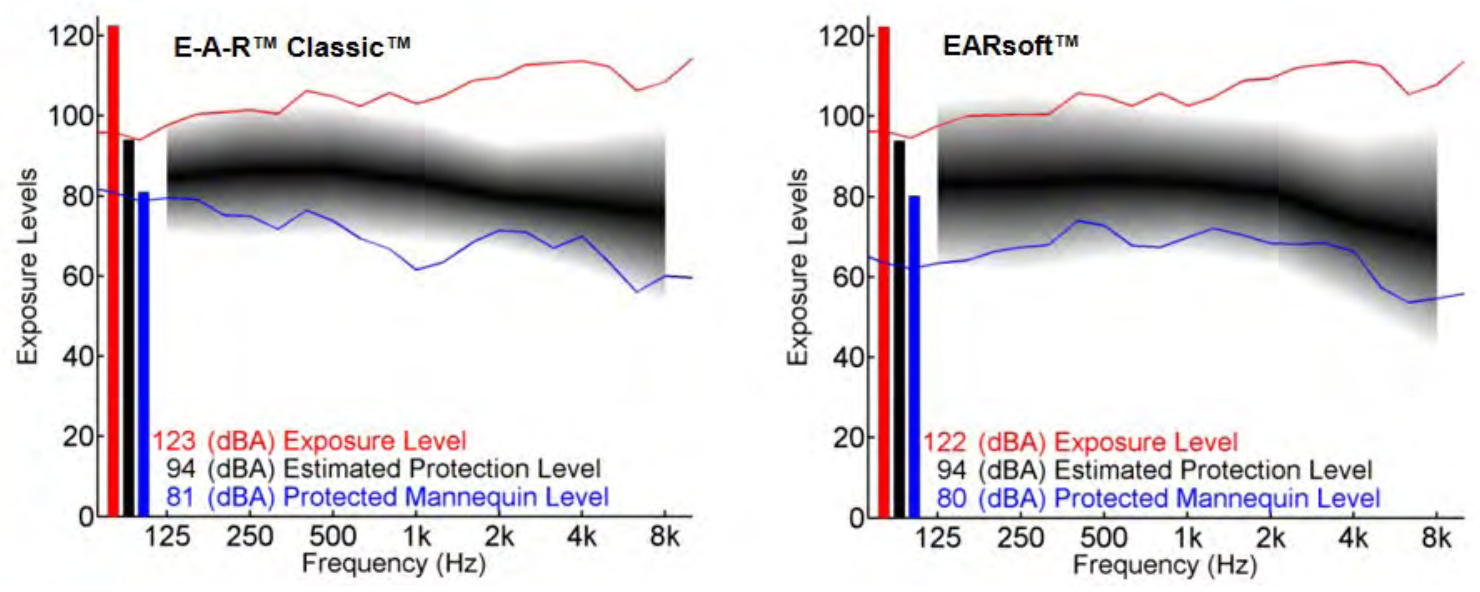

Figure 17. Hearing protector attenuation test results for two insert-type hearing protectors at hammer 5-4.
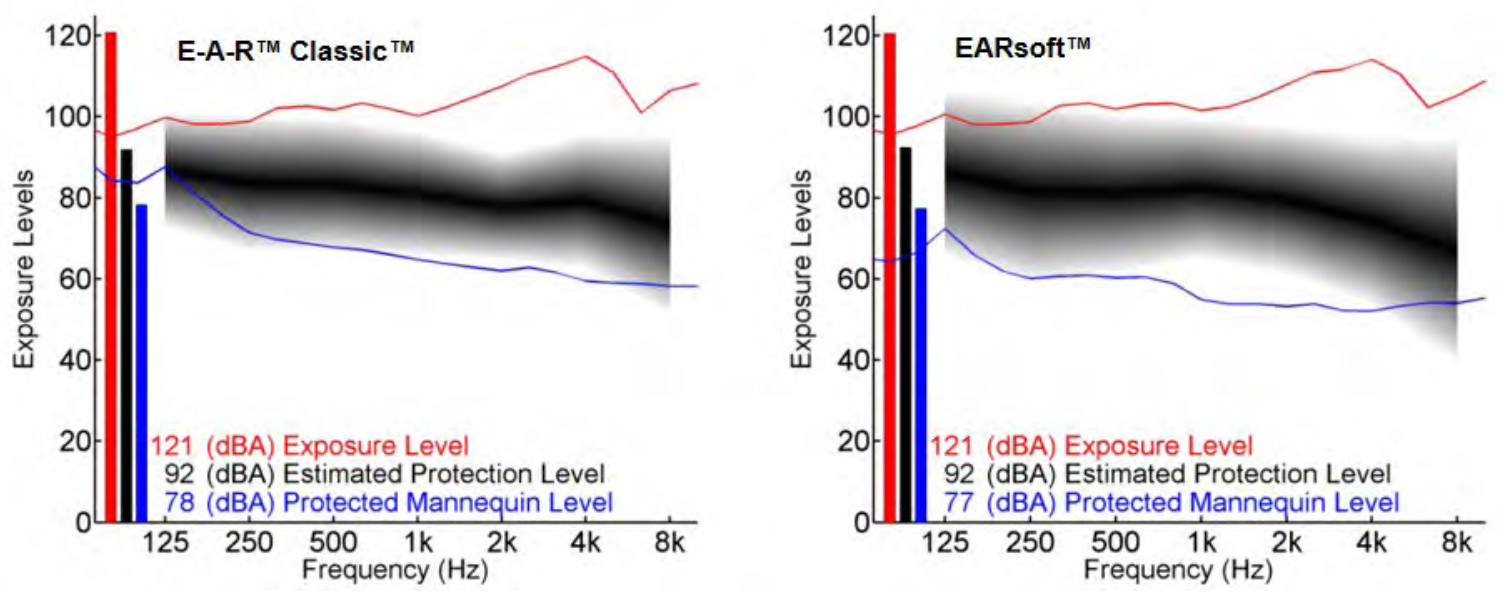

Figure 18. Hearing protector attenuation test results for two insert-type hearing protectors at hammer 10-2. 
According to the hearing protector manufacturer E-A-R Classic had a noise reduction rating (NRR) of $31 \mathrm{~dB}$ and the E-A-Rsoft had a NRR of $33 \mathrm{~dB}$. The manufacturers' NRR is a rating of the hearing protector attenuation which is determined by the manufacturer under laboratory test procedures specified by American National Standards Institute (ANSI) S3.19-1974, "American National Standard for the Measurement of Real-Ear Hearing Protector Attenuation and Physical Attenuation of Earmuffs." However, our testing of the attenuation for these hearing protectors in the mannequin head and the range of attenuation achieved by subject fit testing show that more noise attenuation than the manufacturers' NRR may be possible with well-fitting hearing protectors. In contrast, subject fit test data also show that poorly fitting hearing protection provides attenuation much worse than the manufacturers' reported NRR [Berger et al. 1996; Berger et al. 1998; Franks et al. 2000; Joseph et al. 2007; Murphy et al. 2011].

The preferred and most effective method for reducing employees' noise exposures is installation of noise controls that decrease noise levels. However, implementation of noise controls that successfully bring noise exposure levels below exposure limits may not be immediately feasible in this workplace. Therefore, employees must continue to be included in the company's hearing conservation program and must continue to wear hearing protection that provides suitable noise reduction. In addition to the two types of insert hearing protectors, the company also provided earmuffs. Employees had the option to wear dual hearing protection, i.e., both insert ear plugs and earmuffs, but it was not required. Most employees preferred to wear insert ear plugs; we observed few employees using dual protection. During annual audiograms, the audiometric test provider conducted training on how to wear hearing protection.

Hearing protection must attenuate noise levels to less than $85 \mathrm{dBA}$ to provide adequate protection. Proper insertion of the hearing protection is critically important to ensure adequate noise attenuation. Noise attenuation of insert-type hearing protection by individual users depends on the type of hearing protector, shape of the user's ear canal, how well the hearing protector fits, and proper insertion of the hearing protector. Several hearing protection manufacturers have developed methods for fit testing individual employees to determine the attenuation they actually receive from the hearing protectors they use.

During our evaluation, we observed that some employees did not wear hearing protection properly. Additionally, research has shown the hearing protectors can appear to be properly inserted into the ear canal but still provide poor attenuation of noise because of factors such as improperly sized hearing protectors or channeling of the hearing protector in which a narrow gap is made in the foam insert hearing protection during the process of rolling them. The gap permits additional noise to enter the ear canal through the channel, reducing the overall attenuation of the hearing protection. NIOSH has previously identified that poor insertion of formable hearing protection into the ear canals reduces the ability of the hearing protectors to attenuate noise exposure [NIOSH 1998]. 


\section{Employee Interviews}

During the first visit in April 2007, we conducted confidential medical interviews with 10 employees across production departments. All 10 employees were male. Some employees reported two job titles including hammer operator, line-up, upset operator, blacksmith, cool coiner, saw operator, and heat treater. These jobs were located in various parts of the facility with three from the north forge, two each from the south forge and shear room, and one each from south hammer shop, upset, and heat treat. Employee age ranged 27-65 years of age (median 54 years). Total time working at their current job ranged 11 months -35 years (median 17.5 years). Job titles of those interviewed include hammer operators (4), saw operator (2), line-up (1), blacksmith (1), cool coiner (1), and heat treat (1).

Three employees reported that the audiometric test provider had informed them that hearing loss was evident on their annual audiometric testing, which had been completed within the previous year. These employees' job titles were hammer operator, blacksmith, and line-up. Their ages ranged 51-65 years. All three reported currently using ear plugs while at work, and one reported currently using dual protection (ear plugs and earmuffs).

We asked employees if they had any other concerns about workplace exposures. Six of the interviewed employees did not have concerns, but four reported multiple concerns about exposures to heat, vibration, noise, and oil mist. Employees were asked separately about workrelated health concerns. Four employees noted repeated eye injuries from scale being knocked off forgings when struck with hammers. In addition, some employees reported that the use of fans and open doors in summer months to reduce heat also resulted in more scale being blown around by air movement and wind gusts. The employees did not report having vision problems, but many felt that eye protection was not adequate. Employees reported that they were provided with safety goggles, but these were often not used because the goggles fogged up in hot weather. One employee suggested a screen could be placed around hammers to catch flying scale. Two employees reported making their own wire mesh temple protectors to prevent scale from being blown into their eyes from the side. One employee reported eight incidents of foreign body eye injuries due to scale but thought he had no lasting eye problems.

All 10 employees reported easy access to company-provided electrolyte sports drinks for cooling/hydration purposes, and those who worked near the furnaces reported being able to wait during the heat treat cycle in air-conditioned control rooms. The company also provided fans to increase air movement in the large, open production area. No employee reported requiring medical care for heat-related illness.

Other work-related hazards that employees reported included dust produced by grinders resulting in black nasal mucous, oil splashes when pallets were dropped into the quench pools resulting in throat irritation from aerosolized oil, and pooling of oil on the floor causing slip hazards. Standing water near hammer 5-3, due to a long-standing drainage problem, was also reported to be a slip hazard. One employee reported having had numbness in his arms and hands while working at the grinder. However, these symptoms had subsided 7 years earlier after moving to another work assignment. An employee raised a concern about the need for better safety guards on the hot trim press because there was no way to stop the 
downward motion of the hammer once the cycle started.

We reviewed OSHA's Form 300 Log of Work-Related Injuries and Illnesses for 2002-2006. The majority of recordable injuries were thermal burns or trauma-related musculoskeletal injuries. One recordable injury during this period was caused by a foreign body in the eye. Seven recordable cases of hearing loss were reported, but none were among the interviewed employees. In 2003, a blacksmith, line-up employee, and an upset department employee (job title not specified on log) had recordable hearing loss. The $2004 \log$ showed that a supervisor, hammer operator, and maintenance worker had recordable hearing loss. The 2005 log did not show any recordable injuries or illnesses. In 2006, a welder had recordable hearing loss.

In 2005, a hammer operator was diagnosed with carpal tunnel syndrome, a condition that affects the median nerve as it crosses the wrist resulting in pain and decreased strength of the hand. The log included a notation indicating that this employee's condition was associated with the use of tongs. Repetitive, forceful movements are well known to be associated with carpal tunnel syndrome. However, exposure to hand-arm vibration can also contribute to nerve damage in the hand and wrist resulting in numbness and tingling, and/or difficultly coordinating movement. We looked for reports of medical conditions that could be consistent with overexposure to whole body vibration produced by the large impact forces from forge hammer strikes, such as herniated discs in the cervical or lumbar spine which can result in numbness, pain, or loss of motor strength in the arms or legs. However, in the logs we reviewed, we did not find any reports of medical conditions associated with exposure to whole body vibration.

\section{Analysis of Audiometric History}

The company used a contractor to complete annual audiometric testing of all workers. Audiometric testing was usually completed in October and November and follow-up testing, if necessary, was completed in December. Audiometric testing was generally completed in the afternoons toward the end of the first shift and before the beginning of the second shift. The audiometric provider conducted pure-tone air-conduction threshold testing at frequencies of $500 \mathrm{~Hz}, 1,000 \mathrm{~Hz}, 2,000 \mathrm{~Hz}, 3,000 \mathrm{~Hz}, 4,000 \mathrm{~Hz}$, and 6,000 Hz. NIOSH recommends that employers consider also testing at $8,000 \mathrm{~Hz}$ to improve decisions about probable etiology of hearing loss [NIOSH 1998].

Some employees reported that they could occasionally hear background noise during the audiometric testing, such as from the backup alarm of a truck or from the hammers. Background noise during audiometric testing can affect the results and potentially result in a false positive threshold shift. Background ambient noise levels in the audiometric test area must meet the requirements specified by ANSI [ANSI 1991].

The audiometric dataset provided to us by the company initially included 7,908 audiograms for 618 employees for the years 1981 to 2006. Before longitudinal analysis of hearing loss, we used NIOSH audiometric quality assurance screening guidelines [Franks 1999] to eliminate audiograms with inaccurate thresholds, incomplete audiograms, or audiograms that had patterns indicating that hearing loss could be a result of non-occupational factors. 
Audiometric screening based on these guidelines has been used in previous NIOSH research [Heyer et al. 2011; Masterson et al. 2013]. After screening, the dataset had 4,750 audiograms from 483 workers. The majority of audiograms were eliminated due to large intra-aural differences in the same frequency thresholds between ears, which are rarely caused by occupational noise exposures [Arslan and Orzan 1998]. The mean number of audiograms per employee was 7.7 (range: 1-27). The company was able to provide hire dates for some of the employees in the dataset. The average duration of employment for the workers for whom we had hire dates $(\mathrm{n}=212)$ was 20.7 years (range: $1.7-45.4$ years).

For employees hired after 1983 for whom we had hire dates $(n=114)$, we analyzed the time between each employee's hire date and the date of his or her baseline audiogram. We selected 1983 because the OSHA hearing conservation standard went into effect that year, requiring baseline audiograms to be completed within 6 months of hire. When a mobile audiometric test van is used to meet audiometric test requirements, OSHA permits baseline audiograms to be completed within 1 year of hire, but only if employees wear hearing protection for periods exceeding 6 months. Results are shown in Table 5. Over $80 \%$ of employees hired in the 1980s and 1990s had audiograms completed within 6 months of hire. This decreased to $51 \%$ for those hired after year 2000. Nearly all of the 114 employees had their first audiograms completed within 1 year of hire. Completing baseline audiograms before new employees begin working allows identification of pre-existing hearing loss before workplace noise exposure occurs. In contrast, if the baseline audiogram shows hearing loss, but was completed after the employee had already been working, it may not be possible to determine whether the hearing loss was pre-existing or occurred after the employee had begun working.

Table 5. Time between employees' hire dates and baseline audiometric test $(n=114)$

\begin{tabular}{lccc}
\hline Decade of hire & \multicolumn{3}{c}{ Number of employees $(\%)$} \\
\cline { 2 - 4 } & $\leq 6$ months & $>6$ months and $<12$ months & $\geq 12$ months \\
\hline $1980 \mathrm{~s}$ & $21(88)$ & $2(8)$ & $1(4)$ \\
$1990 \mathrm{~s}$ & $16(84)$ & $3(16)$ & $0(0)$ \\
$2000 \mathrm{~s}$ & $36(51)$ & $34(48)$ & $1(1)$ \\
\hline Overall & $73(64)$ & $39(34)$ & $2(2)$ \\
\hline
\end{tabular}

We also looked for trends in the percent of employees identified each year with hearing threshold shifts or NIOSH-defined material hearing impairment. OSHA and NIOSH use different hearing threshold shift criteria. OSHA defines a standard threshold shift (STS) as an average change in hearing threshold, relative to the baseline, of $10 \mathrm{~dB}$ or more across the audiometric test frequencies of 2,000 Hz, 3,000 Hz, and 4,000 Hz. NIOSH defines a hearing threshold shift as a change in hearing threshold, relative to the baseline, of $15 \mathrm{~dB}$ or more in any of the audiometric test frequencies. NIOSH defines material hearing impairment as an average hearing threshold level (HTL) for both ears of $25 \mathrm{~dB}$ or more at 1,000 Hz, 2,000 Hz, 3,000 Hz, and 4,000 Hz [NIOSH 1998]. From 1983 to 2006, we did not observe an upward or 
downward trend in the percent of employees identified each year with hearing threshold shifts or NIOSH-defined material hearing impairment (Figure 19). The annual percent of workers with an OSHA STS ranged 4\%-18\%. The annual percent of employees with a NIOSH hearing threshold shift was higher, ranging from $15 \%-44 \%$. Approximately $15 \%-35 \%$ of workers each year had a material hearing impairment, on the basis of the NIOSH definition.

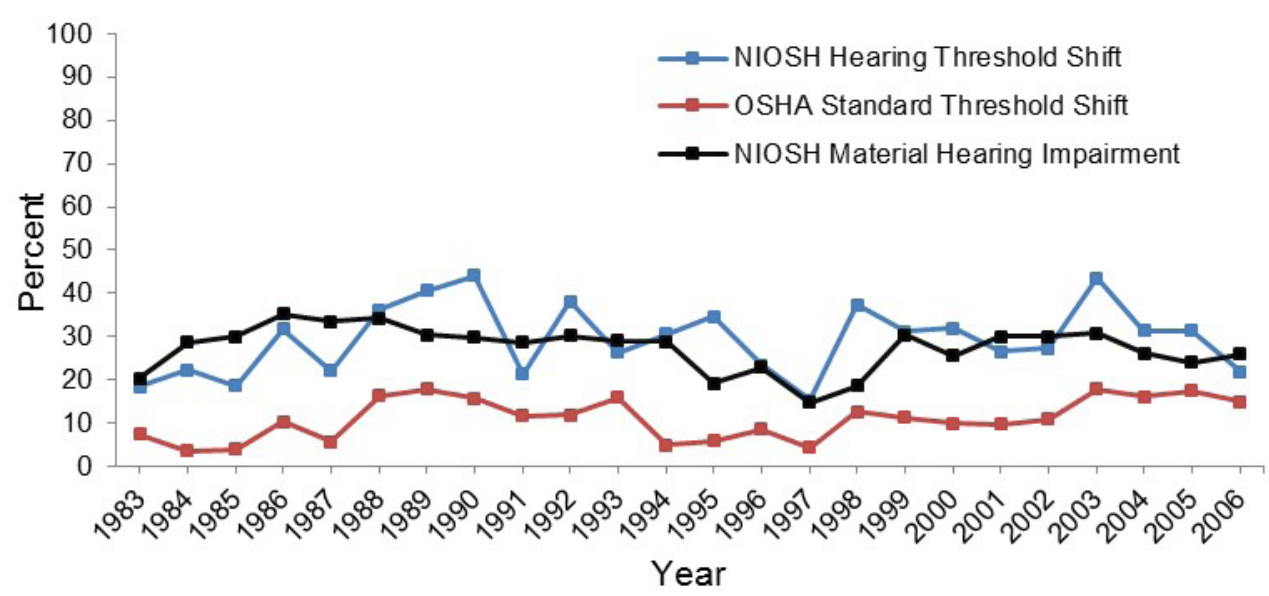

Figure 19. Percent of employees each year with a NIOSH hearing threshold shift, OSHA STS, and $\mathrm{NIOSH}$ defined material hearing impairment.

Our analysis of the audiometric history for the 483 forge employees who had more than one valid audiometric test completed indicated that 395 (82\%) had experienced a hearing threshold shift since their baseline audiogram, on the basis of NIOSH hearing threshold shift criteria. Using OSHA STS criteria, 303 (63\%) had experienced an OSHA STS since their baseline audiogram. Similarly, after analysis of a large audiometric database of aluminum company workers, Rabinowitz et al. [2007] also found that NIOSH criteria for identifying hearing threshold shifts identified more workers than OSHA STS criteria. Our analysis showed that all of the employees with an OSHA STS previously had a NIOSH hearing threshold shift. However, 23\% (92/395) of employees with a NIOSH hearing threshold shift had not advanced to an OSHA STS.

For the 303 employees who had an OSHA STS, we analyzed the length of time between when employees were first identified with a NIOSH hearing threshold shift to when they were first identified with an OSHA STS. Overall results and results stratified by age group are shown in Figure 20. On average, 7.25 years (range: 0-24 yrs) elapsed between when employees were first identified with a NIOSH hearing threshold shift to when they were first identified with an OSHA STS. The elapsed time was longest for the 25-34 year and 35-44 year age groups and somewhat less for the under 24 years and the $45-54$ year age group. The elapsed time was the shortest for the 55-64 year age group.

For workers $(n=308)$ with a normal baseline audiogram $(\mathrm{HTL}<20 \mathrm{~dB})$ preceding hearing threshold shifts, we stratified the length of time from their baseline audiogram to a hearing 
threshold shift by their age at the time of the baseline audiogram (Table 6). On the basis of NIOSH hearing threshold shift criteria, we saw little difference by age group. Overall, 4.6 years elapsed from a normal baseline to a NIOSH hearing threshold shift. Using OSHA criteria, workers less than 45 years of age at the time of their baseline audiogram had an OSHA STS after approximately 9 years employment in the forge, whereas older employees progressed to an OSHA STS after approximately 5 years. It is unclear why these older workers progressed to OSHA STS more quickly. We did not adjust for age-related hearing loss, so this higher rate of progression could be a result of aging along with noise exposure. Other possible explanations include less consistent use of hearing protection or assignment of older, more experienced workers to jobs with higher noise exposures. We did not have hearing protection use or job title information to further examine these possibilities.

Table 6. Mean number of years from normal baseline audiogram to NIOSH and OSHA threshold shift, stratified by age at time of baseline audiogram

\begin{tabular}{lcccc}
\hline Age group & $\begin{array}{c}\text { Number of } \\
\text { subjects }\end{array}$ & $\begin{array}{c}\text { Years to NIOSH } \\
\text { threshold shift }\end{array}$ & $\begin{array}{c}\text { Number of } \\
\text { subjects }\end{array}$ & $\begin{array}{c}\text { Years to OSHA } \\
\text { threshold shift }\end{array}$ \\
\hline$<25$ & 21 & 5.0 & 8 & 9.4 \\
$25-34$ & 135 & 4.8 & 107 & 9.3 \\
$35-44$ & 104 & 4.5 & 85 & 9.0 \\
$45-54$ & 43 & 4.5 & 35 & 5.5 \\
$55-64$ & 5 & 3.5 & 3 & 5.1 \\
\hline Overall & 308 & 4.6 & 238 & 8.6 \\
\hline
\end{tabular}

NIOSH hearing threshold shifts always preceded OSHA STS for this worker population. Although the company followed OSHA criteria for identifying STS in annual audiograms, using NIOSH criteria for identifying hearing threshold shifts would lead to earlier identification and intervention to potentially prevent further hearing loss for many of the workers. This could help reduce the number of employees who eventually progress to an OSHA STS and to OSHA recordable hearing loss.

Probability of a hearing threshold shift using NIOSH criteria, stratified by length of tenure, was about two to five times greater than the probability of an OSHA STS (Table 7). In general, the probability of an OSHA STS, NIOSH hearing threshold shift, and NIOSHdefined material hearing impairment increased with length of tenure, after the first 10 years of noise exposure. For the first 10 years of employment, the probability of material hearing impairment was similar or slightly less than the risk of an OSHA STS. After 10 years of employment, the risk of material hearing impairment was progressively greater than the risk of an OSHA STS. Probability of a NIOSH hearing threshold shift was greater than probability of material hearing impairment, regardless of length of tenure. 
Table 7. Percent probability of hearing threshold shifts and material hearing impairment, stratified by length of tenure

\begin{tabular}{|c|c|c|c|c|c|c|c|}
\hline \multirow[t]{2}{*}{$\begin{array}{l}\text { Tenure } \\
\text { (years) }\end{array}$} & \multirow[t]{2}{*}{$\begin{array}{l}\text { Mean } \\
\text { tenure } \\
\text { (years) }\end{array}$} & \multirow[t]{2}{*}{$\begin{array}{l}\text { Number } \\
\text { of } \\
\text { subjects }\end{array}$} & \multirow[t]{2}{*}{$\begin{array}{c}\text { Number } \\
\text { of } \\
\text { audiograms }\end{array}$} & \multirow[t]{2}{*}{$\begin{array}{l}\text { Mean } \\
\text { age in } \\
\text { years }\end{array}$} & \multirow[t]{2}{*}{$\begin{array}{l}\text { Percent probability } \\
\text { of NIOSH material } \\
\text { hearing impairment }\end{array}$} & \multicolumn{2}{|c|}{$\begin{array}{c}\text { Percent probability } \\
\text { of hearing } \\
\text { threshold shift }\end{array}$} \\
\hline & & & & & & $\mathrm{NIOSH}$ & OSHA \\
\hline$<2$ & 0.9 & 68 & 114 & 32 & 6 & 10 & 2 \\
\hline $2-4$ & 2.9 & 45 & 67 & 34 & 4 & 24 & 4 \\
\hline $4-6$ & 4.9 & 38 & 59 & 33 & 0 & 24 & 5 \\
\hline $6-10$ & 8.0 & 82 & 173 & 34 & 3 & 13 & 6 \\
\hline 10-15 & 12.5 & 112 & 360 & 36 & 8 & 22 & 6 \\
\hline $15-20$ & 17.3 & 107 & 388 & 40 & 12 & 26 & 9 \\
\hline $20-30$ & 24.5 & 88 & 607 & 46 & 21 & 31 & 11 \\
\hline$>30$ & 33.3 & 66 & 237 & 54 & 32 & 39 & 18 \\
\hline Overall & 18.0 & 606 & 2005 & 41 & 15 & 26 & 9 \\
\hline
\end{tabular}

Table 8 shows HTL for the forge employees stratified by age at the time of their most recent audiogram. The youngest two age groups had similar hearing thresholds at audiometric test frequencies greater than $1,000 \mathrm{~Hz}$, and neither had substantial hearing loss. The under 25 year age group showed relatively worse hearing at 0.5 and 1.0 kilohertz $(\mathrm{kHz})$. However, this age group only had eight subjects, and this result might have occurred because of the effects of background noise or undiagnosed ear pathology in one or more of the test results, rather than evidence of poorer hearing across this age group at these frequencies. Each subsequent age group had progressively higher HTLs (worse hearing). The highest HTLs were in the $4 \mathrm{kHz}$ and $6 \mathrm{kHz}$ frequencies.

Table 9 shows HTL for the forge employees stratified by length of tenure. HTLs for the 0.5 and $1.0 \mathrm{kHz}$ test frequencies were generally similar across tenures. For the remaining test frequencies, HTLs were progressively higher (worse hearing) with increasing tenure. The highest HTLs were in the $4 \mathrm{kHz}$ and $6 \mathrm{kHz}$ frequencies. This is a typical pattern for noiseinduced hearing loss (NIHL) [NIOSH 1998]. HTLs in the $6 \mathrm{kHz}$ frequency were slightly greater across age levels and in tenures of more than 5 years.

Table 8. Hearing levels stratified by age group, based on age at time of most recent audiogram

\begin{tabular}{lccccccc}
\hline \multirow{2}{*}{$\begin{array}{l}\text { Age } \\
\text { group }\end{array}$} & $\begin{array}{c}\text { Number of } \\
\text { subjects }\end{array}$ & \multicolumn{5}{c}{ Hearing threshold levels in dB by test frequency } \\
\cline { 3 - 7 } & $0.5 \mathrm{kHz}$ & $1 \mathrm{kHz}$ & $2 \mathrm{kHz}$ & $3 \mathrm{kHz}$ & $4 \mathrm{kHz}$ & $6 \mathrm{kHz}$ \\
\hline$<25$ & 8 & 21.6 & 9.4 & 5.6 & 7.2 & 8.1 & 11.9 \\
$25-34$ & 19 & 10.4 & 4.7 & 4.1 & 9.1 & 10.1 & 12.6 \\
$35-44$ & 92 & 10.4 & 7.7 & 8.3 & 18.2 & 22.0 & 23.4 \\
$45-54$ & 115 & 12.1 & 9.9 & 15.3 & 30.5 & 37.0 & 36.4 \\
$55-64$ & 212 & 15.6 & 15.9 & 25.1 & 41.4 & 47.1 & 49.6 \\
$>65$ & 6 & 13.3 & 12.5 & 25.4 & 41.7 & 53.3 & 55.4 \\
\hline
\end{tabular}


Table 9. Hearing levels stratified by years of exposure, based on age at time of most recent audiogram

\begin{tabular}{lcccccccc}
\hline \multirow{2}{*}{$\begin{array}{l}\text { Length of } \\
\text { tenure (years) }\end{array}$} & Mean & Number of & \multicolumn{5}{c}{ Hearing threshold levels in dB by test frequency } \\
\cline { 5 - 9 } & age & subjects & $0.5 \mathrm{kHz}$ & $1 \mathrm{kHz}$ & $2 \mathrm{kHz}$ & $3 \mathrm{kHz}$ & $4 \mathrm{kHz}$ & $6 \mathrm{kHz}$ \\
\hline$<2$ & 33 & 22 & 10.9 & 7.6 & 7.0 & 15.1 & 17.7 & 15.5 \\
$2-4$ & 40 & 11 & 7.5 & 6.1 & 12.5 & 23.6 & 31.4 & 26.8 \\
$5-9$ & 38 & 11 & 5.5 & 4.3 & 1.6 & 11.8 & 15.9 & 16.6 \\
$10-14$ & 42 & 14 & 8.2 & 6.1 & 7.3 & 13.6 & 19.5 & 15.9 \\
$15-19$ & 44 & 23 & 8.7 & 8.2 & 8.0 & 19.5 & 21.8 & 24.4 \\
$20-29$ & 48 & 23 & 8.5 & 7.2 & 13.6 & 25.5 & 31.0 & 32.6 \\
$\geq 30$ & 56 & 66 & 11.4 & 11.4 & 16.4 & 30.9 & 38.9 & 40.2 \\
\hline
\end{tabular}

The trend of worse hearing with age and length of tenure was also observed by Taylor et al. [1984] in a study of workers from seven forges in the United Kingdom. However, HTLs in press operators and hammer operators in that study were higher than the HTLs we found in these forge workers. We did not have job title and work history information, therefore our analysis of audiometric records included all workers and was not limited to only hammer and press operators. Therefore, our results may not reflect higher hearing loss that might be more likely to occur in jobs with the highest TWA and impulsive noise exposures, specifically those jobs closest to the hammer. Forge workers in our population may have had better use of hearing protection because of the OSHA hearing conservation standard, which went into effect in 1983.

During our site visit, all employees we observed wore hearing protection. During interviews and informal discussions, employees reported that they consistently used hearing protection. However, some long-term employees noted that before 1980 hearing protection was not used consistently. Some employees also reported stuffing cotton in their ears at that time for hearing protection. Taylor et al. [1984] reported that $61 \%$ of workers in that study wore hearing protection for 1 to 4 years and the remaining employees were unprotected over their working lifetime. We did not quantify use of hearing protection in our evaluation and cannot compare hearing protection use over time.

Figure 20 shows the differences in HTLs after 10 years of noise exposure in the forge for workers who started working before 1980 compared to workers who started after 1980. HTLs for forge workers starting after 1980 were lower than for workers who started before 1980 . This may be further evidence of improved hearing protection use beginning in the 1980s after the OSHA hearing conservation standard went into effect. 


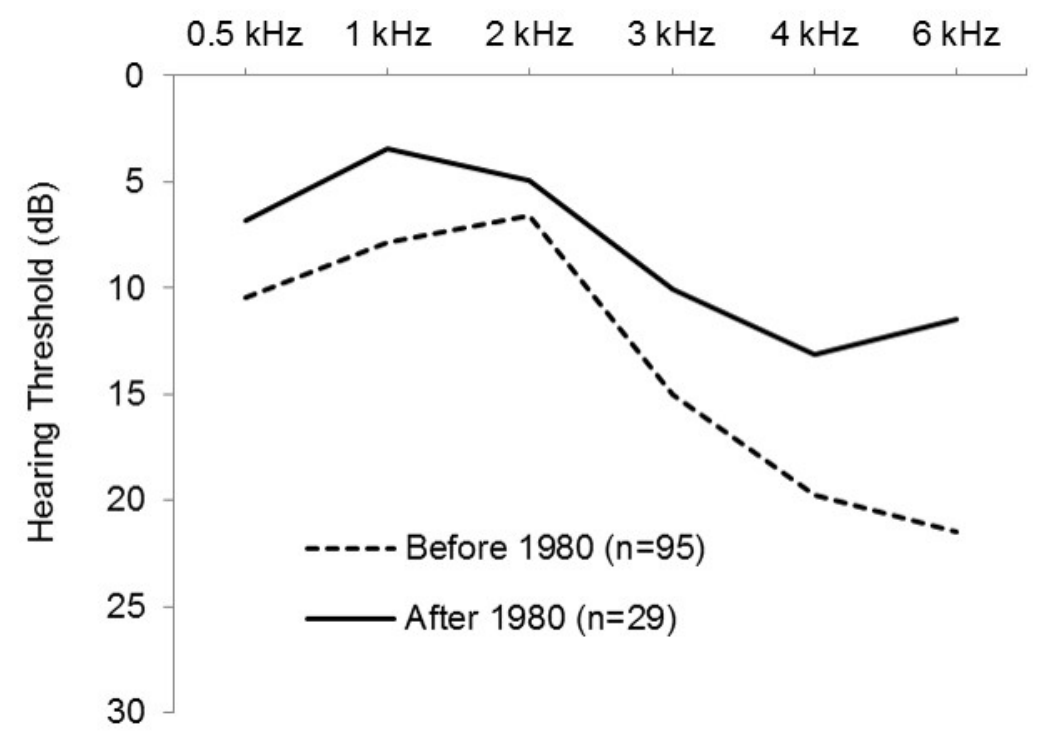

Figure 20. Comparison of HTLs after 10 years of noise exposure in forge workers by hire date (before or after 1980).

Figure 21 shows the HTLs in the forge population, stratified by age group, compared to an ISO reference population, which consists of unscreened workers from the ISO 1999:2013 standard, Annex B3, from the U.S. population [ISO 1999]. The 50th percentile HTLs for the forge population was similar to the 50th percentile HTLs for the ISO reference population for most age groups. HTLs for the 45-54 year and 55-64 year age forge workers were slightly worse at the higher frequencies. The 90th percentile HTLs for the forge workers were slightly worse than the 90th percentile for the reference population for some frequencies in all but the youngest age group. Differences were particularly prominent in the 35-44 year and 45-54 year age groups. Noise research has shown that exposure to impulsive noise is more likely to cause hearing loss than exposure to continuous noise [Pfander et al. 1980; Sulkowski 1980; Starck et al. 1988]. Therefore, we might have expected the forge workers to have worse hearing than the reference population, which did not have impulsive noise exposure. Some potential hearing loss in this forge population may be mitigated by the heat wait periods built into the work cycle. Employees commonly spent the heat wait in quieter areas. The time spent in lower noise areas provides an opportunity for recovery of temporary hearing losses and may decrease the risk of permanent hearing loss [Kryter et al. 1966]. 

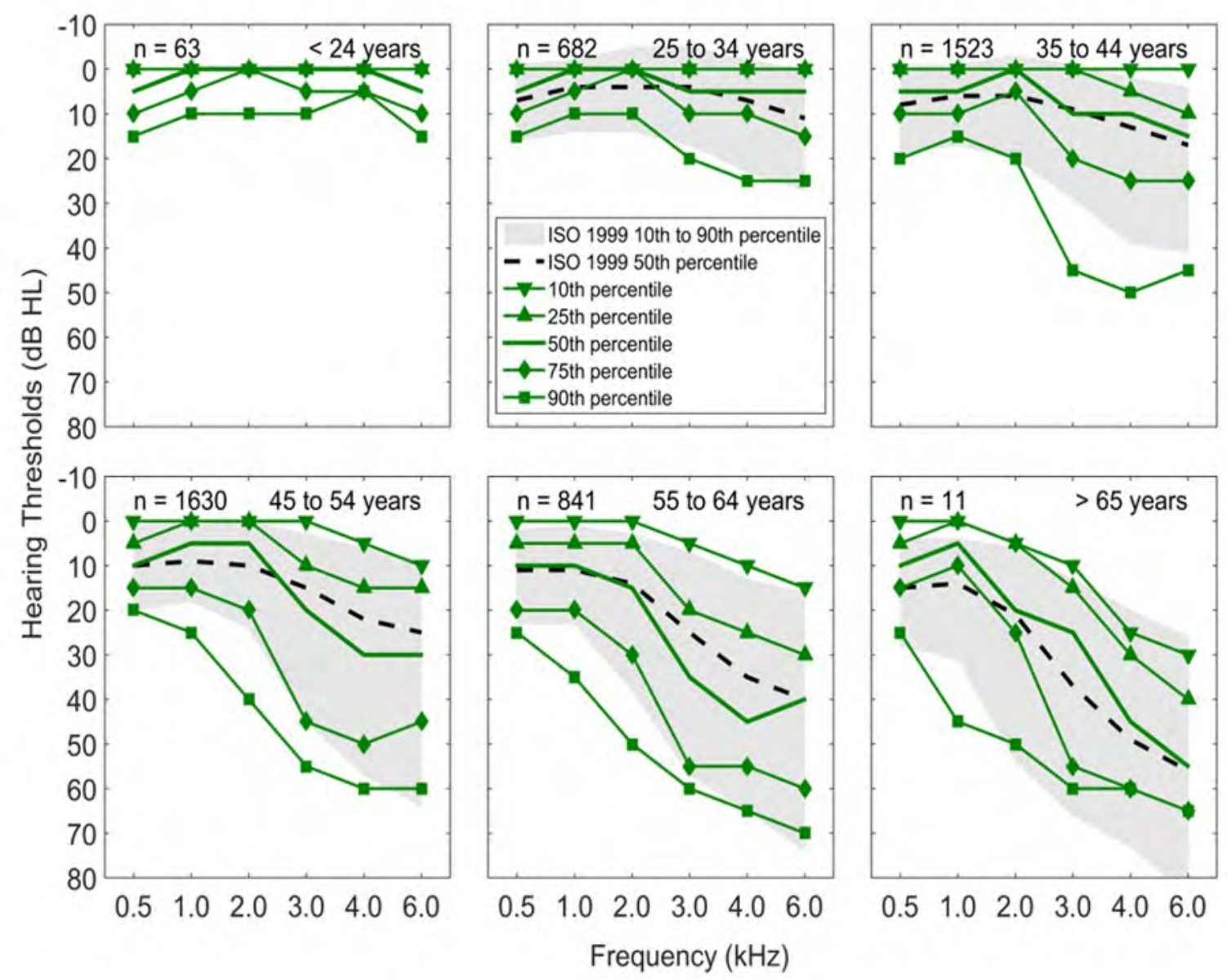

Figure 21. Comparison of forge worker HTLs to the ISO 1999:2013 standard, Annex B3 reference (unscreened) population HTLs.

\section{Whole Body and Hand-Arm Vibration}

Results of whole body vibration measurements at five hammers and a shear are reported in Table 10. Because forge workers at the hammer and shear do their work while standing, whole body vibration is transmitted through their feet in an up and down direction (z-axis). We measured whole body vibration across all frequencies from $0.1 \mathrm{~Hz}-400 \mathrm{~Hz}$, and the results are reported as acceleration root mean square (ARMS) values. Mean ARMS values at the hammers ranged $0.02-0.56$ meter per second squared $\left(\mathrm{m} / \mathrm{s}^{2}\right)$, and the maximum ARMS values were $0.03-1.1 \mathrm{~m} / \mathrm{s}^{2}$. The mean ARMS value for the shear operator was $0.15 \mathrm{~m} / \mathrm{s}^{2}$. The mean ARMS value was $1.1 \mathrm{~m} / \mathrm{s}^{2}$ for a measurement taken on the shear chopper. This measurement shows the vibration transmitted to the shear frame when ingots were mechanically sheared. Mean peak levels were $0.2-9.2 \mathrm{~m} / \mathrm{s}^{2}$ at the hammers and was $1.9 \mathrm{~m} / \mathrm{s}^{2}$ for the shear operator. Peak values are a measure of the highest absolute value of the acceleration waveform. 
Table 10. Whole body vibration measurement results

\begin{tabular}{|c|c|c|c|c|c|c|c|}
\hline \multirow[t]{2}{*}{ Job title } & \multirow[t]{2}{*}{$n$} & \multicolumn{3}{|c|}{ Acceleration root mean square } & \multirow{2}{*}{$\begin{array}{l}\text { Peak } \\
\text { level } \\
\text { mean } \\
\left(\mathrm{m} / \mathrm{s}^{2}\right)\end{array}$} & \multirow{2}{*}{$\begin{array}{c}\text { Crest } \\
\text { factor } \\
\text { mean } \\
\text { (no units) }\end{array}$} & \multirow{2}{*}{$\begin{array}{c}\text { Fourth } \\
\text { power } \\
\text { vibration } \\
\text { dose mean } \\
\text { (no units) }\end{array}$} \\
\hline & & $\begin{array}{l}\text { mean } \\
\left(\mathrm{m} / \mathrm{s}^{2}\right)\end{array}$ & $\underset{\left(\mathrm{m} / \mathrm{s}^{2}\right)}{\operatorname{minimum}}$ & $\underset{\left(\mathrm{m} / \mathrm{s}^{2}\right)}{\operatorname{maximum}}$ & & & \\
\hline $\begin{array}{l}\text { Hammer 10-1 } \\
\text { operator }\end{array}$ & 1 & 0.19 & 0.02 & 0.56 & 2.2 & 10 & 2.7 \\
\hline $\begin{array}{l}\text { Hammer 10-2 } \\
\text { operator }\end{array}$ & 4 & $0.05-0.30$ & 0.00 & 0.84 & $0.6-9.2$ & $10-12$ & $2.7-3.0$ \\
\hline $\begin{array}{l}\text { Hammer 5-1 } \\
\text { operator }\end{array}$ & 1 & 0.02 & 0.00 & 0.03 & 0.2 & 9.7 & 1.9 \\
\hline $\begin{array}{l}\text { Hammer 5-2 } \\
\text { operator }\end{array}$ & 2 & $0.28-0.56$ & 0.03 & 1.1 & $3.0-5.0$ & $8.7-11$ & $2.2-3.1$ \\
\hline $\begin{array}{l}\text { Hammer } 5-4 \\
\text { operator }\end{array}$ & 2 & $0.15-0.34$ & 0.01 & 0.69 & $1.8-5.6$ & $10-12$ & $2.6-2.8$ \\
\hline $\begin{array}{l}\text { Shear } 700 \\
\text { operator }\end{array}$ & 1 & 0.15 & 0.10 & 0.31 & 1.9 & 12 & 2.8 \\
\hline $\begin{array}{l}\text { Shear } 700 \\
\text { (on shear } \\
\text { chopper) }\end{array}$ & 1 & 1.1 & 0.31 & 2.0 & 11 & 9.9 & 2.2 \\
\hline
\end{tabular}

For whole body vibration, all of the mean ARMS values for hammer operators and the shear operator were below the daily exposure limit value of $1.15 \mathrm{~m} / \mathrm{s}^{2}$, and all but one were below the daily exposure action value of $0.5 \mathrm{~m} / \mathrm{s}^{2}$ recommended by the Commission of the European Communities and the Health and Safety Executive [CEC 2002; HSE 2005]. The mean ARMS values were also below the ISO health guidance caution zone recommended limits specified in Annex B of the standard [ISO 1997]. The ISO health guidance caution zone recommended exposure limits range from $0.63-1.2 \mathrm{~m} / \mathrm{s}^{2}$ for an exposure duration of 4 hours and from $0.5-0.8 \mathrm{~m} / \mathrm{s}^{2}$ for an exposure duration of 8 hours per day. The ISO standard guidance in Annex B was based on available research data on the response of seated persons to z-axis vibration and may, therefore, have limitations in its applicability to standing positions.

Crest factors are a measure of the impulsiveness of vibrations and are calculated by dividing the peak vibration acceleration values by the average vibration acceleration values. Vibration that is more impulsive is considered to be potentially more harmful than vibration that is not impulsive or has very low crest factor values. Nearly all the crest factors we measured were greater than 9 and ranged 8.7-12 (no units). The American Conference of Governmental Industrial Hygienists (ACGIH $\left.{ }^{\circledR}\right)$ notes that its threshold limit value (TLV®) is not valid for vibration with crest factors greater than 6 [ACGIH 2015a]. Additionally, the ISO indicates that when crest factors are greater than 9, the basic vibration evaluation method could underestimate the severity of vibration with respect to discomfort [ISO 1997].

For whole body vibration crest factors greater than 9, ISO standard 2631-1 suggests using the "fourth power vibration dose method" to evaluate potential health risk from vibration because the method is more sensitive to vibrational peaks [ISO 1997]. Fourth power vibration dose 
calculation results that exceed a ratio value of 1.75 indicate a potential concern for health effects [ISO 1997]. Our calculations using the fourth power vibration dose method, shown in Table 10, exceeded the 1.75 reference value and ranged 1.9-3.1 (no units). The heat wait breaks that hammer operators take while waiting for ingots to heat in the furnace provide them with a built-in break away from the hammer that allows for recovery time from whole body vibration exposure and may help decrease potential health risk. Shear operators do not have heat wait breaks; however, they have periodic breaks in production during the work shift, such as waiting for steel rods to be delivered from the yard. Some employees stood on wooden platforms and/or vibration isolation mats when working on the hammer or shear, which could also reduce whole body vibration. However, not all work stations had mats and some mats appeared to be excessively worn and not likely as effective.

Hand-arm vibration is measured as the average acceleration in all directions ( $\mathrm{x}-, \mathrm{y}-$, and $\mathrm{z}$-axes) across all frequencies. Results of measurements at the grinder are shown in Table 11. During grinding on heavy metal forgings, grinder operators rested the forging on the work rest while holding it and pushing it against the grinder using their hands. Vibration was transferred from the forging to the work rest and also to the employees' hands. We assumed that vibration was transferred about equally to the work rest and to the operator's hands. Therefore, we are using the results from measurements taken at the work rest to represent the workers' hand-arm vibration exposures. The average ARMS level was slightly above the ACGIH TLV of $4 \mathrm{~m} / \mathrm{s}^{2}$ for daily exposure durations of 4 to 8 hours, but below the TLV of $6 \mathrm{~m} / \mathrm{s}^{2}$ for daily exposure durations of 2 to 4 hours [ACGIH 2015a]. This indicates that employees' exposures could exceed the TLV when they grind for more than 4 hours in a shift. Additionally, their exposures were between the exposure action value of $2.5 \mathrm{~m} / \mathrm{s}^{2}$ and the exposure limit value of $5 \mathrm{~m} / \mathrm{s}^{2}$ used by the European Union [CEC 2002]. The range of ARMS values show that hand-arm vibration exposures ranged from well below these reference standards to nearly double the TLV for 4 to 8 hours of exposure. The high peak level and crest factor also indicate that the vibration has impulsive characteristics. Relatively low vibration values on the grinder body measurement results show that not much of the vibration was transmitted during grinding to the grinder. Exposures will vary on the basis of the size and type of forgings that employees grind.

Table 11. Hand-arm vibration measurements at grinders

\begin{tabular}{|c|c|c|c|c|c|}
\hline \multirow[t]{2}{*}{ Location } & \multicolumn{3}{|c|}{ Acceleration root mean square } & \multirow{2}{*}{$\begin{array}{c}\text { Peak level } \\
\text { mean } \\
\left(\mathrm{m} / \mathrm{s}^{2}\right)\end{array}$} & \multirow{2}{*}{$\begin{array}{c}\text { Crest factor } \\
\text { mean } \\
\text { (no units) }\end{array}$} \\
\hline & $\begin{array}{l}\text { mean } \\
\left(\mathrm{m} / \mathrm{s}^{2}\right)\end{array}$ & $\begin{array}{c}\operatorname{minimum} \\
\left(\mathrm{m} / \mathrm{s}^{2}\right)\end{array}$ & $\begin{array}{c}\operatorname{maximum} \\
\left(\mathrm{m} / \mathrm{s}^{2}\right)\end{array}$ & & \\
\hline On work rest & 4.40 & 0.60 & 8.43 & 57.5 & 11.1 \\
\hline On grinder body & 0.50 & 0.14 & 0.93 & 5.27 & 9.48 \\
\hline
\end{tabular}


Exposure and risk from hand arm vibration can be reduced by control measures such as efficient grinding wheels with suitable hardness and grit size, properly balanced spindles, and work rests mounted independently from the grinder. In addition, limiting long periods of continuous exposure, limiting total daily exposure time, and using gloves that keep employees hands warm and dry can also reduce risk. Although anti-vibration gloves can also be used, the effectiveness of these gloves in preventing vibration-related adverse health effects may be limited. Some research has indicated that anti-vibration gloves could put the wearer at risk for additional health problems due to the increased grip strength needed to perform tasks while wearing the glove. Furthermore, decreased dexterity may also increase risk for injury [Hewitt et al. 2015].

\section{Heat Stress}

Typical outdoor temperatures for late July and early August range $62^{\circ} \mathrm{F}-83^{\circ} \mathrm{F}$ [NOAA 2015]. On the days of our site visit, outdoor temperatures were slightly above normal. During the second shift on July 31,2007 , outdoor temperatures were $72^{\circ} \mathrm{F}-88^{\circ} \mathrm{F}$, and the relative humidity was $40 \%-73 \%$. During the first shift on August 1, 2007, outdoor temperatures were $63^{\circ} \mathrm{F}-89^{\circ} \mathrm{F}$, and the relative humidity was $38 \%-93 \%$.

Our measurements of heat stress conditions are provided in Table 12. We took WBGT measurements at four stationary locations in the forge buildings where employees worked. Because WBGT measurements include the effect of temperature, relative humidity, and radiant heat, these measurements are helpful in assessing heat stress conditions. Most employees did not stay near the hammers for their entire work shift. They almost always went to cooler areas during heat wait periods. Most employees said they usually spent about 15 to 20 minutes at the hammer, trim press, or furnace during production runs, but the amount of time ranged from 10 minutes to more than 30 minutes. The heat wait periods between production runs typically lasted the same amount of time as production runs. Our observations of the amount and relative proportion of employee time in production and heat wait also corresponded with what employees had reported. Spot checks of WBGT levels in the areas where employees spent their heat wait are provided in Table 13. These WBGT levels were substantially lower than average levels measured in the production areas. 
Table 12. Heat stress measurements during second shift on July 31,2007 , and first shift on August 1, 2007.

\begin{tabular}{|c|c|c|c|c|c|c|c|}
\hline \multirow[t]{2}{*}{ Location } & \multirow[t]{2}{*}{ Shift } & \multirow{2}{*}{$\begin{array}{c}\text { Relative } \\
\text { humidity } \\
(\%) \\
\text { (Range) }\end{array}$} & \multicolumn{5}{|c|}{ Temperature $\left({ }^{\circ} \mathrm{F}\right)$} \\
\hline & & & $\begin{array}{c}\text { Heat } \\
\text { index } \\
\text { (Range) }\end{array}$ & $\begin{array}{l}\text { Indoor } \\
\text { WBGT } \\
\text { (Range) }\end{array}$ & $\begin{array}{c}\text { Wet } \\
\text { bulb } \\
\text { (Range) }\end{array}$ & $\begin{array}{l}\text { Dry bulb } \\
\text { (Range) }\end{array}$ & $\begin{array}{l}\text { Globe } \\
\text { (Range) }\end{array}$ \\
\hline $\begin{array}{l}\text { South forge } 5-4 \\
\text { (10 feet from } \\
\text { furnace) }\end{array}$ & Second & $\begin{array}{c}29 \\
(17-46)\end{array}$ & $\begin{array}{c}88 \\
(85-97)\end{array}$ & $\begin{array}{c}87 \\
(80-93)\end{array}$ & $\begin{array}{c}78 \\
(75-81)\end{array}$ & $\begin{array}{c}94 \\
(85-100)\end{array}$ & $\begin{array}{c}109 \\
(92-123)\end{array}$ \\
\hline $\begin{array}{l}\text { Heat treat } \\
\text { department }\end{array}$ & Second & $\begin{array}{c}32 \\
(25-46)\end{array}$ & $\begin{array}{c}101 \\
(94-113)\end{array}$ & $\begin{array}{c}84 \\
(80-87)\end{array}$ & $\begin{array}{c}76 \\
(74-78)\end{array}$ & $\begin{array}{c}100 \\
(91-106)\end{array}$ & $\begin{array}{c}103 \\
(93-109)\end{array}$ \\
\hline $\begin{array}{l}\text { South forge } 5-1 \\
\text { (near hammer) }\end{array}$ & Second & $\begin{array}{c}37 \\
(28-55)\end{array}$ & $\begin{array}{c}91 \\
(83-101)\end{array}$ & $\begin{array}{c}82 \\
(78-87)\end{array}$ & $\begin{array}{c}75 \\
(73-78)\end{array}$ & $\begin{array}{c}91 \\
(82-98)\end{array}$ & $\begin{array}{c}98 \\
(87-108)\end{array}$ \\
\hline $\begin{array}{l}\text { North forge } 10-2 \\
\text { ( } 9 \text { feet from } \\
\text { furnace) }\end{array}$ & Second & $\begin{array}{c}37 \\
(31-48)\end{array}$ & $\begin{array}{c}91 \\
(84-96)\end{array}$ & $\begin{array}{c}82 \\
(78-86)\end{array}$ & $\begin{array}{c}75 \\
(73-78)\end{array}$ & $\begin{array}{c}90 \\
(84-94)\end{array}$ & $\begin{array}{c}98 \\
(89-106)\end{array}$ \\
\hline $\begin{array}{l}\text { Heat treat } \\
\text { department }\end{array}$ & First & $\begin{array}{c}32 \\
(21-59)\end{array}$ & $\begin{array}{c}94 \\
(83-103)\end{array}$ & $\begin{array}{c}87 \\
(76-93)\end{array}$ & $\begin{array}{c}78 \\
(73-82)\end{array}$ & $\begin{array}{c}97 \\
(81-107)\end{array}$ & $\begin{array}{c}107 \\
(82-118)\end{array}$ \\
\hline $\begin{array}{l}\text { South forge } 35-2 \\
\text { ( } 8 \text { feet from } \\
\text { furnace) }\end{array}$ & First & $\begin{array}{c}45 \\
(29-65)\end{array}$ & $\begin{array}{c}96 \\
(82-112)\end{array}$ & $\begin{array}{c}83 \\
(76-91)\end{array}$ & $\begin{array}{c}76 \\
(71-81)\end{array}$ & $\begin{array}{c}92 \\
(79-103)\end{array}$ & $\begin{array}{c}100 \\
(85-118)\end{array}$ \\
\hline Upset press & First & $\begin{array}{c}36 \\
(24-63)\end{array}$ & $\begin{array}{c}87 \\
(75-96)\end{array}$ & $\begin{array}{c}81 \\
(73-87)\end{array}$ & $\begin{array}{c}75 \\
(70-78)\end{array}$ & $\begin{array}{c}89 \\
(75-97)\end{array}$ & $\begin{array}{c}94 \\
(80-106)\end{array}$ \\
\hline $\begin{array}{l}\text { North forge } 10-1 \\
\text { (10 feet from } \\
\text { furnace) }\end{array}$ & First & $\begin{array}{c}46 \\
(33-74)\end{array}$ & $\begin{array}{c}86 \\
(70-95)\end{array}$ & $\begin{array}{c}80 \\
(72-87)\end{array}$ & $\begin{array}{c}74 \\
(69-78)\end{array}$ & $\begin{array}{c}85 \\
(71-93)\end{array}$ & $\begin{array}{c}95 \\
(79-108)\end{array}$ \\
\hline
\end{tabular}

Table 13. Wet bulb globe temperature levels for heat wait locations on July 31,2007

\begin{tabular}{lc}
\hline Location & Indoor WBGT $\left({ }^{\circ} \mathrm{F}\right)$ \\
\hline $\begin{array}{l}\text { North forge line-up office } \\
\text { (inside air conditioned room) }\end{array}$ & 66 \\
$\begin{array}{l}\text { North forge line-up office } \\
\text { (outside of air conditioned room) }\end{array}$ & 74 \\
$\begin{array}{l}\text { South forge line-up office } \\
\text { (inside air conditioned room) }\end{array}$ & 67 \\
Heat wait bench in south forge & 77 \\
$\begin{array}{l}\text { Upset press staging office } \\
\text { Heat wait bench in upset press area }\end{array}$ & 71 \\
$\begin{array}{l}\text { Break room in heat treat department } \\
\text { (air conditioned) }\end{array}$ & 75 \\
\hline
\end{tabular}


Air temperatures in the forge buildings (measured with the dry bulb thermometer) averaged $85^{\circ} \mathrm{F}-100^{\circ} \mathrm{F}$ and were sometimes over $100^{\circ} \mathrm{F}$ in the south forge and heat treat areas. The temperatures in the forge building were higher than outdoors because of heat generated by the furnaces and heated metal parts. Relative humidity ranged $17 \%-74 \%$. This range was similar to that of the relative humidity outdoors. Average WBGT measurements were $80^{\circ} \mathrm{F}-87^{\circ} \mathrm{F}$ and reached a maximum of $93^{\circ} \mathrm{F}$. Heat stress measurements did not differ substantially between first and second shifts.

Because metal ingots and parts are heated to temperatures above $2,400^{\circ} \mathrm{F}$, substantial radiant heat is generated by the hot metal. Radiant heat (measured with the globe bulb thermometer) averaged $94^{\circ} \mathrm{F}-109^{\circ} \mathrm{F}$, but reached maximum levels greater than $115^{\circ} \mathrm{F}$ in the south forge and heat treat area and maximum levels of $108^{\circ} \mathrm{F}$ in the north forge and $106^{\circ} \mathrm{F}$ at the upset press. Although fans were used in these areas to move air, at these temperatures employees absorb heat rather than lose heat unless proper shielding is provided. Nearly all employees reported during informal interviews that they normally wear long pants and long sleeve shirts to help protect against radiant heat.

We characterized employees' work effort in the forges as requiring moderate metabolic rates (i.e., moderate work effort). Moderate is defined as "sustained moderate hand and arm work, moderate arm and leg work, moderate arm and trunk work, or light pushing and pulling, and normal walking" [ACGIH 2015a]. For employees with a moderate work level and a work to rest ratio of $50 \%$, the ACGIH screening criteria for heat stress indicates that the action limit is reached at a WBGT value of $80.6^{\circ} \mathrm{F}$, and the TLV is reached at a WBGT value of $86^{\circ} \mathrm{F}$ [ACGIH 2015a]. The NIOSH REL for heat stress is a WBGT value of $86^{\circ} \mathrm{F}$ [NIOSH 1986].

If employees spent their entire work shift in the production areas of the forges, their heat stress exposures would exceed the ACGIH screening criteria levels for the action limit and would sometimes exceed the ACGIH screening criteria level for the TLV and the NIOSH REL. However, employees usually spent the heat wait in cooler areas. Therefore, we calculated their TWA WBGT levels assuming that half of the work time was spent in cooler areas. Adjusted WBGT values indicated that employees' heat stress exposures were below the ACGIH action limit for workers with moderate work effort and a work rest cycle of $50 \%$. Figure 22 shows when the ACGIH action limit is exceeded in the forge on the basis of the WBGT level in the production location and heat wait locations. On days in which temperatures are warmer than those measured during the site visit, employees could exceed the action limit or TLV for heat stress, particularly if they spent their heat wait on the work benches near the hammers and furnaces. 


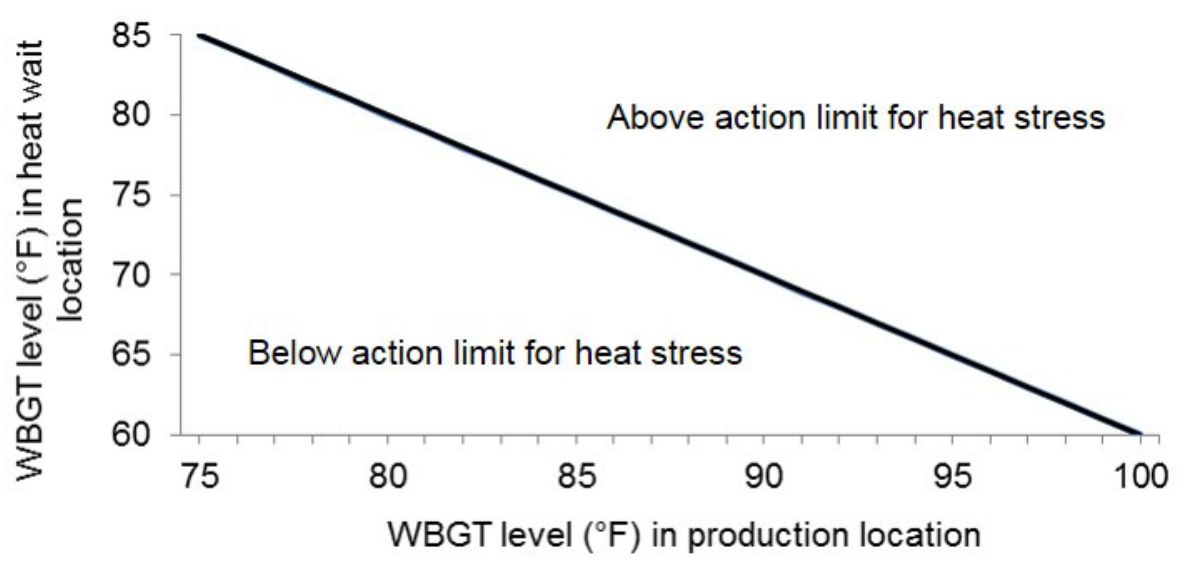

Figure 22. ACGIH action limit for heat stress based on measured WBGT levels in production locations and heat wait locations for employees with moderate work level and work to rest cycle of $50 \%$.

The heat index, which reflects the effect of humidity on perceived temperature, averaged $86^{\circ} \mathrm{F}-101^{\circ} \mathrm{F}$ across the measurement locations. The maximum heat index was $113^{\circ} \mathrm{F}$. On the basis of these measurements, OSHA considers the risk of heat-related illness to range from "caution" to "moderate." OSHA recommends basic heat safety planning when the heat index is below $91^{\circ} \mathrm{F}$ (caution) and recommends that companies implement precautions and heighten awareness of heat illness when the heat index is $91^{\circ} \mathrm{F}$ to $103^{\circ} \mathrm{F}$ [OSHA 2015].

Most employees we spoke with reported that they felt the company adequately addressed heat stress. In particular, employees noted their ability to spend the heat wait periods in cooler areas outside the building or in air-conditioned offices. They also noted that the company provided sports hydration drinks on hot days. We observed that large fans were available and used. Each forge building also had water fountains available. The forge buildings also had full-sized refrigerators available, which employees used to store water or other drinks. Employees reported that the company provided training about heat stress during monthly safety meetings and encouraged them to drink plenty of fluids and take breaks if they were feeling overheated. Although most employees did not express concerns about heat stress, several suggested that the company should increase the number of fans near the furnaces or forges.

\section{Conclusions}

Employees in all jobs we monitored, except machinists, had full-shift noise exposures that exceeded the NIOSH REL and OSHA AL. Similarly, all jobs except machinists and die repair were above the OSHA PEL. Noise exposures of hammer operators, trim press operators, and heaters were above $100 \mathrm{dBA}$. Peak noise levels during hammer impacts reached up to $148 \mathrm{dBA}$. Our analysis of the audiometric history for 483 forge employees showed $82 \%$ had experienced a NIOSH-defined hearing threshold shift, and $63 \%$ had experienced an OSHA STS since their baseline audiogram. The mean number of years from a normal baseline audiogram to a threshold shift was about 5 years for a NIOSH threshold shift and was about 9 years for an OSHA STS. Because of the high noise exposures and high impact noise levels, 
overall hearing levels among employees worsened with age and length of employment.

Employees' average exposures to whole body vibration at the hammers were below the Commission of the European Communities and the Health and Safety Executive daily exposure limit, but exposures at one of the hammers were slightly above the daily exposure action value. Because the vibration at the hammers was highly impulsive, calculations using ISO criteria indicate a potential concern for health effects. Employees' exposures to handarm vibration at the grinders sometimes exceeded the ACGIH TLV. A hammer operator was diagnosed with carpal tunnel syndrome, which was associated with daily use of tongs. However, exposure to hand-arm vibration can also contribute to carpal tunnel syndrome. Although employees were exposed to high heat levels near the furnaces and hammers, spending the heat wait cycles in lower temperature areas and employees' ability to hydrate during the work shift reduced their risk of heat stress. We calculated that employees' heat stress exposures were below the ACGIH action limit.

\section{Recommendations}

On the basis of our findings, we recommend the actions listed below. We encourage the company to use a labor-management health and safety committee or working group to discuss our recommendations and develop an action plan. Those involved in the work can best set priorities and assess the feasibility of our recommendations for the specific situation at the facility.

Our recommendations are based on an approach known as the hierarchy of controls (Appendix B). This approach groups actions by their likely effectiveness in reducing or removing hazards. In most cases, the preferred approach is to eliminate hazardous materials or processes and install engineering controls to reduce exposure or shield employees. Until such controls are in place, or if they are not effective or feasible, administrative measures and personal protective equipment may be needed.

\section{Engineering Controls}

Engineering controls reduce employees' exposures by removing the hazard from the process or by placing a barrier between the hazard and the employee. Engineering controls protect employees effectively without placing primary responsibility of implementation on the employee.

1. Maintain all equipment to eliminate unnecessary rattles and compressed air leakages.

2. Reduce the distance that ingots or forgings drop into metal bins, chutes, and vibrating conveyor pans.

3. Use thicker metal or constrained layer damped metal to increase the thickness of surfaces on metal chutes, vibrating conveyor pans, and walls and floor of metal bins. Alternatively, replace metal bins with bins made of durable plastic polymer materials.

4. Attach resilient plastic polymer material to the surface of metal chutes and vibrating conveyor pans to reduce noise from ingots or forgings bouncing or moving on these surfaces.

5. Ensure that all vibrating conveyors, shears, and grinders are placed on vibration 
isolation pads. Promptly replace the pads when they are worn.

6. Contact the grinding wheel manufacturer to help identify and select grinding wheels that generate less noise. Decreasing the rotational speed of the grinding wheel may also reduce noise levels.

7. Replace open tube compressed air nozzles with nozzles that are designed to produce less turbulence and noise, and that also meet OSHA safety standards for maximum air pressure.

8. Construct sound insulating, freestanding observation booths near the heat wait benches for employees to observe hammer operations during heat waits or at other times.

9. Place vibration isolation pads on the feet or vibration isolation mats on the surface of the hammer work platforms that employees stand on to reduce whole body vibration. Replace these pads when worn.

10. Ensure that the grinding wheels have properly balanced spindles and that the wheels have suitable hardness and grit size to efficiently and quickly grind forgings.

11. Mount work rests independently from the machine grinders and place the work rests on vibration isolation pads. Additional information on control measures for handarm vibration is available at http:/www.hse.gov.uk/vibration/hav/advicetoemployers/ controlrisks.htm.

12. Place screens around hammers and grinders that may emit particulates or oil mist from strikes to prevent scale eye injuries, respiratory irritation, and slip hazards from pooled oil.

\section{Administrative Controls}

The term administrative controls refers to employer-dictated work practices and policies to reduce or prevent hazardous exposures. Their effectiveness depends on employer commitment and employee acceptance. Regular monitoring and reinforcement are necessary to ensure that policies and procedures are followed consistently.

1. Modify work practices in the grinder area so that employees more gently place or drop forging into bins.

2. Implement a long-term strategy to reduce noise exposures by purchasing new equipment that generates less noise and less vibration. Information on Buy Quiet programs is available at http://www.cdc.gov/niosh/topics/buyquiet/.

3. Consult with acoustical noise control engineers who have expertise in forging industry noise reduction approaches for additional guidance on noise controls. The noise control engineers should be board certified by the Institute of Noise Control Engineers.

4. Refer to OSHA's Technical Manual for additional information on noise and noise control at https://www.osha.gov/dts/osta/otm/new_noise/index.html. NIOSH has noise control information at http://www.cdc.gov/niosh/topics/noisecontrol/.

5. Conduct noise measurement surveys after noise controls have been installed to evaluate whether the controls have adequately reduced noise levels and employees' noise exposures. 
6. Continue to provide annual audiometric evaluations. To improve detection of potential hearing loss, use NIOSH criteria in addition to OSHA criteria to identify hearing threshold shifts. Include the $8,000-\mathrm{Hz}$ frequency in audiometric tests. Refer to NIOSH audiometric evaluation and monitoring recommendations at http:/www.cdc.gov/ niosh/docs/98-126/ for additional information on audiometric testing and hearing loss prevention programs.

7. Advise employees to report any hearing problems or problems related to whole body or hand-arm vibration exposure to their healthcare provider and to the company.

8. Ensure that background noise during hearing tests does not exceed threshold levels specified by OSHA. Encourage employees to report to the audiometric test provider any time they hear background noise.

9. Provide machine grinders with breaks to ensure that they do not have long periods of continuous exposure to hand-arm vibration at the grinders.

10. Implement health surveillance to identify employees who could be developing vibration related disease, and train employees about the health effects of whole body and handarm vibration exposure and symptoms of vibration disease. Refer to information provided by the European Health and Safety Executive for additional guidance, http:// www.hse.gov.uk/vibration/hav/advicetoemployers/healthsurveillance.htm.

\section{Personal Protective Equipment}

Personal protective equipment is the least effective means for controlling hazardous exposures. Proper use of personal protective equipment requires a comprehensive program and a high level of employee involvement and commitment. The right personal protective equipment must be chosen for each hazard. Supporting programs such as training, changeout schedules, and medical assessment may be needed. Personal protective equipment should not be the sole method for controlling hazardous exposures. Rather, personal protective equipment should be used until effective engineering and administrative controls are in place.

1. Require all forge employees to wear dual hearing protection, which includes ear plugs and earmuffs. For maximum protection, provide ear plugs that have a high level of noise attenuation.

2. Perform hearing protector fit testing to determine the noise attenuation of the hearing protectors used by forge employees.

3. Ensure that workers are properly trained on how to wear hearing protection, specifically how to properly insert hearing protectors. Training should include demonstrations from instructors and an opportunity for workers to practice inserting hearing protectors properly.

4. Ensure that machine grinders keep their hands warm and dry during cold or damp weather. Use gloves that fit snugly and have good grip.

5. Provide safety goggles that are not prone to fogging in hot environments. 


\section{Appendix A: Figures}
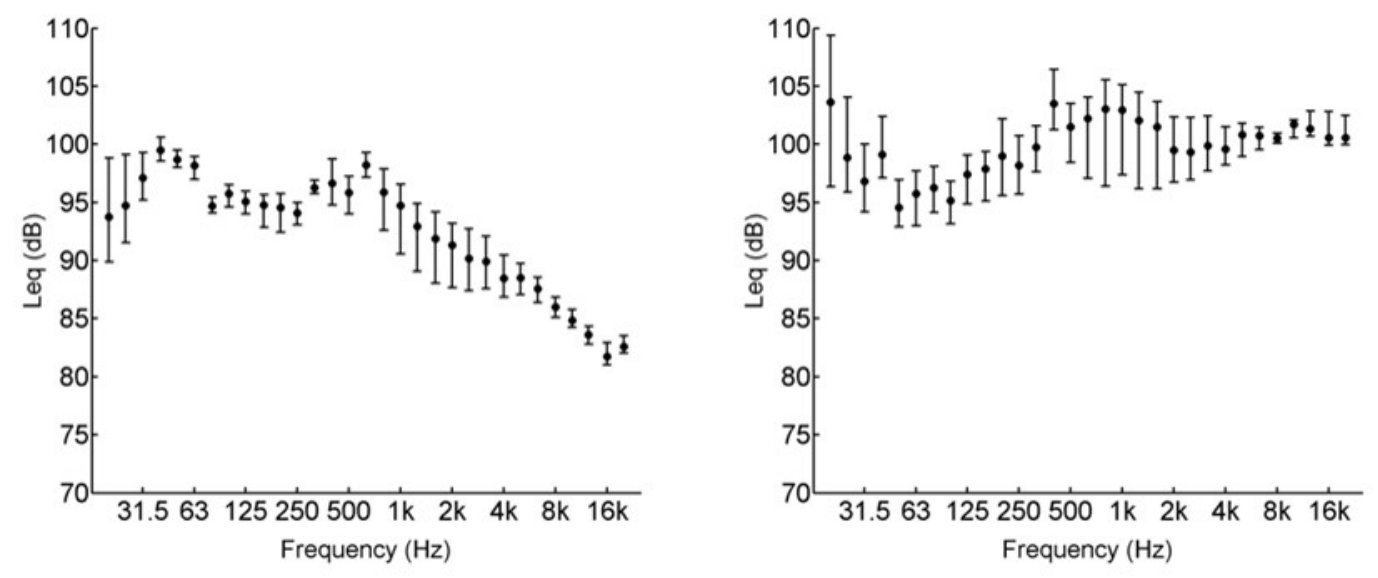

Figure A1. Octave band analysis for hammer 5-1 (figure on left shows noise measurements taken at a distance of 2 meters from the hammer and figure on right shows noise measurements taken close to the hammer).
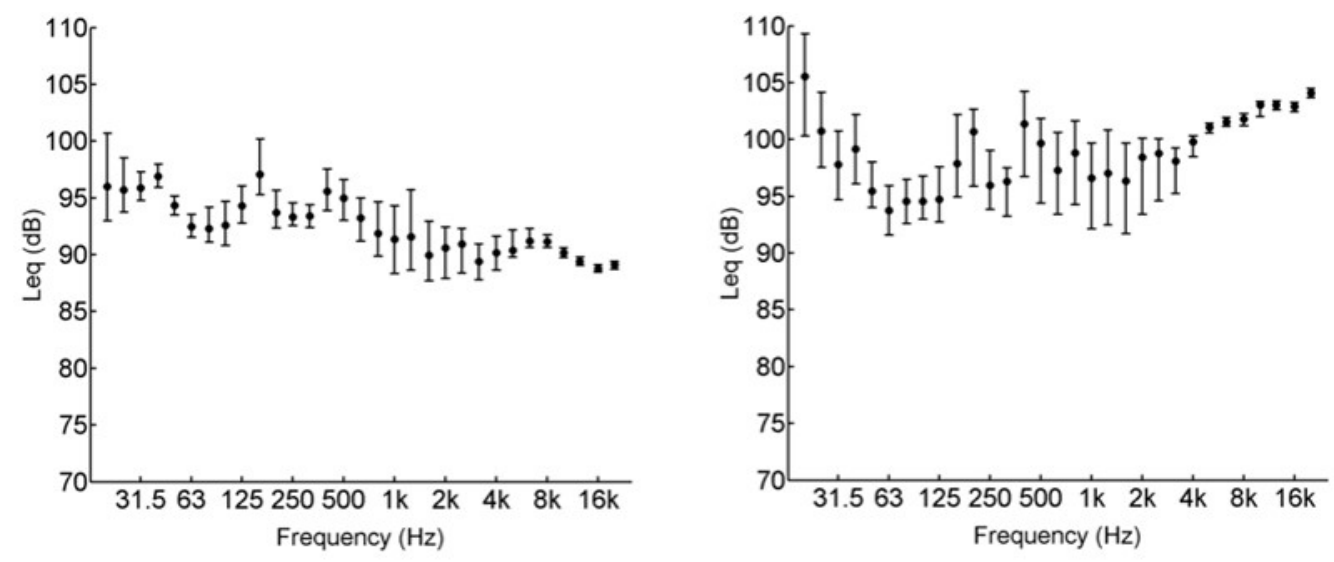

Figure A2. Octave band analysis for hammer 5-2 (figure on left shows noise measurements taken at a distance of 2 meters from the hammer and figure on right shows noise measurements taken close to the hammer). 

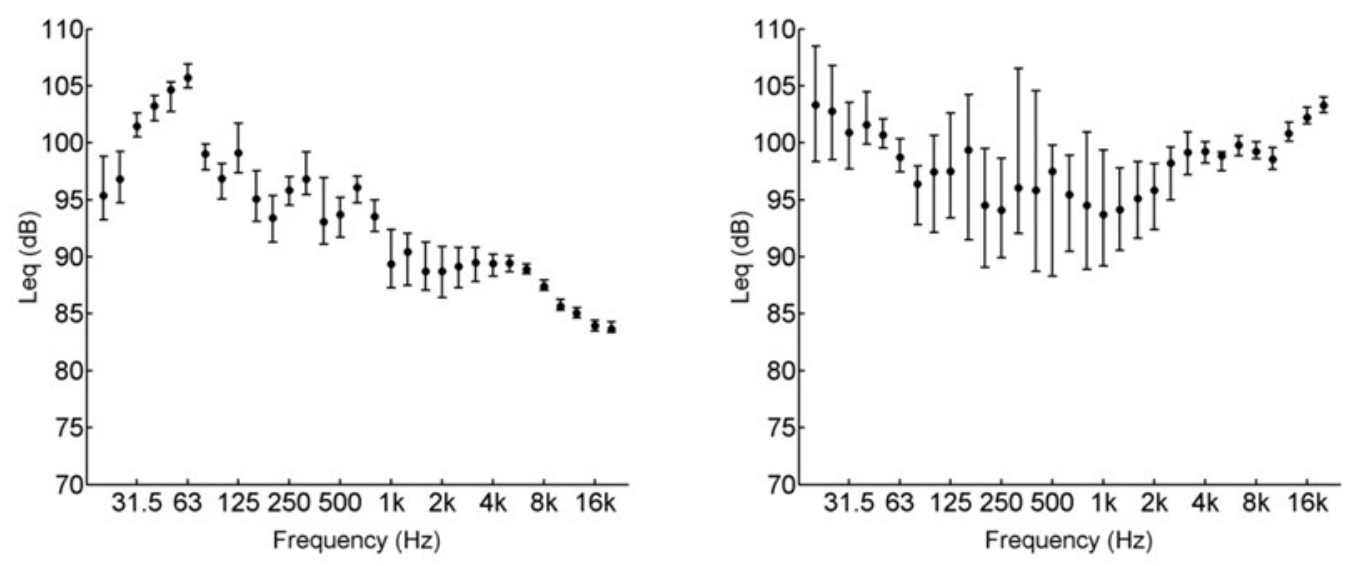

Figure A3. Octave band analysis for hammer 10-1 (figure on left shows noise measurements taken at a distance of 2 meters from the hammer and figure on right shows noise measurements taken close to the hammer).
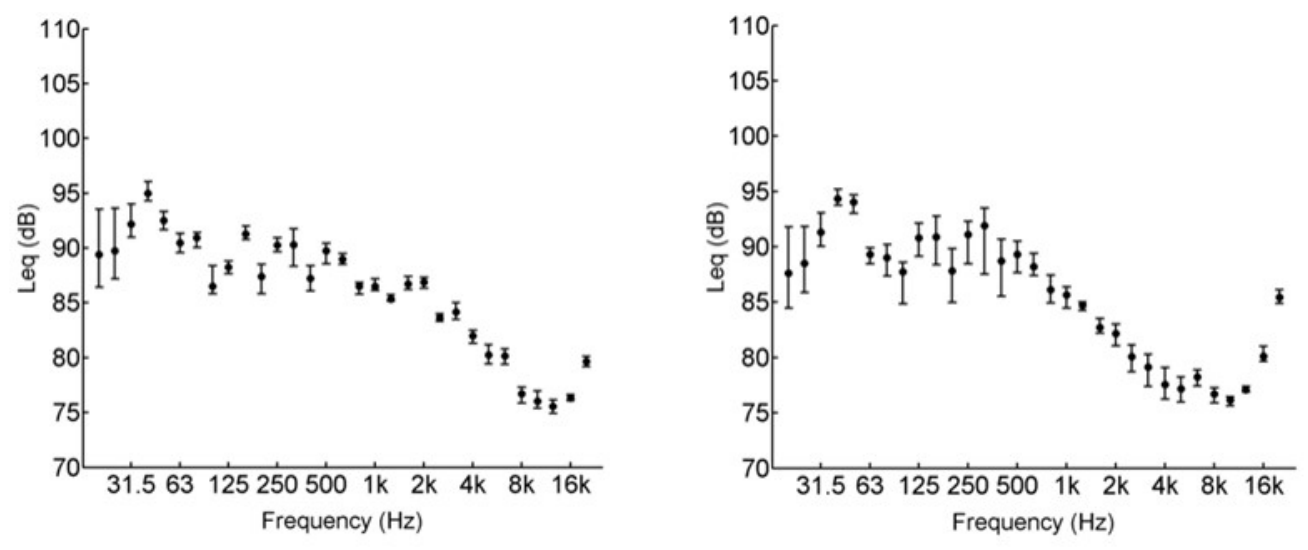

Figure A4. Octave band analysis for the 8-inch upset press (figure on left shows noise measurements taken at a distance of 2 meters from the upset press and the figure on right shows noise measurements taken close to the upset press). 

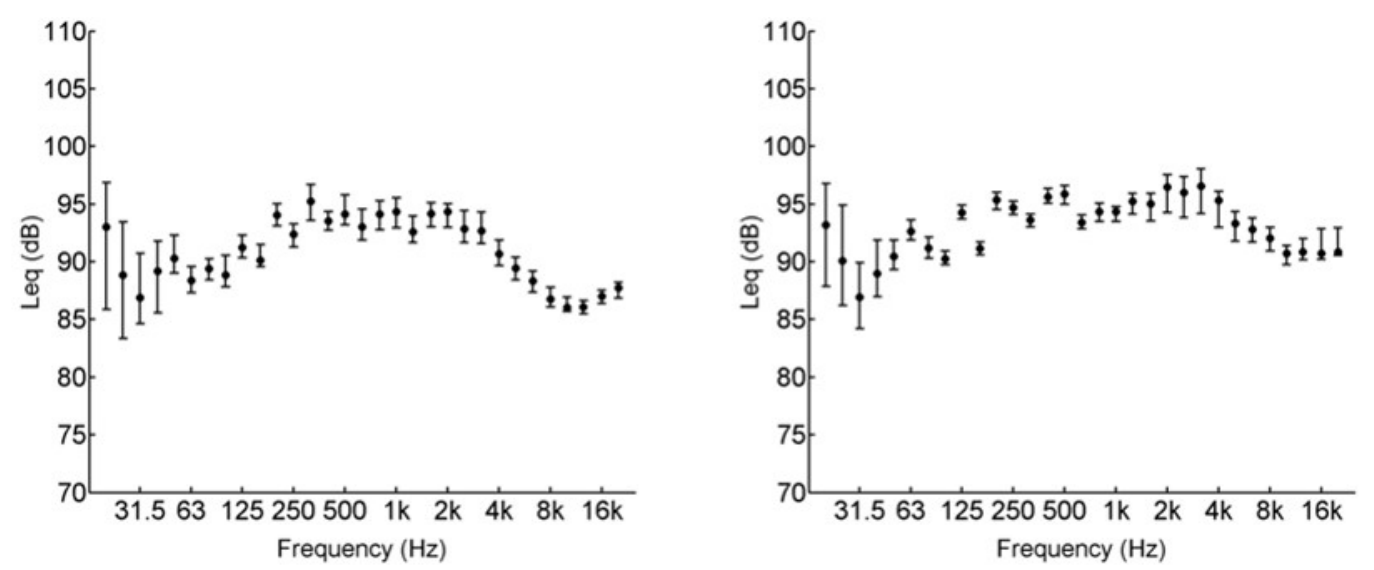

Figure A5. Octave band analysis for the 700-pound shear (figure on left shows noise measurements taken at a distance of 2 meters from the shear and the figure on right shows noise measurements taken close to the shear).
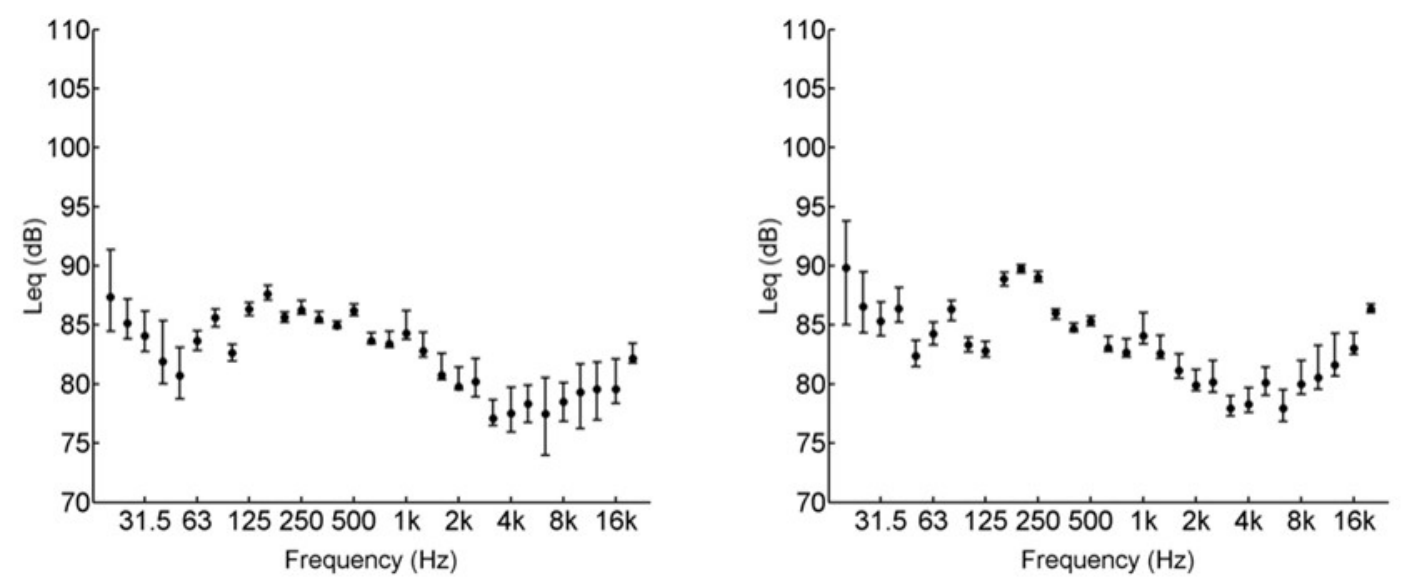

Figure A6. Octave band analysis for the grinder (figure on left shows noise measurements taken at a distance of 2 meters from the grinder and the figure on right shows noise measurements taken close to the grinder). 


\section{Appendix B: Occupational Exposure Limits and Health Effects}

NIOSH investigators refer to mandatory (legally enforceable) and recommended occupational exposure limits (OELs) for chemical, physical, and biological agents when evaluating workplace hazards. OELs have been developed by federal agencies and safety and health organizations to prevent adverse health effects from workplace exposures. Generally, OELs suggest levels of exposure that most employees may be exposed to for up to 10 hours per day, 40 hours per week, for a working lifetime, without experiencing adverse health effects. However, not all employees will be protected if their exposures are maintained below these levels. Some may have adverse health effects because of individual susceptibility, a pre-existing medical condition, or a hypersensitivity (allergy). In addition, some hazardous substances act in combination with other exposures, with the general environment, or with medications or personal habits of the employee to produce adverse health effects. Most OELs address airborne exposures, but some substances can be absorbed directly through the skin and mucous membranes.

Most OELs are expressed as a TWA exposure. A TWA refers to the average exposure during a normal 8- to 10-hour workday. Some chemical substances and physical agents have recommended short-term exposure limits or ceiling values. Unless otherwise noted, the shortterm exposure limit is a 15-minute TWA exposure. It should not be exceeded at any time during a workday. The ceiling limit should not be exceeded at any time.

In the United States, OELs have been established by federal agencies, professional organizations, state and local governments, and other entities. Some OELs are legally enforceable limits; others are recommendations.

- The U.S. Department of Labor OSHA PELs (29 CFR 1910 [general industry]; 29 CFR 1926 [construction industry]; and 29 CFR 1917 [maritime industry]) are legal limits. These limits are enforceable in workplaces covered under the Occupational Safety and Health Act of 1970.

- NIOSH RELs are recommendations based on a critical review of the scientific and technical information and the adequacy of methods to identify and control the hazard. NIOSH RELs are published in the NIOSH Pocket Guide to Chemical Hazards [NIOSH 2010]. NIOSH also recommends risk management practices (e.g., engineering controls, safe work practices, employee education/training, personal protective equipment, and exposure and medical monitoring) to minimize the risk of exposure and adverse health effects.

- Other OELs commonly used and cited in the United States include the TLVs, which are recommended by the ACGIH, a professional organization, and the workplace environmental exposure levels (WEELs), which are recommended by the American Industrial Hygiene Association, another professional organization. The TLVs and WEELs are developed by committee members of these associations from a review of the published, peer-reviewed literature. These OELs are not consensus standards. TLVs are considered voluntary exposure guidelines for use by industrial hygienists and others trained in this discipline "to assist in the control of health hazards" [ACGIH 2015a]. 
WEELs have been established for some chemicals "when no other legal or authoritative limits exist" [AIHA 2015].

Outside the United States, OELs have been established by various agencies and organizations and include legal and recommended limits. The Institut für Arbeitsschutz der Deutschen Gesetzlichen Unfallversicherung (Institute for Occupational Safety and Health of the German Social Accident Insurance) maintains a database of international OELs from European Union member states, Canada (Québec), Japan, Switzerland, and the United States. The database, available at http://www.dguv.de/ifa/GESTIS/GESTIS-Stoffdatenbank/index-2.jsp, contains international limits for more than 1,500 hazardous substances and is updated periodically.

OSHA requires an employer to furnish employees a place of employment free from recognized hazards that cause or are likely to cause death or serious physical harm [Occupational Safety and Health Act of 1970 (Public Law 91-596, sec. 5(a)(1))]. This is true in the absence of a specific OEL. It also is important to keep in mind that OELs may not reflect current health-based information.

When multiple OELs exist for a substance or agent, NIOSH investigators generally encourage employers to use the lowest OEL when making risk assessment and risk management decisions. NIOSH investigators also encourage use of the hierarchy of controls approach to eliminate or minimize workplace hazards. This includes, in order of preference, the use of (1) substitution or elimination of the hazardous agent, (2) engineering controls (e.g., local exhaust ventilation, process enclosure, dilution ventilation), (3) administrative controls (e.g., limiting time of exposure, employee training, work practice changes, medical surveillance), and (4) personal protective equipment (e.g., respiratory protection, gloves, eye protection, hearing protection). Control banding, a qualitative risk assessment and risk management tool, is a complementary approach to protecting employee health. Control banding focuses on how broad categories of risk should be managed. Information on control banding is available at http://www.cdc.gov/niosh/topics/ctrlbanding/. This approach can be applied in situations where OELs have not been established or can be used to supplement existing OELs.

\section{Noise}

Noise induced hearing loss is an irreversible condition that progresses with noise exposure. It is caused by damage to the nerve cells of the inner ear and, unlike some other types of hearing disorders, cannot be treated medically [Berger et al. 2003]. More than 22 million U.S. workers are estimated to be exposed to workplace noise levels above $85 \mathrm{dBA}$ [Tak et al. 2009]. NIOSH estimates that workers exposed to an average daily noise level of $85 \mathrm{dBA}$ over a 40 -year working lifetime have an $8 \%$ excess risk of material hearing impairment. This excess risk increases to $25 \%$ for an average daily noise exposure of $90 \mathrm{dBA}$ [NIOSH 1998]. NIOSH defines material hearing impairment as an average of the HTLs for both ears that exceeds $25 \mathrm{~dB}$ at frequencies of $1,000 \mathrm{~Hz}, 2,000 \mathrm{~Hz}, 3,000 \mathrm{~Hz}$, and 4,000 Hz.

Although hearing ability commonly declines with age, exposure to excessive noise can increase the rate of hearing loss. In most cases, NIHL develops slowly from repeated exposure to noise over time, but the progression of hearing loss is typically the greatest 
during the first several years of noise exposure. NIHL can also result from short duration exposures to high noise levels or even from a single exposure to an impulse noise or a continuous noise, depending on the intensity of the noise and the individual's susceptibility to NIHL [Berger et al. 2003]. Noise exposed workers can develop substantial NIHL before it is clearly recognized. Even mild hearing losses can impair one's ability to understand speech and hear many important sounds. In addition, some people with NIHL also develop tinnitus. Tinnitus is a condition in which a person perceives hearing sound in one or both ears, but no external sound is present. Persons with tinnitus often describe hearing ringing, hissing, buzzing, whistling, clicking, or chirping like crickets. Tinnitus can be intermittent or continuous and the perceived volume can range from soft to loud. Currently, no cure for tinnitus exists.

The preferred unit for reporting of noise measurements is the decibel, A-weighted. A-weighting is used because it approximates the "equal loudness perception characteristics of human hearing for pure tones relative to a reference of $40 \mathrm{~dB}$ at a frequency of $1,000 \mathrm{~Hz}$ " and is considered to provide a better estimation of hearing loss risk than using unweighted or other weighting measurements [Earshen 2003]. The dB unit is dimensionless, and it represents the logarithmic ratio of the measured sound pressure level to an arbitrary reference sound pressure (20 micropascals, which is defined as the threshold of normal human hearing at a frequency of 1,000 Hz). Decibels are used because of the very large range of sound pressure levels audible to the human ear. Because the $\mathrm{dB}$ is logarithmic, an increase of $3 \mathrm{~dB}$ is a doubling of the sound energy, an increase of $10 \mathrm{~dB}$ is a 10 -fold increase, and an increase of $20 \mathrm{~dB}$ is a 100-fold increase in sound energy. Noise exposures expressed in $\mathrm{dB}$ cannot be averaged using the arithmetic mean.

Workers exposed to noise should have baseline and yearly hearing tests to evaluate their hearing thresholds and determine whether their hearing has changed over time. Hearing testing should be done in a quiet location, such as an audiometric test booth where background noise does not interfere with accurate measurement of hearing thresholds. In workplace hearing conservation programs, hearing thresholds must be measured at $500 \mathrm{~Hz}$, $1,000 \mathrm{~Hz}, 2,000 \mathrm{~Hz}, 3,000 \mathrm{~Hz}, 4,000 \mathrm{~Hz}$, and 6,000 Hz. Additionally, NIOSH recommends that $8,000 \mathrm{~Hz}$ should also be tested [NIOSH 1998]. The OSHA hearing conservation standard requires analysis of changes from baseline hearing thresholds to determine if the changes are substantial enough to meet OSHA criteria for a STS. OSHA defines a STS as a change in hearing threshold relative to the baseline hearing test of an average of $10 \mathrm{~dB}$ or more at $2,000 \mathrm{~Hz}, 3,000 \mathrm{~Hz}$, and 4,000 Hz in either ear [29 CFR 1910.95]. If a STS occurs, the company must determine if the hearing loss also meets the requirements to be recorded on the OSHA Form 300 Log of Work-Related Injuries and Illnesses [29 CFR 1904.1]. In contrast to OSHA, NIOSH defines a significant threshold shift as an increase in the hearing threshold level of $15 \mathrm{~dB}$ or more, relative to the baseline audiogram, at any test frequency in either ear measured twice in succession [NIOSH 1998].

Hearing test results are often presented in an audiogram, which is a plot of an individual's hearing thresholds (y-axis) at each test frequency (x-axis). HTLs are plotted such that fainter sounds are shown at the top of the y-axis, and more intense sounds are plotted below. Typical audiograms show HTLs from -10 or $0 \mathrm{~dB}$ to about $100 \mathrm{~dB}$. Lower frequencies are 
plotted on the left side of the audiogram, and higher frequencies are plotted on the right. NIHL often manifests itself as a "notch" at 3,000 Hz, 4,000 Hz, or 6,000 Hz, depending on the frequency spectrum of the workplace noise and the anatomy of the individual's ear [ACOM 1989; Osguthorpe and Klein 2001; Suter 2002; Schlaucha and Carneya 2011]. A notch in an individual with normal hearing may indicate early onset of NIHL. For NIOSH Health Hazard Evaluations, a notch is defined as the frequency where the HTL is preceded by an improvement of at least $10 \mathrm{~dB}$ at the previous test frequency and followed by an improvement of at least $5 \mathrm{~dB}$ at the next test frequency.

NIOSH has an REL for noise of $85 \mathrm{dBA}$, as an 8-hour TWA. For calculating exposure limits, $\mathrm{NIOSH}$ uses a 3-dB time/intensity trading relationship, or exchange rate. Using this criterion, an employee can be exposed to $88 \mathrm{dBA}$ for no more than 4 hours, $91 \mathrm{dBA}$ for 2 hours, $94 \mathrm{dBA}$ for 1 hour, $97 \mathrm{dBA}$ for 0.5 hours, etc. Exposure to impulsive noise should never exceed $140 \mathrm{dBA}$. For extended work shifts NIOSH adjusts the REL to $84.5 \mathrm{dBA}$ for a 9-hour shift, 84.0 dBA for a 10-hour shift, 83.6 dBA for an 11-hour shift, and 83.2 dBA for a 12-hour work shift. When noise exposures exceed the REL, NIOSH recommends the use of hearing protection and implementation of a hearing loss prevention program [NIOSH 1998].

The OSHA noise standard specifies a PEL of $90 \mathrm{dBA}$ and an AL of $85 \mathrm{dBA}$, both as 8-hour TWAs. OSHA uses a less conservative 5-dB exchange rate for calculating the PEL and AL. Using the OSHA criterion, an employee may be exposed to noise levels of $95 \mathrm{dBA}$ for no more than 4 hours, $100 \mathrm{dBA}$ for 2 hours, $105 \mathrm{dBA}$ for 1 hour, $110 \mathrm{dBA}$ for 0.5 hours, etc. Exposure to impulsive or impact noise must not exceed $140 \mathrm{~dB}$ peak noise level. OSHA does not adjust the PEL for extended work shifts. However, the AL is adjusted to 84.1 dBA for a 9-hour shift, $83.4 \mathrm{dBA}$ for a 10-hour shift, 82.7 dBA for an 11-hour shift, and 82.1 dBA for a 12-hour work shift. OSHA requires implementation of a hearing conservation program when noise exposures exceed the AL [29 CFR 1910.95].

An employee's daily noise dose, based on the duration and intensity of noise exposure, can be calculated according to the formula: Dose $=100 \times(\mathrm{C} 1 / \mathrm{T} 1+\mathrm{C} 2 / \mathrm{T} 2+\ldots+\mathrm{Cn} / \mathrm{Tn})$, where $\mathrm{Cn}$ indicates the total time of exposure at a specific noise level and $\mathrm{Tn}$ indicates the reference exposure duration for which noise at that level becomes hazardous. A noise dose greater than $100 \%$ exceeds the noise exposure limit.

To calculate the noise dose using NIOSH criteria, the reference duration (Tn) for each time period must be calculated using the following formula: $\mathrm{T}$ (minutes) $=480 / 2(\mathrm{~L}-85) / 3$, where $\mathrm{L}=$ the measured noise exposure level for each time period. To calculate noise dose using OSHA criteria, the reference duration ( $\mathrm{Tn}$ ) for each time period must be calculated using a slightly different formula: $\mathrm{T}$ (minutes) $=480 / 2(\mathrm{~L}-90) / 5$, where $\mathrm{L}=$ the measured noise exposure level for each time period.

\section{Whole Body Vibration}

In the United States, an estimated 7 million employees are exposed to whole body vibration at work [Wasserman et al. 1974]. Exposure can cause acute effects that affect worker safety and chronic effects that affect health [Wasserman and Badger 1973; Cohen et al. 1977]. An example of an acute effect is a driver losing the grip on a steering wheel, potentially leading 
to an accident. Most of the known chronic effects of whole body vibration are concerned with changes in the spine and back of affected workers. Strong evidence of an association between whole body vibration and low back disorder was found in 15 of 19 studies reviewed by NIOSH. Whole body vibration may act in combination with other work factors, such as prolonged sitting, lifting, and awkward positions, to cause increased risk of back disorders [NIOSH 1997].

Neither NIOSH nor OSHA has exposure limits for whole body vibration. ACGIH has a TLV for whole body vibration that measures ARMS in $\mathrm{m} / \mathrm{s}^{2}$ for the one-third octave bands from $1 \mathrm{~Hz}$ to $80 \mathrm{~Hz}$ [ACGIH 2015a]. The one-third octave bands are weighted the same for the $\mathrm{x}$ - and $\mathrm{y}$-axes but differently for the z-axis. The $\mathrm{x}$-axis and $\mathrm{y}$-axis are maximally sensitive at the frequencies of 1 to $2 \mathrm{~Hz}$, while the z-axis is most sensitive between $4 \mathrm{~Hz}$ and $8 \mathrm{~Hz}$. These most sensitive bands correspond to the natural resonances of the human body when it is vibrated in these directions. Resonance is the condition where vibration is optimally transmitted from the vibrating source to the person, with the individual actually amplifying the acceleration, possibly exacerbating the effects of the whole body vibration [Coermann 1962].

Acceleration measurements are simultaneously collected in each of the three orthogonal axes and compared to the TLV's two weighting functions. The criterion has exposure time limits from 1 minute to 24 hours that correspond to the ARMS measured at each one-third octave band. The TLV also presents formulas to calculate the single-vector sum of the weighted accelerations from all three orthogonal axes. According to the ACGIH TLV, this single value of the sum of the weighted accelerations can be compared to the Commission of the European Communities directive [CEC 2002]. Specifically, the directive requires a daily exposure limit value standardized to an 8-hour reference period of $1.15 \mathrm{~m} / \mathrm{s}^{2}$ and a daily exposure action value of $0.5 \mathrm{~m} / \mathrm{s}^{2}$ for the same standardized period. Once the exposure action value has been exceeded, the employer should establish a program to reduce exposure to mechanical vibration. The program can include engineering controls, new equipment that produces lower levels of vibration, changes in work practices, and training programs to instruct workers in the use of the equipment to reduce vibration.

The ISO has defined methods for the measurement of periodic, random, and transient whole body vibration to indicate the degree to which vibration exposure will be acceptable [ISO 1997]. The standard presents different weighting factors of one-third octave bands for the frequency range of 0.5 to $80 \mathrm{~Hz}$ in each of the three orthogonal directional axes. The principal weighting curves vary depending on whether the standard is being applied to health, comfort, or perception guidelines and whether the worker is seated, standing, or recumbent. As is the case with the ACGIH TLV, the weighting curves are maximally sensitive at the natural resonance of the human body, 1 to $2 \mathrm{~Hz}$ in the $\mathrm{x}$ and $\mathrm{y}$ directions, and 4 to $8 \mathrm{~Hz}$ in the $\mathrm{z}$ direction. The standard contains informative guides to the effects of vibration on health, comfort, and perception in a series of appendices. The guidance on health effects is primarily intended to reduce the risk of injury to the lumbar spine and the nervous system. A health guidance caution zone is presented in the standard to which the ARMS value of the frequency-weighted accelerations can be compared for varying exposure durations from 10 minutes to 24 hours. The lower boundary of the health guidance caution zone runs from approximately $3 \mathrm{~m} / \mathrm{s}^{2}$ for 10 minutes or less to $0.25 \mathrm{~m} / \mathrm{s}^{2}$ for 24 -hour exposures. 


\section{Hand-Arm Vibration}

In the United States, approximately 1 million employees are exposed to hand-arm vibration at work [Wasserman et al. 1974]. Overexposure can lead to hand-arm vibration syndrome, which causes circulatory, neurological, and musculoskeletal disturbances. Sufferers may experience vasospasms, a sudden constriction of bloods vessels, in the hands which reduces blood flow in the fingertips and can cause the fingers to turn white. Vasospasms are usually triggered by cold temperatures. Additional symptoms include numbness, tingling, and reduced sense of touch and temperature after years of hand-arm vibration exposure. These disturbances are caused by damage to the sensory nerves in the hand and arm and are more permanent than circulatory disturbances [Pelmear and Taylor 1991]. Some musculoskeletal problems can also be attributed to hand-arm vibration. Muscle fatigue is the most common outcome, and is probably linked to the neurological sensitivity threshold shift which may cause workers to unintentionally and unnecessarily over-grip the tool. A widely used method for classifying the circulatory and neurological symptoms is the Stockholm Workshop Scales [Brammer et al. 1987; Gemne et al. 1987]. Currently, no such scale exists for rating the musculoskeletal symptoms caused by exposure to hand-arm vibration.

Standards and recommended criteria for assessing hand-arm vibration include the following:

- American National Standard Institute ANSI S2.70-2006, Guide for the measurement and evaluation of human exposure to vibration transmitted to the hand [ANSI 2006]

- International Standards Organization ISO 5349-1986, Mechanical vibration guidelines for the measurement and the assessment of human exposure to handtransmitted vibration [ISO 1986]

- European Directive 2002/44/EC - human vibration. Council directive on the minimum health and safety requirements regarding the exposure of workers to the risks arising from physical agents (vibration) [CEC 2002]

- ACGIH TLVs [ACGIH 2015a]

- NIOSH criteria for a recommended standard: occupational exposure to hand-arm vibration [NIOSH 1989]

The ANSI, ISO, and the Commission of the European Communities Directive provide similar measurement and reporting techniques. These standards define the biodynamic and basicentric coordinate systems for positioning the accelerometers used to measure the vibration in the three orthogonal axes of direction; up and down, side to side, and back and forth. These standards have an exposure action value of $2.5 \mathrm{~m} / \mathrm{s}^{2}$ and an exposure limit value of $5 \mathrm{~m} / \mathrm{s}^{2}$. The ANSI, ISO, and ACGIH require weighting the one-third octave band acceleration data to find an overall acceleration value for the one-third octave center band frequencies 6.3 through $1,250 \mathrm{~Hz}$. The weighting factors for each center band frequency are given in both the ANSI and ISO standards. These factors gradually reduce the significance of acceleration beyond $20 \mathrm{~Hz}$ and are used to calculate the overall weighted acceleration. ACGIH TLVs determine a time-weighted average of the overall weighted acceleration for the dominant axis of each exposure, defined as the axis with the highest overall acceleration. 
The ACGIH TLV is $4 \mathrm{~m} / \mathrm{s}^{2}$ for daily exposure durations of 4 to 8 hours, $6 \mathrm{~m} / \mathrm{s}^{2}$ for exposures of 2 to 4 hours, $8 \mathrm{~m} / \mathrm{s}^{2}$ for exposures of 1 to 2 hours, and $12 \mathrm{~m} / \mathrm{s}^{2}$ for exposures less than 1 hour [ACGIH 2015a].

Neither OSHA nor NIOSH has exposure limits for hand-arm vibration. The NIOSH criteria document emphasizes reporting unweighted data and conducting hand-arm vibration measurements from 5 to $5,000 \mathrm{~Hz}$. Although no current standard exists that links unweighted acceleration levels to health risks, high frequency vibration may cause more damage than once believed [NIOSH 1989; Hampel 1992].

\section{Heat Stress}

NIOSH updated its heat stress criteria document in February 2016 [NIOSH 2016]. NIOSH defines heat stress exposure as the sum of the heat generated in the body (metabolic heat) plus the heat gained from the environment (environmental heat) minus the heat lost from the body to the environment, primarily through evaporation. Many bodily responses to heat stress are desirable and beneficial because they help regulate internal temperature and, in situations of appropriate repeated exposure, help the body adapt (acclimatize) to the work environment. However, at some stage of heat stress, the body's compensatory measures cannot maintain internal body temperature at the level required for normal functioning. As a result, the risk of heat-induced illnesses, disorders, and accidents substantially increases. Increases in unsafe behavior, which may lead to accidents, are also seen as the level of physical work of the job increases [NIOSH 2016].

Many heat stress guidelines have been developed to protect people against heat-related illnesses. The objective of any heat stress index is to prevent a person's core body temperature (CBT) from rising excessively. The World Health Organization concluded that, "it is inadvisable for CBT to exceed $100.4^{\circ} \mathrm{F}$ or for oral temperature to exceed $99.5^{\circ} \mathrm{F}$ in prolonged daily exposure to heavy work and/or heat" [WHO 1969]. According to NIOSH, a CBT of $102.2^{\circ} \mathrm{F}$ should be considered reason to terminate exposure even when CBT is being monitored. This does not mean that an employee with a CBT exceeding those levels will necessarily experience adverse health effects; however, the number of unsafe acts increases as does the risk of developing heat stress illnesses [NIOSH 2016].

NIOSH recommends controlling total heat exposure so that unprotected healthy employees are not exposed to metabolic and environmental heat combinations that exceed the applicable NIOSH criteria. These criteria state that most healthy employees who work in hot environments and are exposed to combinations of environmental and metabolic heat less than the NIOSH recommended action limit for non-acclimatized employees or the NIOSH REL for acclimatized employees should be able to tolerate total heat stress without substantially increasing their risk of incurring acute adverse health effects. Also, no employee should be exposed to metabolic and environmental heat combinations that exceed applicable ceiling limits without being provided with and properly using appropriate and adequate heatprotective clothing and equipment [NIOSH 2016].

ACGIH guidelines require the use of a decision-making process that provides step-by-step situation-dependent instructions that factor in clothing insulation values and physiological 
evaluation of heat strain [ACGIH 2015b]. ACGIH WBGT screening criteria factor in the ability of the body to cool itself (clothing insulation value, humidity, and wind) and, like the NIOSH criteria, can be used to develop work/rest regimens for acclimatized and unacclimatized employees. The ACGIH WBGT-based heat exposure assessment was developed for a traditional work uniform of long-sleeved shirt and pants, and represents conditions under which it is believed that nearly all adequately hydrated, unmedicated, healthy employees may be repeatedly exposed without adverse health effects. Clothing insulation values and the appropriate WBGT adjustments, as well as descriptors of the other decision-making process components can be found in ACGIH's "Documentation of the Threshold Limit Values for Chemical Substances and Physical Agents and Biological Exposure Indices" [ACGIH 2015b]. The ACGIH TLV for heat stress provides a framework for the control of heat-related illnesses only. Although accidents and injuries can increase with increasing levels of heat stress, it is important to note that the TLVs are not directed toward controlling these [ACGIH 2015b].

NIOSH and ACGIH criteria can only be used when WBGT data for the immediate work area are available and must not be used when employees wear encapsulating suits or garments that are impermeable or highly resistant to water vapor or air movement. Further assumptions regarding work demands include an 8-hour work day, 5-day work week, two 15-minute breaks, and a 30-minute lunch break, with rest area temperatures the same as, or less than, those in work areas, and at least some air movement. While NIOSH and ACGIH guidelines distinguish between safe and dangerous levels, professional judgment must be used in administering a heat stress management program to ensure adequate protection. The OSHA technical manual's section on heat stress refers to the ACGIH document for guidelines to evaluate employee heat stress and how to investigate the workplace [OSHA 1999].

\section{Heat Strain}

The body's response to heat stress is called heat strain. Operations involving high air temperatures, radiant heat sources, high humidity, direct physical contact with hot objects, and strenuous physical activities have a high potential for inducing heat strain in employees. Heat strain is highly individual and cannot be predicted on the basis of environmental heat stress measurements. Physiological monitoring for heat strain becomes necessary when impermeable clothing is worn, when heat stress screening criteria are exceeded, or when data from a detailed analysis (such as the ISO required sweat rate index) shows excess heat stress.

ACGIH considers one indicator of physiological strain, sustained peak heart rate, to be the best sign of acute, high-level exposure to heat stress. Sustained peak heart rate, defined by ACGIH as 180 beats per minute minus an individual's age, is a leading indicator that thermal regulatory control may not be adequate and that increases in CBTs have or will soon occur [ACGIH 2015b]. According to ACGIH, an individual's heat stress exposure should be discontinued when any of the following heat strain indicators occur:

- Sustained (over several minutes) heart rate exceeds 180 beats per minute minus the individual's age in years, (180 beats per minute minus age) for those with normal cardiac performance 
- CBT is greater than $100.4^{\circ} \mathrm{F}$ for unselected, unacclimatized personnel and greater than $101.3^{\circ} \mathrm{F}$ for medically fit, heat-acclimatized personnel

- Recovery heart rate at 1 minute after a peak work effort exceeds 110 beats per minute

- Presence of symptoms of sudden and severe fatigue, nausea, dizziness, or lightheadedness

An individual may be at greater risk of heat strain if:

- Profuse sweating is sustained over several hours

- Weight loss over a shift is greater than $1.5 \%$ of body weight

- 24-hour urinary sodium excretion is less than 55 millimoles

\section{Acclimatization}

When employees are first exposed to a hot environment, they show signs of distress and discomfort, experience increased CBTs and heart rates, and may have headaches and/ or nausea. On repeated exposure marked adaptation to the hot environment known as acclimatization occurs. The loss of acclimatization begins when the activity under those heat stress conditions is discontinued, and a noticeable loss occurs after 4 days. This loss is usually rapidly made up so that by Tuesday, employees who were off on the weekend are as well acclimatized as they were on the preceding Friday. Chronic illness, an acute episode of mild illness (e.g., gastroenteritis), the use or misuse of pharmacologic agents, a sleep deficit, a suboptimal nutritional state, or a disturbed water and electrolyte balance may reduce an employee's capacity to acclimatize [ACGIH 2015b].

\section{Volume Depletion}

When working in hot environments, it is often difficult to completely replace lost fluids as the day's work proceeds. Sweat contains water and salt, and excessive sweating can cause volume depletion and electrolyte imbalances. Volume depletion is different from pure dehydration, and occurs when loss of both water and salt/sodium results in a reduced circulatory blood volume [Mange et al. 1997]. Some studies have shown that even small deficits adversely affect performance. Volume depletion also negates the advantage granted by high levels of aerobic fitness and heat acclimatization.

Several studies have shown that volume depletion or dehydration increases CBT during exercise in temperate and hot environments. Because water is the most abundant constituent in the body, comprising approximately $60 \%$ of the body weight in men and $50 \%$ in women, maintaining enough water improves the body's overall function. Disorders of water regulation result in hyponatremia or hypernatremia. Most individuals with acute exercise-induced heat disorder are volume depleted with normal to mildly increased serum sodium and serum osmolality (hypernatremia). Increased water intake before and during activities in hot environments is highly emphasized to prevent volume depletion and heat illness. However, drinking too much water can lead to decreased serum sodium concentrations (water toxicity or hyponatremia). Many people with hyponatremia due to water overload have increased their total body water by about 1 gallon to achieve such low serum sodium values. 
The most significant clinical signs of hyponatremia involve the central nervous system, and symptoms vary from subtle changes in one's ability to think, to decreases in energy levels, to severe alterations such as coma or seizure. Symptoms generally parallel the rate of development and degree of hyponatremia.

\section{Fluid Replacement}

Palatability of any fluid replacement solution is important to ensure adequate rehydration. Evidence shows that adding sweeteners to drinks leads to increased consumption. Glucoseelectrolyte solutions have been shown to facilitate sodium and water absorption. Also, the glucose in these solutions provides energy for muscular activity in endurance events that require vigorous exercise [Rolls et al. 1990]. However, employees should be cautioned to avoid drinking large amounts of sugar-laden beverages in hot climates as this causes an osmotic diuresis (increased urine production) that increases fluid loss through urination. Caffeinated beverages and alcohol intake also increase urinary fluid loss and should be avoided. The temperature of the drink also influences consumption of fluids. Ideally, fluids should be ingested at temperatures of $50^{\circ} \mathrm{F}-60^{\circ} \mathrm{F}$, in small quantities ( $5-7$ ounces), and at frequent intervals (every 15-20 minutes).

Average Americans consume adequate, if not excessive, amounts of sodium in their usual diet such that for mild volume depletion, only water replacement is needed. However, in moderate volume depletion or when involved in events resulting in prolonged sweating, electrolyte (i.e., sodium) replacement is indicated. Many oral electrolyte replacement formulas such as those found in common sports drinks are available. Salt tablets are not recommended as they can irritate the stomach, leading to vomiting, which can exacerbate fluid losses and do not address water replacement needs. Those with nausea and vomiting from heat stress may require intravenous saline administration to replace their water and sodium. 


\section{Appendix C: Methods}

\section{Noise Dosimetry}

We measured full-shift personal noise exposures using Quest Technologies NoisePro ${ }^{\circledR}$ DLX noise type 2 dosimeters. For noise measurements, each dosimeter was attached to the wearer's belt and a 3/8-inch random incidence microphone was fastened to the wearer's shirt at a point midway between the ear and the outside of the shoulder. Windscreens were placed over the microphones to reduce or eliminate artifact noise, which can occur if wind from a fan blows across an unprotected microphone or something bumps into an unprotected microphone. We set up the dosimeters to collect data using different settings to allow comparison of noise measurement results with the three different noise exposure limits referenced in this health hazard evaluation report (Table C1). During measurements, noise levels below the threshold level were not integrated by the dosimeter for accumulation of dose and calculation of TWA noise level. The dosimeters averaged noise levels every second. We calibrated the dosimeters before and after the measurement periods according to the manufacturer's instructions.

Table C1. Dosimeter settings

\begin{tabular}{lccc}
\hline $\begin{array}{l}\text { Exposure limit } \\
\text { parameters }\end{array}$ & OSHA AL & OSHA PEL & NIOSH REL \\
\hline Response & Slow & Slow & Slow \\
Exchange rate & 5 & 5 & 3 \\
Criterion level & 90 & 90 & 85 \\
Threshold & 80 & 90 & 80 \\
\hline
\end{tabular}

We measured area noise levels at several work stations or pieces of equipment using a Quest Technologies SoundPro ${ }^{\circledR}$ Model SE/DL sound level meter. The instrument was equipped with a $1 / 2$-inch free-field Type 2 electret microphone and measured noise levels from $10-140 \mathrm{~dB}$. The microphone had a frequency response range ( $\pm 2 \mathrm{~dB})$ from $20 \mathrm{~Hz}-17 \mathrm{kHz}$. During measurements, the sound level meters were either hand-held or mounted on a tripod at a height of approximately 5 feet.

We downloaded noise measurement data collected using dosimeters and sound level meters to a personal computer for interpretation with QuestSuite ${ }^{\circledR}$ Professional II for Windows ${ }^{\circledR}$ computer software. All noise monitoring equipment were calibrated before and after use according to the manufacturer's instructions.

\section{Impact Noise Measurements}

We measured impact noise forge hammers, upset presses, shear presses, and shot blast units. We used a National Instruments model 9162 USB carrier with model 9215 voltage board to acquire impact noise data at a $100 \mathrm{kHz}$ sampling rate (i.e., 100,000 samples per sec). We used 
Brüel and Kjær model 4136 microphones for impact noise measurements. A signal conditioner model Nexus provided power for the microphones. During data collection the 0.5 -inch microphones were supported on boom stands and oriented in grazing incidence at the nominal hearing zone, which was 5 to 6 feet high. Two noise measurements were simultaneously taken at each location. One measurement was collected near the position of the worker and a second measurement was taken approximately 6 feet from the worker. Extension cables were used as necessary to accommodate distance from the microphones to the signal conditioner. The signal conditioner, laptop, and data acquisition chassis were set on a mobile cart.

Time records were acquired and streamed to a binary format and later reprocessed. The microphones were calibrated each morning before measurements were made with a Brüel and Kjær piston phone calibrator, model 4228 B\&K. Noise measurements and recordings were made for each individual part. The file format for recordings was a binary single precision floating point format with units of $\mathrm{Pa}$ for the sound data.

NIOSH engineers used Matlab Mathworks to write several programs to analyze and describe impulsive and continuous sound. A program named Impulsive Noise Meter, identified each peak, placed the peak in a 0.5 -sec time window with $25 \%$ of the time before the peak, and then calculated the impulsive noise metrics. The metrics were stored in a Matlab structure along with descriptive information. In addition to the impulsive noise analysis, a continuous analysis of the data was accomplished with the Matlab program named Continuous Sound and Vibrations. This program created 5-sec time windows and then calculated the continuous sound and vibrations metrics and stored the metrics in a Matlab data structure. For each work area where we measured impulsive noise, another Matlab program, Main_Metrics, was used to combine the metrics, calculate descriptive statistics, and make summary data plots.

\section{Hearing Protector Attenuation Measurements}

We used an acoustical mannequin head custom manufactured by the Institut FrancoAllemand de Recherches de Saint-Louis to assess the performance of the hearing protection used at two hammers during operation. The mannequin head was completely sealed and made of solid hard plastic. The ISL Mannequin head had a model 4157 B\&K 60711 ear simulator fitted with a B\&K model 4165 1/2-inch microphone. The mannequin was placed near the hammer operator at a height of 5 to 6 feet. Additionally, a B\&K model 4136 1/4inch microphone was placed on a boom stand outside of head near the right ear in grazing incidence. This microphone measured noise outside of the hearing protectors.

\section{Vibration Measurement}

We measured whole body vibration at hammers using a Larson Davis Model HVM100 Human Vibration Meter. We used adhesive cement to securely attach PCB Piezotronics Model 339M19P triaxial accelerometers to the work platforms that workers stood on when working at the hammers. The accelerometers were connected to the whole body vibration data acquisition system with cables. The triaxial accelerometers were calibrated by a factory authorized laboratory just before the evaluation, and the determined voltage sensitivities were used to calibrate the HVM100. 
The HVM100 was set to two different criteria for vibration measurements. The first criterion used the weighting functions specified by the ISO International Standard for evaluation of the comfort of a standing person [ISO 1997]. This criterion uses a frequency weighting function $\left(\mathrm{W}_{\mathrm{d}}\right)$ for the $\mathrm{x}$-axis (belly-to-back) and y-axis (side-to-side) acceleration values and a different frequency weighting function $\left(\mathrm{W}_{\mathrm{k}}\right)$ for the $\mathrm{z}$-axis (head-to-feet) acceleration values over the frequency range of $0.4 \mathrm{~Hz}$ to $100 \mathrm{~Hz}$. Both ARMS and peak acceleration values were calculated over a 30 -sec averaging period and stored in the vibration meter. The meter was set to the auto store mode so that each 30 -sec averaging period was stored over a 1 -hour total measurement period. The second criterion used a flat weighting function on each of the three directional axes. Peak and root mean square acceleration values were calculated and stored over 30-sec averaging periods for an entire hour of measurements. We measured hand-arm vibration using the same equipment and methods. However, accelerometers were attached to the work rest of the grinder and to the body of the grinder.

\section{Analysis of Audiometric Test Records}

We received a database from the company that contained 7,908 audiometric measurements for 618 workers. The database included an employee identifier, date of birth, record number, date of the audiometric test, and the hearing thresholds for the right and left ears. For a subset of records, the company was also able to provide employee hire dates. NIOSH removed personal identifiers and then assigned new employee numbers sequentially. To ensure quality and accuracy of the audiograms for analysis, an experienced audiologist used previously established NIOSH audiometric quality assurance screening guidelines [Franks 1999] to identify and remove audiograms that were incomplete or had audiometric patterns indicating hearing loss could have resulted from non-occupational factors or inaccurate audiometric thresholds, as detailed below. Following screening, we analyzed the remaining audiometric data to identify hearing loss trends and compare NIOSH and OSHA compliance metrics.

NIOSH audiometric quality assurance guidelines for screening audiograms:

(1) General rules

a. All records containing only one audiogram must be deleted.

b. All audiograms containing a "No Response" threshold must be deleted.

c. An audiogram must be deleted if it contains a threshold that differs by $50 \mathrm{~dB}$ or more from the thresholds at both adjacent frequencies.

Note: At the highest and lowest test frequencies, an audiogram should be deleted if the threshold differs by $50 \mathrm{~dB}$ or more from the one adjacent frequency.

(2) Intra-aural difference rules

An audiogram must be deleted if there is a difference in threshold between ears at the same frequency of $25 \mathrm{~dB}$ or more at $500 \mathrm{~Hz}$ and $1,000 \mathrm{~Hz}$ or $40 \mathrm{~dB}$ or more at $2,000 \mathrm{~Hz}$, $3,000 \mathrm{~Hz}, 4,000 \mathrm{~Hz}, 6,000 \mathrm{~Hz}$, or $8,000 \mathrm{~Hz}$. 


\section{(3) Negative slope rules}

An audiogram must be deleted if the threshold at $500 \mathrm{~Hz}$ in either ear is $15 \mathrm{~dB}$ or more poorer than the threshold at $1,000 \mathrm{~Hz}$ in the same ear or if the threshold at $1,000 \mathrm{~Hz}$ in either ear is $10 \mathrm{~dB}$ or more poorer than the threshold at $2,000 \mathrm{~Hz}$ in the same ear, unless all three of the following conditions are met:

a. The thresholds at $500 \mathrm{~Hz}, 1,000 \mathrm{~Hz}$, and 2,000 Hz in the ear in question are all $20 \mathrm{~dB}$ or better.

b. The threshold at $500 \mathrm{~Hz}$ is better than or equal to the threshold at $1,000 \mathrm{~Hz}$ in the ear in question.

c. The threshold at $1,000 \mathrm{~Hz}$ is no more than $10 \mathrm{~dB}$ poorer than the threshold at $2,000 \mathrm{~Hz}$ in the ear in question.

\section{(4) $\quad 15-\mathrm{dB}$ shift rules}

Rule 1: Do not include audiograms marked for deletion.

Each audiogram is compared to the valid audiogram immediately preceding it. If the immediately preceding audiogram has been deleted, the last retained audiogram is used for comparison.

\section{a. Unconfirmed decrease in hearing ability}

An audiogram must be deleted if it differs from its comparison audiogram at any frequency in either ear by $15 \mathrm{~dB}$ or more and the new threshold is not confirmed within $\pm 10 \mathrm{~dB}$ on the next valid audiogram.

Note: If the threshold on the confirmation audiogram differs by more than $10 \mathrm{~dB}$ in the same direction as the shift and this change is confirmed on the majority of future audiograms, the audiogram should be retained.

\section{b. Confirmed improvement in hearing ability}

Note: Because we are interested in permanent threshold shifts, if hearing improves from a previous audiogram and this improvement is confirmed in the next audiogram, then the initial audiogram in this sequence must be marked for deletion.

The exception in this rule is based on not wanting to discard an audiogram that shows hearing loss in another frequency; it is an override rather than an exception.

Note: This rule addresses learning and only applies to the initial audiograms.

The first audiogram in a set must be deleted if a threshold at any one frequency in either ear improves by $15 \mathrm{~dB}$ or more on the next valid audiogram, and the improved threshold is confirmed $( \pm 10 \mathrm{~dB})$ unless a threshold at another frequency in either ear worsens and is confirmed. In this case (i.e., some thresholds improving and some getting poorer between the first and second audiograms with confirmation on the next test), both audiograms should be retained. 
Example: A frequency $2,000 \mathrm{~Hz}$ in left ear: first reading is $30 \mathrm{~dB}$, second reading is $10 \mathrm{~dB}$ (this is a $20 \mathrm{~dB}$ improvement and more than meets the first criterion).

Possible Outcome 1:

Third reading is $20 \mathrm{~dB}$. This is the worst reading that can confirm the improvement within $\pm 10 \mathrm{~dB}$. The audiogram would be deleted unless there was evidence of hearing loss at a different frequency.

Possible Outcome 2:

Third reading is $25 \mathrm{~dB}$. This reading does not confirm the improvement within $\pm 10 \mathrm{~dB}$; it is $15 \mathrm{~dB}$ different from the improved reading. Thus, the audiogram would not be deleted even though this reading still shows some improvement.

This rule only applies to improvements in threshold between the first two valid audiograms. If all threshold shifts are in the poorer direction, and this worsening is confirmed, the initial audiogram will still be considered valid, and the decreased thresholds will be considered a threshold shift. It will be assumed that the initial audiogram with the better threshold was obtained under better conditions than subsequent audiograms, and the initial threshold will be considered a true threshold. If there are improvements and decreases between the first two valid audiograms, it will be assumed that these changes represent true changes in hearing and are not due to environmental factors, and both tests will be retained.

If thresholds continue to improve on subsequent audiograms (i.e., thresholds improve from the first audiogram to the second, and again from the second audiogram to the third, etc.), delete subsequent audiograms until the thresholds remain stable or at least one threshold becomes poorer. This rule only applies to audiograms at the beginning of a record. Once thresholds stabilize or begin to worsen, later audiograms which show improvements should be retained (provided the improvements are confirmed).

Rule 2: To exclude audiograms marked for deletion, it is necessary to iterate these tests until no more audiograms are deleted.

A shift on one audiogram must be confirmed by the next valid audiogram. If an audiogram that confirmed a threshold shift is later determined to be invalid, the threshold shift must be reconfirmed using the next valid audiogram. If the next valid audiogram does not confirm the shift, the audiogram in question must be deleted.

Exception: If the confirmation audiogram is the last audiogram in the series that is being deleted, the shift will still be considered confirmed. If several consecutive audiograms are deleted at the end of a record, any shifts on the audiogram immediately preceding them will still be considered confirmed, if indeed they were considered confirmed before the audiograms were deleted. 
Example: Audiograms A B C.......V W X Y Z

Audiogram W shows shift relative to Audiogram V.

Audiogram X confirms the shift; Audiogram W is retained.

Audiogram X shows shift relative to Audiogram W.

Audiogram Y does not confirm shift; Audiogram X is deleted.

Audiograms $\mathrm{Y}$ and $\mathrm{Z}$ are similarly deleted.

Audiogram $\mathrm{W}$ is still retained.

Conversely, an audiogram that was deleted because of an unconfirmed shift should be restored if the confirmation audiogram (i.e., that audiogram that showed the shift to be unconfirmed) is later determined to be invalid, and the next valid audiogram confirms the previously unconfirmed shift.

Example: Audiograms A B C D E...

Audiogram B shows shift relative to Audiogram A.

Audiogram C does not confirm shift; delete Audiogram B.

Audiogram C shows shift relative to Audiogram A.

Audiogram D does not confirm shift; delete Audiogram C.

Compare Audiogram A and B again; Audiogram D confirms shift.

Restore Audiogram B.

The last audiogram in a series must be deleted if it shows a shift relative to the last valid audiogram, because there is no future audiogram to use to confirm the threshold change.

\section{Heat Stress Measurements}

We measured the WBGT and relative humidity using Quest Technologies, Inc.

QUESTemp ${ }^{\circ} 36$ instruments. The instruments measure temperatures of $23^{\circ} \mathrm{F}-212^{\circ} \mathrm{F}$ and relative humidity of $0 \%-100 \%$. Temperature measurements are accurate to within $\pm 0.9^{\circ} \mathrm{F}$, and humidity measurements are accurate to within $\pm 5 \%$. The WBGT index is a useful way to look at the environmental contribution to heat stress for indoor environments. It includes dry bulb temperature (a standard measure of air temperature taken with a thermometer), wet bulb temperature (simulates the effects of evaporative cooling), and black globe temperature (estimates radiant [infrared] heat load). 


\section{References}

ACGIH [2015a]. 2015 TLVs ${ }^{\circledR}$ and BEIs ${ }^{\circledR}$ : threshold limit values for chemical substances and physical agents and biological exposure indices. Cincinnati, $\mathrm{OH}$ : American Conference of Governmental Industrial Hygienists.

ACGIH [2015b]. Documentation of the threshold limit values and biological exposure indices. 7th ed. Cincinnati, OH: American Conference of Governmental Industrial Hygienists.

ACOM [1989]. Occupational noise-induced hearing loss. American College of Occupational Medicine Noise and Hearing Conservation Committee. J Occup Med 31(12):996.

AIHA [2015]. AIHA 2015 emergency response planning guidelines (ERPG) \& workplace environmental exposure levels (WEEL) handbook. Fairfax, VA: American Industrial Hygiene Association.

ANSI [1991]. American national standard: maximum permissible ambient noise levels for audiometric test rooms. New York, New York: American National Standards Institute. American National Standard ANSI S3.1-1991.

ANSI [2006]. American national standard: guide for the measurement and evaluation of human exposure to vibration transmitted to the hand. New York, New York: American National Standards Institute. American National Standard ANSI S2.70.

Arslan E, Orzan E [1998]. Audiological management of noise induced hearing loss. Scand Audiol Suppl 48:131-145.

Berger EH, Franks JR, Lindgren F [1996]. International review of field studies of hearing protection attenuation. In: Axelsson A, Borchgrevink H, Hamernik RP, Hellstrom PA, Henderson D, Salvi RJ, eds. Scientific basis of noise-induced hearing loss. New York: Thieme Medical Publishers, pp. 361-377.

Berger EH, Franks JR, Behar A, Casali JG, Dixon-Ernst C, Kieper RW, Merry CJ, Mozo BT, Nixon CW, Ohlin D, Royster JD, Royster LH [1998]. Development of a new standard laboratory protocol for estimating the field attenuation of hearing protection devices. Part III. The validity of using subject-fit data. J Acoust Soc Am 103(2):665-672.

Berger EH, Royster LH, Royster JD, Driscoll DP, Layne M, eds. [2003]. The noise manual. 5th rev. ed. Fairfax, VA: American Industrial Hygiene Association.

Brammer A, Taylor W, Lundborg G [1987]. Sensorineural stages of the hand-arm vibration syndrome. Scand J Work Environ Health 13(4):279-283.

CEC [2002]. European Directive 2002/44/EC - human vibration. Council directive on the minimum health and safety requirements regarding the exposure of workers to the risks arising from physical agents (vibration). Luxembourg: European Union, Commission of the European Communities. 
CFR. Code of Federal Regulations. Washington, DC: U.S. Government Printing Office, Office of the Federal Register.

Coermann R [1962]. The mechanical impedance of the human body in sitting and standing positions at low frequencies. Hum Factors 4:225-227.

Cohen HH, Wasserman DE, Hornung R [1977]. Human performance and transmissibility under sinusoidal and mixed vertical vibration. Ergonomics 20(3):207-216.

Driscoll DP, Royster LH [2003]. Noise control engineering. In: Berger EH, Royster LH, Royster JD, Driscoll DP, Layne M. eds. The noise manual, 5th ed. Akron, OH: American Industrial Hygiene Association, pp. 279-378 [Reference: Table 9.5, pp. 298-300].

Earshen J [2003]. Sound measurement: instrumentation and noise descriptors. In Berger EH, Royster LH, Royster JD, Driscoll DP, Layne M, eds. The noise manual. 5th rev. ed. Fairfax, VA: American Industrial Hygiene Association, pp. 41-100.

Franks J [1999]. The role of audiometric data management in hearing loss prevention: audiometric data management. In: Proceedings: best practices in hearing loss prevention. Cincinnati, OH: U.S. Department of Health and Human Services, Centers for Disease Control and Prevention, National Institute for Occupational Safety and Health, DHHS (NIOSH) Publication No. 2001-157.

Franks JR, Murphy WJ, Johnson JL, Harris DA [2000]. Four earplugs in search of a rating system. Ear Hear 21(3):218-226.

Gemne G1, Pyykkö I, Taylor W, Pelmear PL [1987]. The Stockholm Workshop scale for the classification of cold-induced Raynaud's phenomenon in the hand-arm vibration syndrome (revision of the Taylor-Pelmear scale). Scand J Work Env Health 13(4):275-278.

Hampel GA [1992]. Hand-arm vibration isolation materials: a range of performance evaluation. Applied Occupational and Environmental Hygiene 7(7):441-452.

Hewitt S, Dong RG, Welcome DE, McDowell TW [2015]. Commentary anti-vibration gloves? Ann Occup Hyg 59(2):127-141. [http://annhyg.oxfordjournals.org/content/59/2/127. full.pdf + html]. Date accessed: May 2016.

Heyer N, Morata TC, Pinkerton LE, Brueck SE, Stancescu D, Panaccio MP, Kim H, Sinclair JS, Waters MA, Estill CF, Franks JR [2011]. Use of historical data and a novel metric in the evaluation of the effectiveness of hearing conservation program components. Occup Envirn Med 68(7):510-517.

HSE [2005]. HSE 2005 No. 1093: Control of vibration at work regulations 2005. United Kingdom: Health and Safety Executive. [http://www.legislation.gov.uk/uksi/2005/1093/ made]. Date accessed: May 2016.

ISO [1986]. International Standard 5349: Mechanical vibration-guidelines for the measurement and the assessment of human exposure to vibration. Geneva, Switzerland: International Standards Organization. 
ISO [1997]. International Standard 2631-1: Mechanical vibration and shock—evaluation of human exposure to whole-body vibration. Geneva, Switzerland: International Standards Organization.

ISO [1999]. International Standard 1999:2013. Acoustics-estimation of noise-induced hearing loss, Annex B3 U.S. population from the NHANES Survey. Geneva, Switzerland: International Standards Organization.

Joseph A, Punch J, Stephenson MR, Paneth N, Wolfe E, Murphy WJ [2007]. The effects of training format on earplug performance. Int J Audiol 46(10):609-618.

Kamal AM, Mikael RA, Faris R [1989]. Follow-up of hearing thresholds among forge hammering workers. Am J Ind Med 16(6):645-658.

Kardous CA, Willson RD, Hayden CS, Szlapa P, Murphy WJ, Reeves ER [2003]. Noise exposure assessment and abatement strategies at an indoor firing range. App Occup Environ Hyg 18(8):629-636.

Kardous CA, Willson RD [2004]. Limitations of using dosimeters in impulse noise environments. J Occup Environ Hyg 1(7):456-462.

Kryter KD, Ward WD, Miller JD, Eldredge DH [1966]. Hazardous exposure to intermittent and steady-state noise. J Acoust Soc Am 39(3):451-464.

Lam YW, Hodgson DC [1993]. The prediction of ringing noise of a drop hammer in a rectangular enclosure. J Acoust Soc Am 93(2):875-884.

Mange K, Matsuura D, Cizman B, Soto H, Ziyadeh FN, Goldfarb S, Neilson EG [1997]. Language guiding therapy: the case of dehydration versus volume depletion. Ann Intern Med 127(9):848-853.

Masterson EA, Tak S, Themann CL, Wall DK, Groenewold MR, Deddens JA, Calvert GM [2013]. Prevalence of hearing loss in the United States by industry. Am J Ind Med 56(6):670-681.

Murphy WJ, Stephenson MR, Byrne DC, Witt B, Duran J [2011]. Effects of training on hearing protector attenuation. Noise Health 13(51):132-141.

NIOSH [1989]. Criteria for a recommended standard: occupational exposure to hand-arm vibration. Cincinnati, OH: U.S. Department of Health and Human Services, Centers for Disease Control and Prevention, National Institute for Occupational Safety and Health, DHHS (NIOSH) Publication No. 89-106.

NIOSH [1997]. Musculoskeletal disorders and workplace factors. A critical review of epidemiological evidence for work-related musculoskeletal disorders of the neck, upper extremity, and low back. Cincinnati, OH: U.S. Department of Health and Human Services, Centers For Disease Control and Prevention, National Institute for Occupational Safety and Health, DHHS (NIOSH) Publication No. 97-141. 
NIOSH [1998]. Criteria for a recommended standard: occupational noise exposure (revised criteria 1998). Cincinnati, OH: U.S. Department of Health and Human Services, Centers for Disease Control and Prevention, National Institute for Occupational Safety and Health, DHHS (NIOSH) Publication No. 98-126.

NIOSH [2010]. NIOSH pocket guide to chemical hazards. Cincinnati, OH: U.S. Department of Health and Human Services, Centers for Disease Control and Prevention, National Institute for Occupational Safety and Health, DHHS (NIOSH) Publication No. 2010-168c. [http://www.cdc.gov/niosh/npg]. Date accessed: May 2016.

NIOSH [2016]. Criteria for a recommended standard: occupational exposure to hot environments, rev. Cincinnati, OH: U.S. Department of Health and Human Services, Centers for Disease Control, National Institute for Occupational Safety and Health, DHHS (NIOSH) Publication No. 2016-106.

NOAA [2015]. Data tools: 1981-2010 normals. National Oceanic and Atmospheric Administration. National Centers for Environmental Information. [http://www.ncdc.noaa. gov/cdo-web/datatools/normal]. Date accessed: May 2016.

Osguthorpe JD, Klein AJ [2001]. Occupational hearing conservation. Clin Audiol 24(2):403-414.

OSHA [1999]. Heat stress. In: OSHA technical manual. Sec 3, Chap 4. Washington, D.C.: U.S. Department of Labor, Occupational Safety and Health Administration, TED 1-0.15A.

OSHA [2015]. Occupational heat exposure. [https:/www.osha.gov/SLTC/heatstress/index. html]. Date accessed: May 2016.

Pelmear PL, Taylor W [1991]. Hand-arm vibration syndrome: clinical evaluation and prevention. J Occ Med 33(11):1144-1149.

Pfander F, Bongartz H, Brinkmann A, Keitz H [1980]. Danger of auditory impairment from impulse noise: a comparative study of the CHABA damage-risk criteria and those of the Federal Republic of Germany. J Acoust Soc Am 67(3):628-633.

Rabinowitz PM, Galusha D, Ernst CD, Slade MD [2007]. Audiometric "early flags" for occupational hearing loss. J Occup Environ Med 49(12):1310-1316.

Rivin E [2007]. Noise abatement of industrial production equipment. In: Crocker M, ed. Handbook of noise and vibration control. Hoboken, NJ: John Wiley and Sons, pp. 987-994.

Rolls BJ, Kim S, Federoff IC [1990]. Effects of drinks sweetened with sucrose or aspartame on hunger, thirst and food intake in men. Physiol Behav 48(1):19-26.

Saidur R, Rahim NA, Hasanuzzaman, M [2010]. A review on compressed-air energy use and energy savings. Renew Sust Energ Rev 14(4):1135-1153.

Schlaucha RS, Carneya E [2011]. Are false-positive rates leading to an overestimation of noise-induced hearing loss? J Speech Lang Hear Res 54(2):679-692. 
Starck J, Pekkarinen J, Pyykkö I [1988]. Impulse noise and hand-arm vibration in relation to sensory neural hearing loss. Scand J Work Env Health 14(4):265-271.

Sulkowski W [1980]. Hearing impairment caused by impulse noise: survey in the drop forging industry. Proceedings of the international symposium of effects of impulse noise on hearing. Scand Audiol Suppl 12:307-317.

Sulkowski W, Kowalska S, Lipowczan A, Prasher D, Raglan E [1999]. Tinnitus and impulse noise-induced hearing loss in drop-forge operators. Int J Occ Med Env Health 12(2):177-182.

Suter AH [2002]. Hearing conservation manual. 4th ed. Milwaukee, WI: Council for Accreditation in Occupational Hearing Conservation.

Suvorov G, Denisov E, Antipin V, Kharitonov V, Starck J, Pyykkö I, Toppila E [2001]. Effects of peak levels and number of impulses to hearing among forge hammering workers. App Occup Environ Hyg 16(8):816-822.

Tak S, Davis RR, Calvert GM [2009]. Exposure to hazardous workplace noise and use of hearing protection devices among U.S. workers-NHANES, 1999-2004. Am J Ind Med 52(5):358-371.

Taylor W, Lempert, Pelmear P, Hemstock I, Kershaw J [1984]. Noise levels and hearing thresholds in the drop forging industry. J Acoust Soc Am 76(3):807-819.

Wasserman DE, Badger DW [1973]. Vibration and its relationship to occupational health and safety. Bulletin of the N.Y. Academy of Medicine 49:887-984.

Wasserman DE, Badger DW, Doyle TE, Margolies L [1974]. Industrial vibration-an overview. J Am Soc Saf Eng 19(6):38-43.

WHO [1969]. Health factors involved in working under conditions of heat stress. Geneva, Switzerland: World Health Organization. Technical Report Series No. 412. 
Keywords: North American Industry Classification System 332111(Iron and Steel Forgings), Indiana, noise, impact noise, impulse noise, hearing loss, NIHL, tinnitus, whole body vibration, heat stress, forge, hammer forge 
The Health Hazard Evaluation Program investigates possible health hazards in the workplace under the authority of the Occupational Safety and Health Act of 1970 (29 U.S.C. § 669(a) (6)). The Health Hazard Evaluation Program also provides, upon request, technical assistance to federal, state, and local agencies to investigate occupational health hazards and to prevent occupational disease or injury. Regulations guiding the Program can be found in Title 42, Code of Federal Regulations, Part 85; Requests for Health Hazard Evaluations (42 CFR Part 85).

\section{Disclaimer}

The recommendations in this report are made on the basis of the findings at the workplace evaluated and may not be applicable to other workplaces.

Mention of any company or product in this report does not constitute endorsement by NIOSH.

Citations to Web sites external to NIOSH do not constitute NIOSH endorsement of the sponsoring organizations or their programs or products. NIOSH is not responsible for the content of these Web sites. All Web addresses referenced in this document were accessible as of the publication date.

\section{Acknowledgments}

Desktop Publisher: Shawna Watts

Editor: Ellen Galloway

Industrial Hygiene Field Assistance: Chandran Achutan

Logistics: Donnie Booher and Karl Feldmann

\section{Availability of Report}

Copies of this report have been sent to the employer, employees, and union at the facility.

The state and local health department and the Occupational Safety and Health Administration

Regional Office have also received a copy. This report is not copyrighted and may be freely reproduced.

This report is available at http://www.cdc.gov/niosh/hhe/reports/pdfs/2007-0075-3251.pdf.

\section{Recommended citation for this report:}

NIOSH [2016]. Health hazard evaluation report: evaluation of impact and continuous noise exposure, hearing loss, heat stress, and whole body vibration at a hammer forge company. By Brueck SE, Eisenberg J, Zechmann E, Murphy WJ, Morata TC, Krieg E. Cincinnati, OH: U.S. Department of Health and Human Services, Centers for Disease Control and Prevention, National Institute for Occupational Safety and Health, NIOSH HHE Report No. 2007-0075-3251. 
Delivering on the Nation's promise:

Safety and health at work for all people through research and prevention

To receive NIOSH documents or more information about occupational safety and health topics, please contact NIOSH:

Telephone: 1-800-CDC-INFO (1-800-232-4636)

TTY: 1-888-232-6348

CDC INFO: www.cdc.gov/info

or visit the NIOSH Web site at www.cdc.gov/niosh

For a monthly update on news at $\mathrm{NIOSH}$, subscribe to

$\mathrm{NIOSH}$ eNews by visiting www.cdc.gov/niosh/eNews. 